(1)

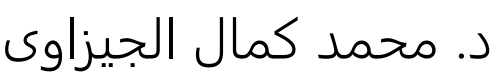

الموافقة المستنيرة

دراسة في الأخلاق الطبية

تعد الأخلاق الطبية أحد أهم فروع الأخلاق التطبيقية، وتهتم ببحث المشكلات

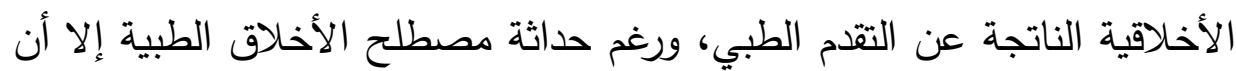

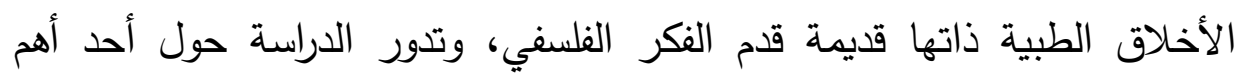

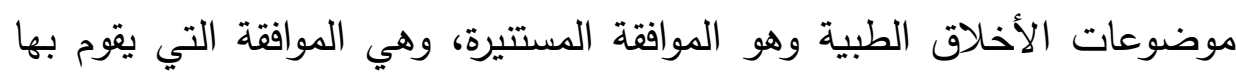

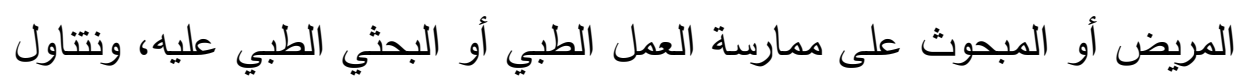

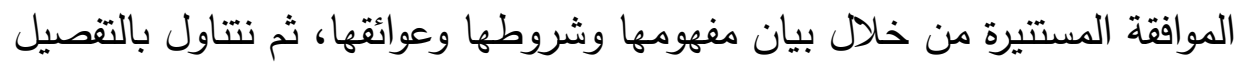
الموافقة المستنيرة في مجال العمل الطبي، والموافقة المستنيرة في الأبحاث الطبية على البشر ، ونختم بحثنا بالنتائج والتوصيات التي توصلنا إليها.

\title{
Informed Consent
}

\section{Study In Medical Ethics}

\section{Abstract}

Medical ethics is one of the most important branches of applied ethics, and is interested in researching ethical problems resulting from medical progress, and despite the recentness of the term medical ethics, medical ethics itself is as old as philosophical thought, and the study revolves around

1- مدرس بقسم الفلسفة، كلية الآداب، جامعة كفر الثيخ. 
مجلة وادي النيل للاراسات والبحوث الإنسانية والاجتماعية ـ مجلة علمية محكمة

(ISSN: 2536 - 9555)

one of the most important topics of medical ethics, which is informed consent, which is the approval that The patient or researcher on the practice of medical work or medical research on it, and we talk about informed consent by explaining its concept, conditions and obstacles, then we explain informed consent in the field of medical work, and informed consent in medical research on humans, and we conclude our research with the results and recommendations that we have reached.

$$
\text { تمهيد: ظهور وتطور الأخلاق الطبية }
$$

شهد القرن العشرين تطورًا هائلاً في العلوم بشكل عام وفي العلوم الطبية بشكل خاص. وترتب على استخدام التكنولوجيا الخوض في مجالات ما كان لأحد أن يحلم بها من قبل. هذا التطور خلف العديد من المعضلات الأخلاقية التي كان

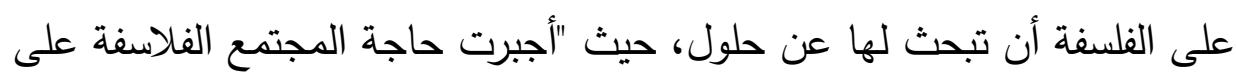

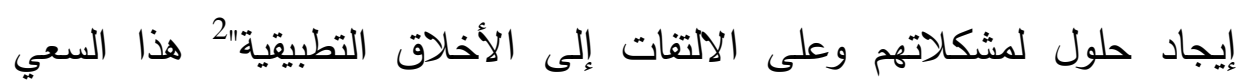
الحثيث من جانب الفلاسفة لإيجاد حلول معاصرة للمشكلات الطبية قد واجه معارضة من البعض الذين يؤكدون على أن الفلسفة ما زالت علمًا معياريًا يفتقد إلى الدقة الموضوعية التي يتمتع بها العلم، هذا التعارض بين التيارين أبرزه د.حسين على في بحثه العلم والتعاليم الأخلاقية رؤية معاصرة مؤكدًا انحيازه للتيار الأول حيث ذهب إلى أن "الفلسفة ليست منعزلة عن الواقع، فهي تبدأ من دراسة 2- ناهدة البقصي: الهندسة الوراثية والأخلاق، عالم المعرفة، الكويت، ع 174، يونيو

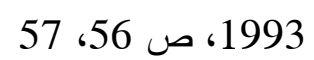


مشكلات الواقع لتضع لها الحلول مستندة على النظريات الفلسفية المختلفة"3. وقد استمر انصار التيار الأول في مجهوداتهم في التصدي للعديد من التحديات الأخلاقية التي نتجت عن استخدام التكنولوجيا الطبية "خاصة في مجال البحوث الطبية الحديثة والتشريعات المواكبة لذلك من الاستنساخ إلى الإجهاض إلى القتل الرحيم والتلقيح الصناعي وغيرها"4. وقد لاقت توجهات وآراء الفلاسفة الكثير من التأييد من داخل المجال الطبي وغيره من المجالات المعرفية والإنسانية الأخرى فانضم لهم "الأطباء ورجال الدين والمحامين فتم تأسيس مجلات ومراكز بحوث ولجان أخلاقية ودرجات خاصة في الأخلاق الطبية"5. ورغم أنه من الصعب وضع تعريف جامع مانع للأخلاق الطبية بين كل فروع المعرفة العلمية إلا أن المهمة ليست بالمستحيلة فقد عرفها البعض بأنها الأفكار التي تواجه الطبيب حين يعالج المرضى أو تواجه الباحث في المجال الطبي حين يجري أبحاثه الطبية، وكذلك "العلاقة التى يجب أن تتوفر بين الطبيب والمريض فى فترة العلاج،

3- د حسين على: العلم والتعاليم الأخلاقية رؤية معاصرة، الفلسفة التطبيقية، تحرير

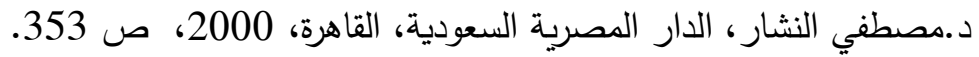

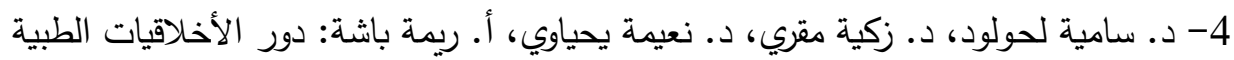

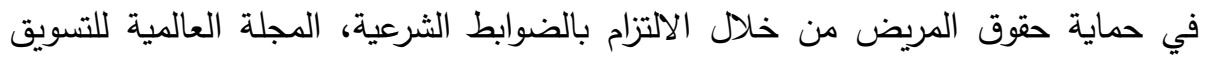

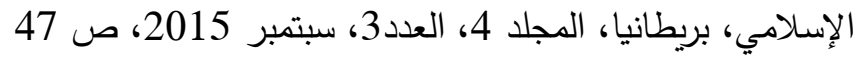

5 -William Ruddick: MEDICAL ETHICS, Encyclopedia of Ethics. Lawrence and Charlotte Becker, eds. 2nd edition. Garland 1998, in http://www.nyu.edu/gsas/dept/philo/faculty/ruddick/papers/medethics.ht $\underline{\mathrm{ml}}$ 
واستخدام التكنولوجيا في الطب وما قد ينتج عنها من مشكلات أخلاقية"6 وبذلك شدد الدكتور حسين على في تعريفه للأخلاق الطبية على جانب مهم وهو طبيعة لهن

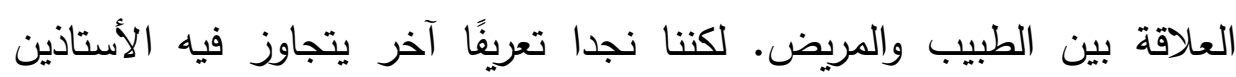
صبحي، زيدان طبيعة هذه العلاقة الشخصية إلى مجال أكثر رحابة وهو تجاوز

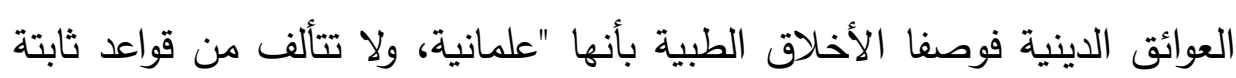
مطلقة وإنما يجري عليها التغير والتعديل حسب كل حالة جزئية. والمقصود

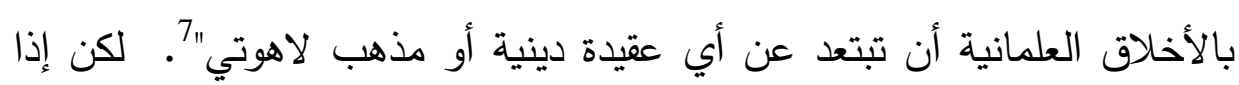
كان الأستاذين صبحي، زيدان لا يركزان على الجانب الديني ولا يعطونه الأهمية

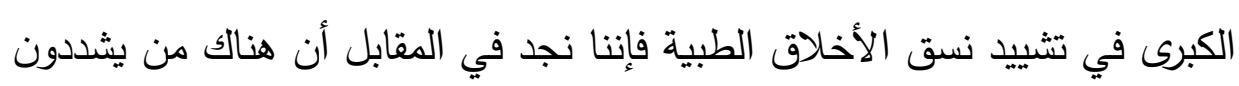

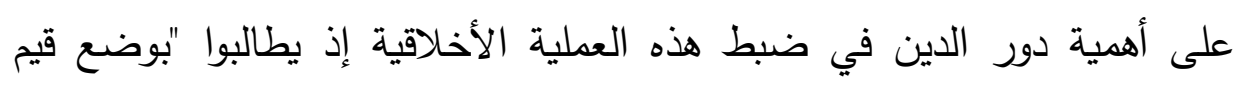

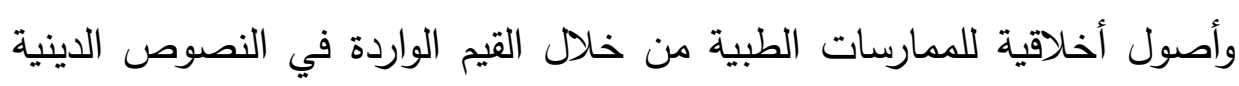
وأدبيات الفطرة البشرية السليمة، والتي تؤدي بنا للتعامل مع المريض تعاملاً كليًا

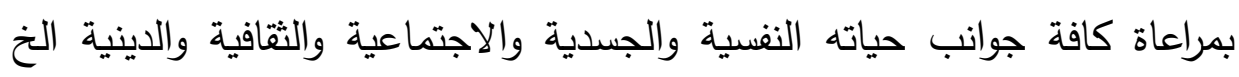
الخها، ورغم الاختلاف الواضح بين التعريفين السابقين إلا أن هناك ثمة تثابه وانيه بينهما وهو الاهتمام بالجانب الإنساني في هذه الأخلاق.

6- د حسين على: فلسفة الطب، الدار المصرية السعودية للطباعة والنشر والتوزيع، القاهرة،

$$
\text { 2009، ص ص صن } 17
$$

7- أحمد محمود صبحي، محمود فهمي زيدان: في فلسفة الطب، دار النهضة العربية،

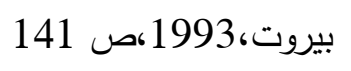

8- د حسن عباس حسن: نظرة في مفهوم الأخلاق الطبية، شبكة أهل البيت، في:

http://www.ahlolbayt.net/modules.php?name=News\&fileprint\&sid=141 
التطور التاريخي للأخلاق الطبية: رغم أننا أشرنا إلى أن مصطلح الأخلاق الطبية مصطلح حديث النشأة ارتبط باستخدام التورات التكنولوجية في مجال الطب، إلا أن هذا لا يعني أن الأخلاق الطبية كانت غائبة في التراث الفكري الإنساني عبر العصور، ورغم أن كثيرين ممن يتحيزون للحضارة الغربية ويستخدمون أطروحة المعزة اليونانية "إلا أن المعزة اليونانية قبلها معجزات ومعجزات. فقد سبقتها آلاف الجهود العالمية في مصر وبلاد ما بين النهرين" لذلك نجد أنه برغم تجاهلهم إلا أن الاهتمام بالأخلاق الطبية يرجع إلى عصور

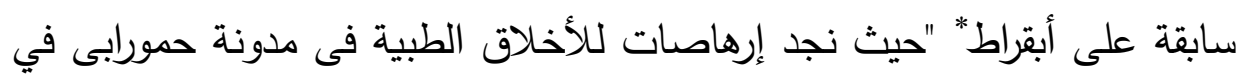

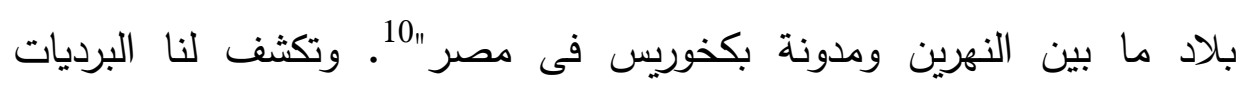

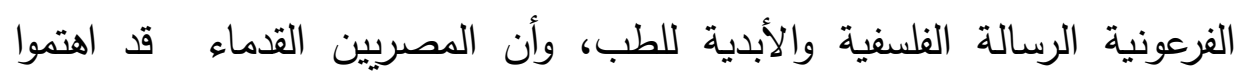
بالعلاج بالسحر في حقبة ما قبل التاريخ، شأنهم في ذلك شأن جميع الشعوب البدائية، وظهر العلاج الطبي عند المصريين القدماء في الحقبة التاريخية في أعقاب اكتشاف الزراعة، حيث أدرك الجميع أهمية فحص المريض ثم علاجه عن طريق المواد والأساليب التي تؤدي إلى أفضل النتائج، وتوجد عشرات البرديات التئه الطبية التي تعود جميعها تقريبًا للدولة الحديثة، وأهمها بردية إييرس Ebers أقدم بردية معروفة وترجع إلى الأسرة الثامنة عشرة 1530ق.م. وكذللك بردية إدوين سميث المكتشفة عام 1862م والتي نشرها برستيد عام 1930م وتتضمن ثماني 9- م. ع. مرحبا، م. د. حسن، ع. ي. زيعور : بدايات الفلسفة الأخلاقية، مؤسسة عز الدين

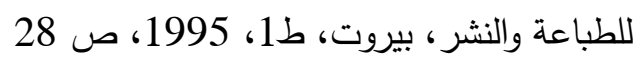

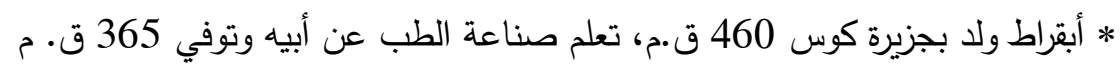

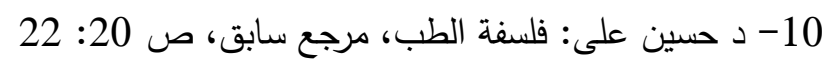


تجارب علمية مثيرة للإعجاب والدهشة 11. وكان الطبيب ملزمًا بتطبيق القواعد الطبية فإن خالفها، ومات المريض بسبب هذه المخالفة، كانت عقوبة الطبيب الإعدام، أما إذا طبق الطبيب القواعد الطبية، ولم يخرج عليها، وبرغم ذلك توفي المريض، فلا عقوبة على الطبيب12، أما في بلاد النهرين فقد اهتمت مدونة الإنة

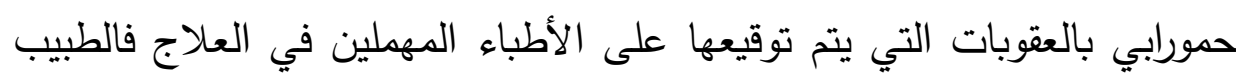
الذي يجري عملية جراحية أو يفتح عين إنسان حر ويتسبب في وفاته أو فقداء بهاه

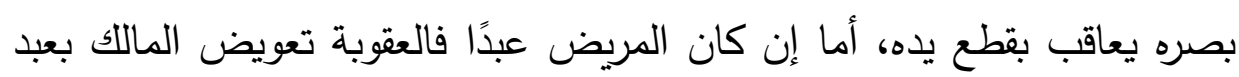

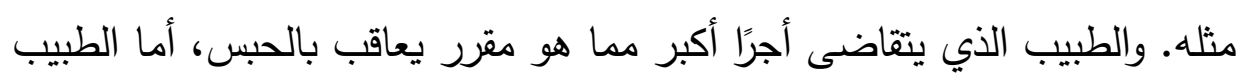

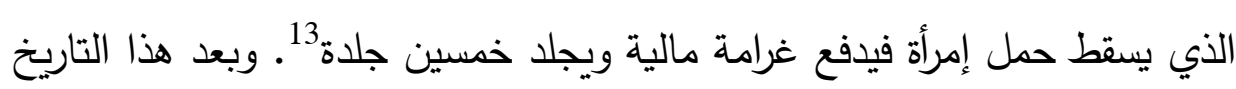
في الشرق ظهر الاهتمام بالأخلاق الطبية في الغرب حين جاء أبقراط ليضع ميثاقًا لمزاولة مهنة الطب يتعهد فيه الطبيب بالعديد من القواعد الأخلاقية حيث يقسم الطبيب لن أعطي عقارًا مميتًا لأي إنسان إذا سألني إياه، ولن أعطي اقتراحًا

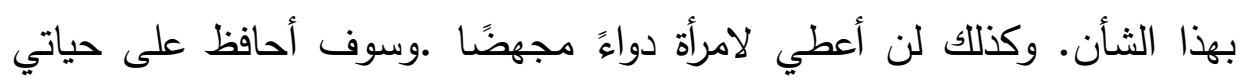
وفني بطهارتي وتقواي. ولن أستخدم الموسى حتى مع الذين يعانون من الحصوات داخل أجسامهم. وسوف أتراجع لمصلحة الرجال المشتغلين بهذا العمل .وأيا كانت

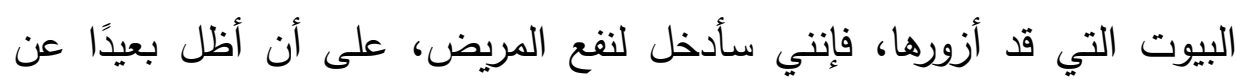

11-كريستيانو داليو : الطب عند الفراعنة، ترجمة إبتسام محمد عبد المجيد، الهيئة المصرية العامة

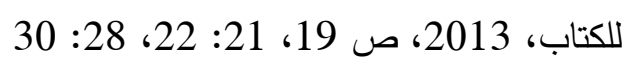

12- د حمح على البار ، د حسان شمسي، د دان عدنان أحمد البار : موسوعة أخلاقيات مهنة الطب،

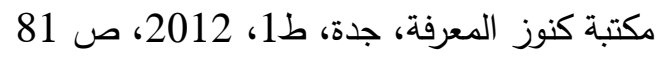

13 - 1السابق ص 82: 83 
جميع أعمال الظلم المتعمَّد، وجميع الإساءات وبخاصة العلاقات الجنسية سواء مع الإناث أو مع الذكور أحرارًا كانوا أو عبيدًا .وسوف أظل حريصًا على منع نفسي عن الكلام في الأمور المخجلة، التي قد أراها أو أسمعها أثناء فترة المعالجة وحتى بعيدًا عن المعالجة فيما يتعلق بحياة الناس، والتي لا يجوز لأحد أن ينشرها. وهو القسم الذي أصبح اساسًا فيما بعد لمزاولة مهنة الطب. وفي إطار ثقافتنا الإسلامية والعربية نجد الدعوة للحفاظ على الجسد من خلال الأمر بالتداوي والعلاج في إطار مقاصد الشريعة وهي الحفاظ على الحياة، والعقل، والجسد، والعرض، والمال. فالتداوي من الأمراض المختلفة والوقاية منها يأتي من باب الحفاظ على حياة الإنسان وسلامة عقله وجسده محققًا بذلك ثلاثة من مقاصد الشريعة الغراء، وحتى يحقق العمل الطبي أهدافه ويعد عملاً أخلاقيًا يجب أن تكون أهدافه مستمدة من الأسس الثرعية مثل قاعدة النية أو القصد فيجب أن يكون هدف الطبيب ونيته العلاج، وأن تشخيص الطبيب لمرض معين وعلاجه هو لحين الحصول على معلومات مؤكدة تشير لغير ذلك، وأن يكون الهدف من التذخل الطبي إزالة الضرر وحدوث الشفاء طبقًا لقاعدة الضرر يزال ولا ضرر ولا ضرار مما يوجب على الطبيب اتخاذ قرار العلاج الأكثر فائدة والأقل ضررًا للمريض، وقاعدة المشقة التي تبيح للطبيب علاج المريض بعلاج يبيح ما لم يكن مباحًا طبقًا لقاعدة الضرورات تبيح المحظورات، وأخيرًا قاعدة العرف14 كما يقدم لنا الرازي مثالاً لما يجب أن يكون عليه سلوك الطبيب في كل العلاقات المتعلقة 14- د. سامية لحولود، د. زكية مقري، د. نعيمة يحياوي، أ. ريمة باشة: مرجع سابق، ص 
بالعمل التي يدخل فيها ففي تعامله مع المرضى "ينبغي للطبيب أن يكون رفيقًا

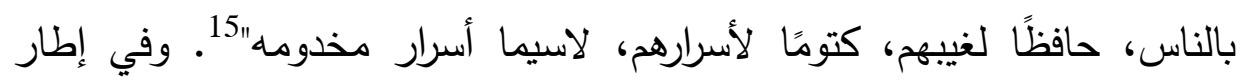

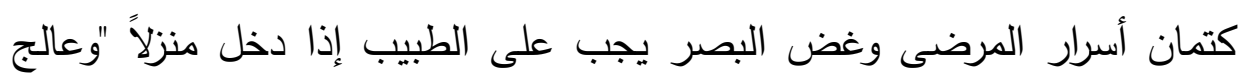

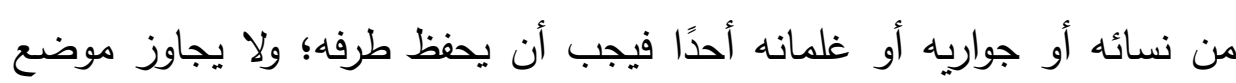

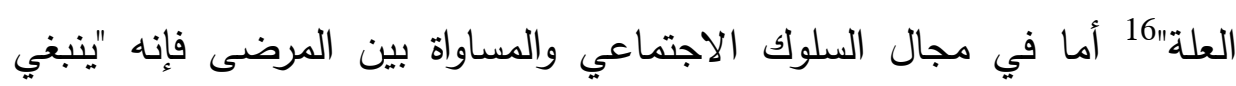
للطبيب أن يعالج الفقراء، كما يعالج الأغنياء"17، وعلى المستوى الثخصي والسلوك الواجب على الطبيب اتباعه حتى يحظى باحترام المرضى ينبغي على الطبيب أن "يمتنع عن معاقرة الخمر "18

أما إذا انتقلنا إلى عصر النهضة والعصر الحديث فنجد أنهما تميزا بوضع القواعد الكبرى في الطب وظهور عباقرة الأطباء وبعض الاكتثافات المبهرة، غير أن هذه التطورات اتسمت بالبطء والاعتماد على العرف والمعتقدات خاصة الدينية، ومع ولوج القرن التاسع عشر حتى اليوم فقد تم وضع قوعد الطب الحديث وظهور الكثير من القضايا الناجمة عن التطور التقني في العلوم الطبية19 وشهد العصر الحديث محاولات متتالية ومضنية من العلماء والأطباء في الصراع " مع

15- أبي بكر محمد بن زكريا الرازي: أخلاق الطبيب، تقديم وتحقيق د عبد اللطيف محم العبد،

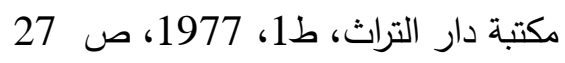

$$
\begin{aligned}
& \text { 16- السابق ص دان } 28 \\
& 17 \text {-السابق ص } 37 \text {-العابق ص } 37 \\
& \text { 18-السابق ص } 65
\end{aligned}
$$

19- عبد اللطيف بربيش: تأملات في المظاهر التقنية والخلقية الناجمة عن تطور العلوم الطبية، الأكاديمية، المغرب، العدد 8، ديسمبر 1999، صالطات في 157، 158 
الأمراض المزمنة والمستعصية ولقد استعمل الأطباء، في تحفزهم للقضاء على آثار الأمراض وإرجاء لحظة النهاية المحتومة إلى حين، وسائل جديدة متعددة"20.2

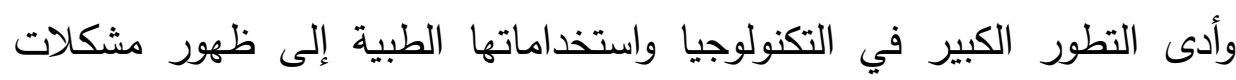
أخلاقية جديدة لم تكن موجودة من قبل، وتزامن ذلك مع زيادة الانتهاكات الأخلاقية في ظل الرغبة العارمة في تحقيق أكبر قدر من الككاسب المادية

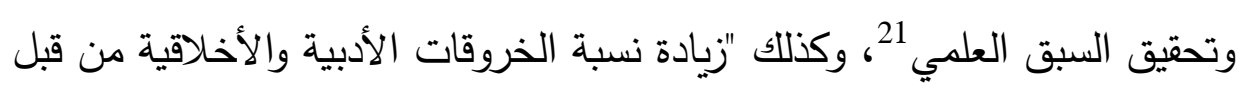

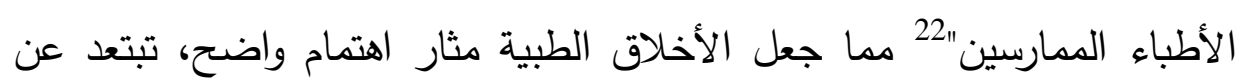

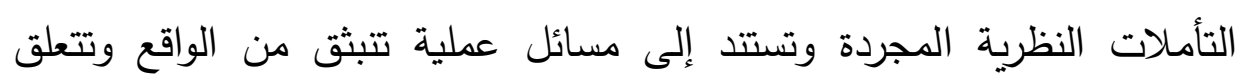
بمشكلات الحياة اليومية وأمور الصحة والمرض 23 وتفرض على المئى المؤسسات المسؤولة عن إعداد الطبيب وفي مقدمتها كليات الطب الاتجاه نحو الاهتمام بتدريس الأخلاقيات الطبية للطلبة وإكسابهم السلوكيات المثلى في التعامل مع المرضى 24. وفي هذا الإطار تم وضع مجموعة من المبادئ أو الأسس التي تقوم

20- د أحمد السعيد شرف الدين: الحدود الإنسانية والثرعية والقانونية للإنعاش الصناعي،

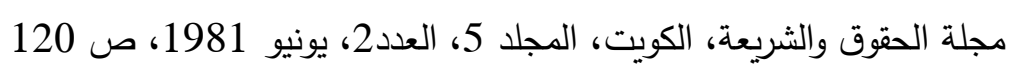

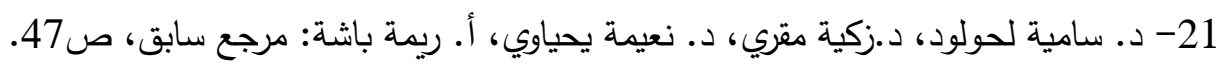

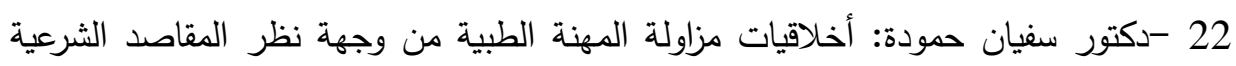

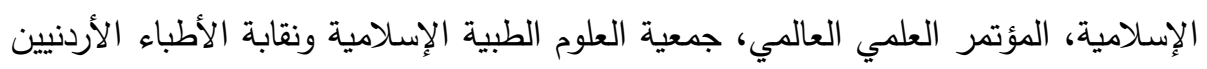
والاتحاد العالمي للجمعيات الطبية الإنسلامية، عمان، 17 تموز من عام العيد 2004 م. 20 م.

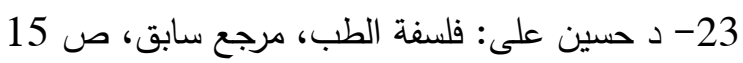

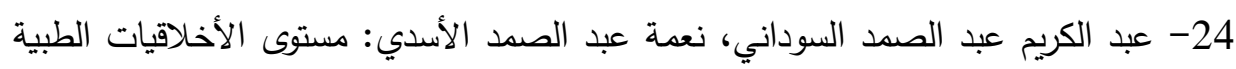

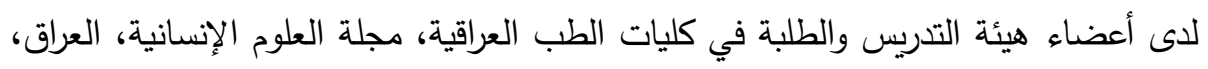

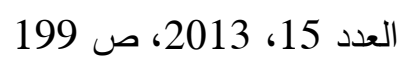


عليها الأخلاقيات الطبية المتطورة سواء العلاجية أو البحثية يحددها البعض بأنها

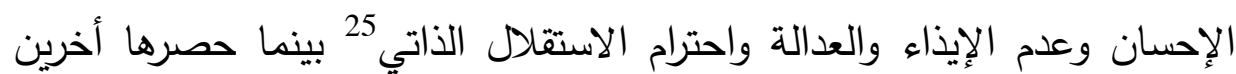

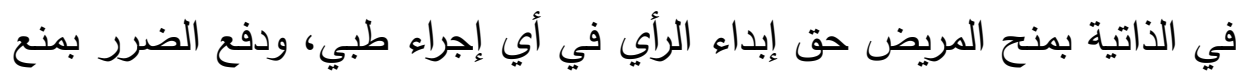
والامتتاع عن كل ما يؤذي المريض، والمنفعة بالقيام بكل ما في صالح المريض

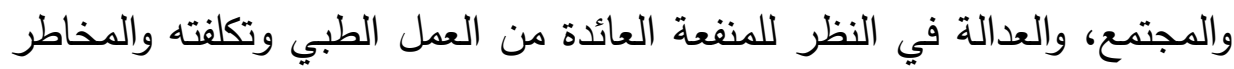
المحتملة26. وقد تتوعت الاهتمامات في الأخلاق الطبية فظهرت أخلاقيات الرعاية ذات الصلة بالعلاقات بين المهنيين والمرضى والتي حددت ريتا مانينغ Rita خصائصها بأنها الاهتمام الأخلاقي بكل حالة على حدة، والتفاهم الودى بالوعي برغبات الأفراد ومصالحهم، وادرالك العلاقات الحساسة في شبكة العلاقات الإنسانية وأدوار المهنيين والمرضى، ومحاولة استيعاب احتياجات ومصالح الجميع²7، وأخلاقيات السياسة الصحية التي تتتاول الموضوعات التينات الصحية من منظور أخلاقي مثل حق المواطنين في معرفة تنظيمات هذا المجال، ومدى احترام حرية وكرامة الأفراد في حملات إشهار التدخين، ومدى التزام مبادئ العدالة والمساواة في دخول مراكز العناية الصحية، وهل هنالك حق في الصحة أم

25- The Bioethics of the Circumcision of Male Children in

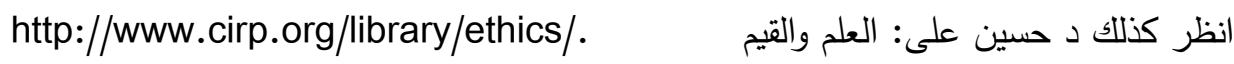
الأخلاقية، العلم والقيم الأخلاقية - رؤية معاصرة، أم القرى للطباعة والنشر والتوزيع، 2008،

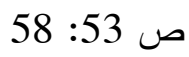
26- د. سامية لحولود، د.زكية مقري، د. نعيمة يحياوي، أ. ريمة باشة: مرجع سابق، ص50. 27- N G Messer: Professional-patient relationships and informed consent, Medical Journal,2004,80, page279 
حق في العلاج 28 وأخلاقيات البحث العلمي في المجال الطبي والتي نتتاولها في إطار بحثنا، ولعل أهم التطورات الحادثة في هذا المجال وما أسفرت عنه نقاشات الفلاسفة وعلماء الاجتماع والقانون والأطباء هو مفهوم الموافقة المستتيرة. المبحث الأول مفهوم الموافقة المستنيرة وشروطها وعوائقها أولاً: تعريف الموافقة المستنيرة Informed Consent يستخدم المفكرون مصطلح الموافقة المستتيرة Informed Consent للدلالة على موافقة المريض أو المبحوث على العمل الطبي أو البحثي الذي يتم إجرائه

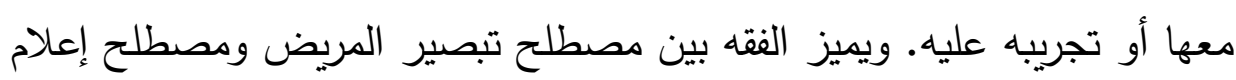

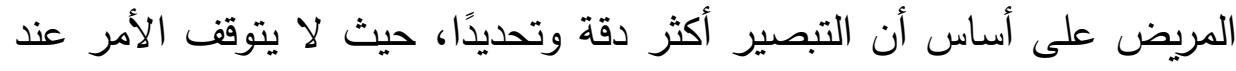

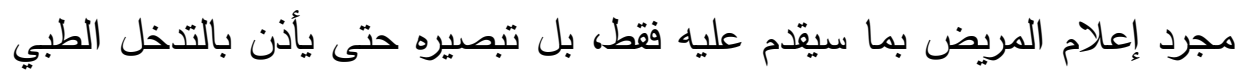

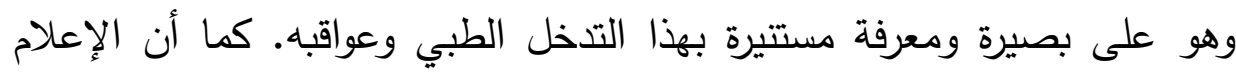
يكون قبل إبرام العقد بينما التبصير يمتد لتنفيذ العقد وتنفيذ الطبيب للالتزامات المكلف بها بما فيها تمكين الطبيب مريضه من معلومات كافية تمكنه من اتخاذ

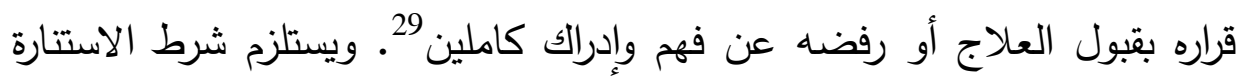

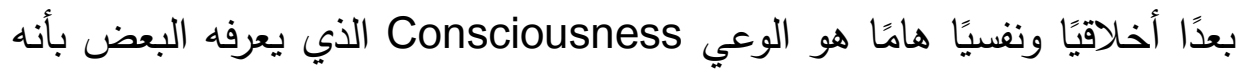

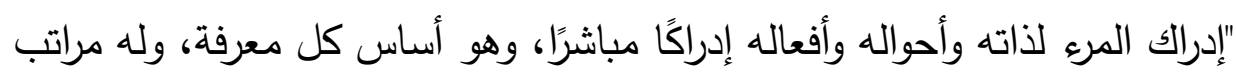

28 -د أحمد عبد الحليم عطية: الأخلاقيات الحيوية الطبية، دفاتر فلسفية، كرسي اليونسكو

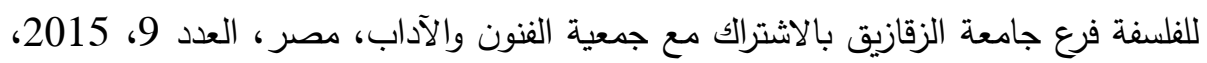
ص ص 109 29 -مراد ابن صغير : مدى التزام الطبيب بتصير المريض: دراسة علمية تأصيلية مقارنة، مجلة الحقوق، الكويت، الجلد 34، العدد 4، ديسمبر 2010، ص 270، 271، 271 
متفاوتة في الوضوح، وبه تدرك الذات أنها تشعر وأنها تعرف ما تعرف"30. كما

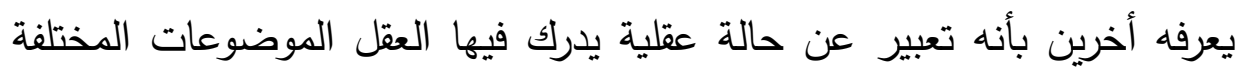

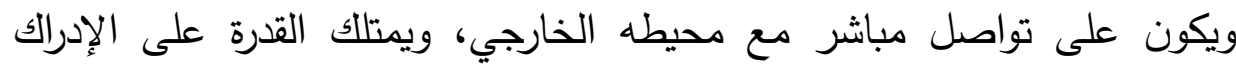

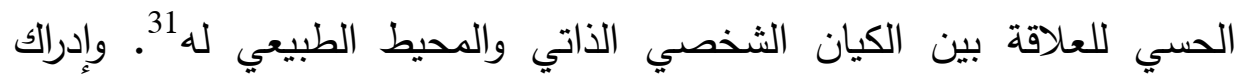

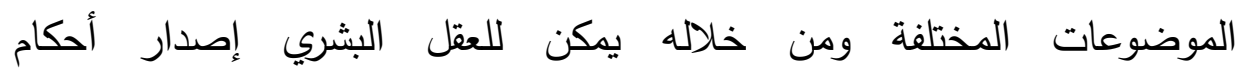
معيارية/قيمية، تلقائية وفورية، على القيمة الأخلاقية لبعض الأعمال الفردية

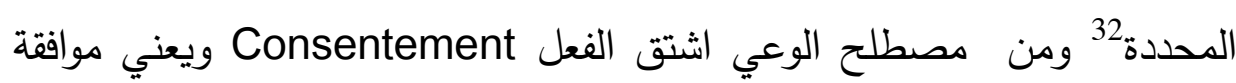

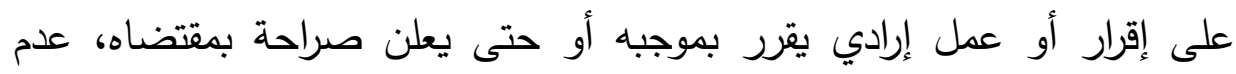

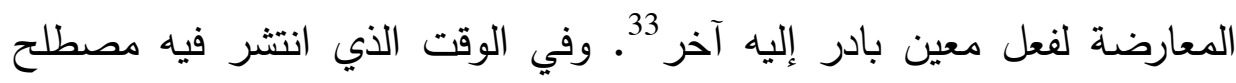
الموافقة المستتيرة فإن البعض يفضل بادر عن حق استخدام مصطلح الاختيار

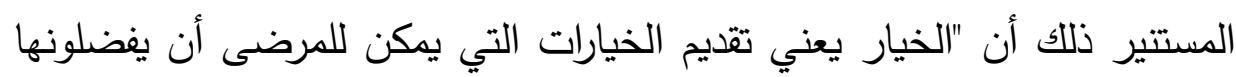
بما في ذللك عدم القيام بفعل"34 وذلك على خلاف الموافقة التي تعطي إيحاءً نفسيًا للمريض أو المبحوث بالموافقة على ما يعرض علئ عليه مسبقًا. وتوجد تعريفات متعددة للموافقة المستتيرة ومنها أنها فعل المقصود منه

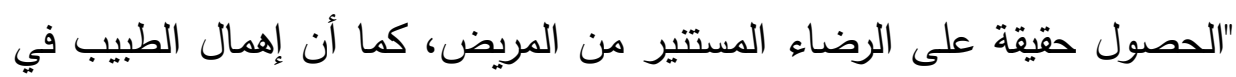

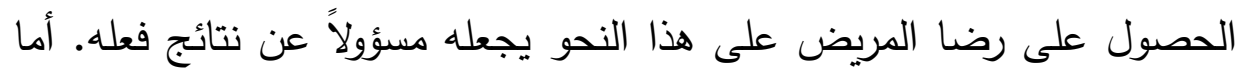

30- د إبراهيخ مدكور وآخرين:المعجم الفلسفي، الهيئة العامة لشئون المطابع الأميرية، مصر ، 1983، ص 215

31 -د مصطفى حسيبة: الدعجم الفلسفي، مرجع سابق، ص 215

32 -أندريه لالاند: موسوعة لالاند الفلسفية، م 1، تعريب خليف صانيل أحمد خليل، منشورات

عويدات، بيروت، ط2، 2001، صناند 211 211، 212

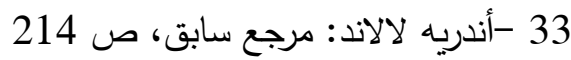

34- M Stirrat, R Gill: Autonomy in medical ethics after O'Neill, journal of medical ethics, 2005, 31, page 129 
الاختيار المستتير فيقصد به أن يكون الرضا عن بصر وبصيرة، بعواقب استخدام التدخل الطبي على جسد المريض، أو على الأقل العلم بمحدودية وضآلة الآثار

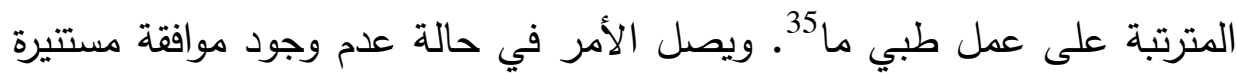
من جانب المريض لأحقيته في الحصول على تعويض عن القيام بالعمل الطبي

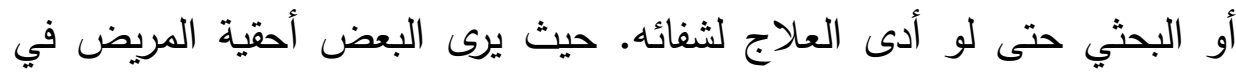
المطالبة بالتعويض، وتزيد إمكانية الحصول على تعويض " إذا كانت إرادة

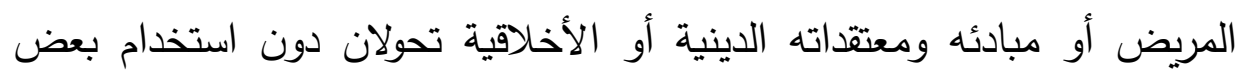

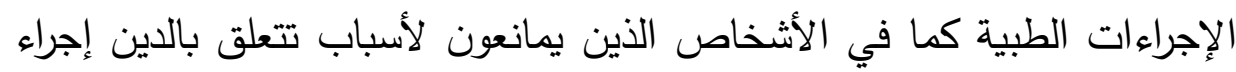

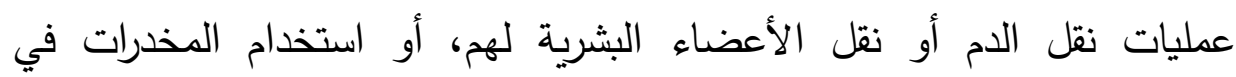

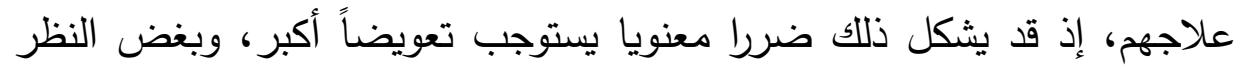

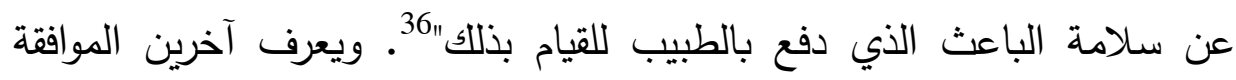
المستتيرة بأنها "العملية التي يقوم من خلاعلها مقدم الرعاية الصحية المعالج

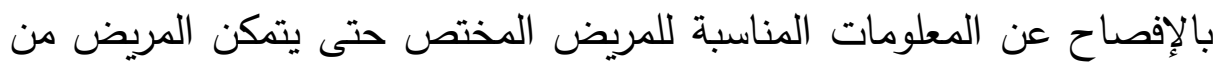
الاختيار الطوعي لقبول أو رفض العلاج"

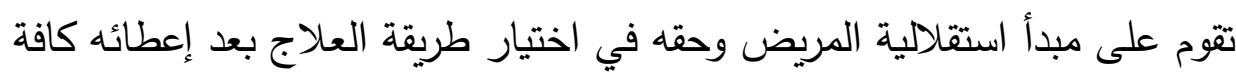

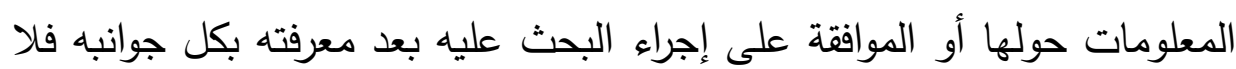
يجوز الحصول على الموافقة الصحيحة إلا من قبل شخص مطلع، يمتلك القدرة

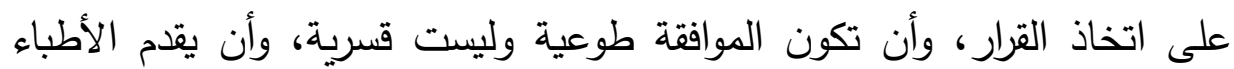

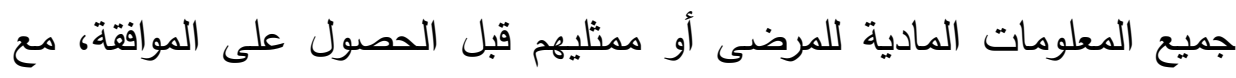

35- الدكتور . هيثم حامد خليل المصاروة: مدى الاعتداد بإرادة المريض في الأعمال الطبية،

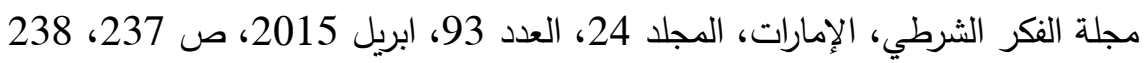
36 -السابق ص 240 37 -Jessica De Bord: Informed Consent, march 2014, University of Washington,in https://depts.washington.edu/bioethx/topics/consent.html 
تقديم معلومات كافية عن العلاجات البديلة38. ويلاحظ أن بعض العاملين في مجال الرعاية الصحية يخطئون حين يظنون أن استمارة الموافقة هي ذاتها الموافقة المستتيرة بينما "الموافقة المستتيرة هي العملية والإجراءات التي تتم إثناء اطلاع المريض أو المبحوث على العلاج أو البحث والتفكير فيه قبل الموافقة عليه، ويؤخذ توقيع المريض أو المبحوث على النموذج المعد ليكون دليلاً على حدوث الموافقة المستتيرة"39، وفي حالة إذا ما رفض المريض القيام بالإجراء العلاجي

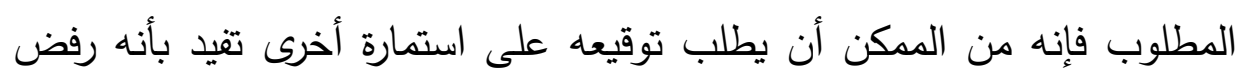
العلاج لإخلاء مسئولية مسئولي الرعاية الطبية

وهناك عناصر ضرورية لابد من وجودها حتى تتحقق الموافقة المستنيرة هي:

1-أن يكون الشخص الذي يعطي الموافقة المستنيرة لديه القدرة أو القابلية لاتخاذ القرار

2-أن يقوم مقدم الخدمة الطبية بالكشف عن المعلومات المتوافرة عن العلاج أو الاختبار أو الإجراء الذي سيتم اتخاذه، والبدائل المختلفة له، بما في ذلك الفوائد والمخاطر المتوقعة جرائه، واحتمال أو إمكانية حدوث المنافع والمخاطر . 3-أن تكون المعلومات التي يتم إخطار المريض بها هي المعلومات ذات الصلة بالعمل الذي سيتم إجرائه مباشرةً بحيث لا يتم تشتيت الشخص في كمية كبيرة من المعلومات بما يحد من قدرته على اتخاذ القرار . 4-إن يتم منح المريض أو المبحوث الوقت الكافي لمناقشة الأمر مع الأسرة أو المستشارين.

38 -The Bioethics of the Circumcision of Male Children, in http:// www. cirp.org/library/ethics/

39- What is informed consent and what does it mean? In https://www.cancer.org/treatment/finding-and-paying-for- treatment/ understanding-financial-and-legal-matters/informed-consent/what-isinformed-consent.html 
5-أن يكون الثخص قادرًا على فهم المعلومات الممنوحة له ولديه القدرة

$$
\text { على استخدام المعلومات لاتخاذ القرار } 40 .
$$

وسوف ننتقل في الصفحات القادمة من الإجمال إلى تفصيل هذه الثروط لنال وعرضها عرضًا تفصيليًا.

وفي الوقت الذي يرى فيه البعض أن الموافقة المستتيرة لا معنى لها ولا

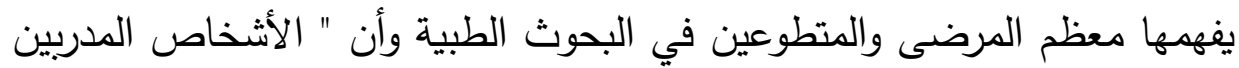
طبيا فقط"، وأحيانا ليس جميعهم، عند تطوعهم كمواضيع للبحوث السريرية غير البرئ

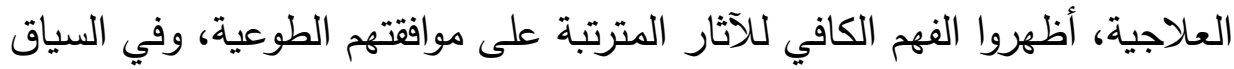

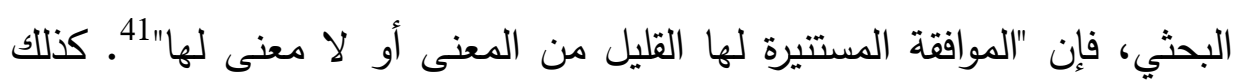

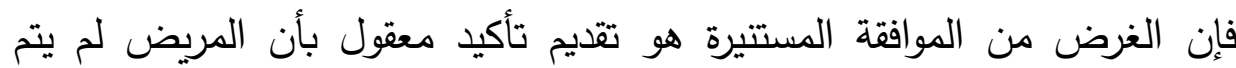

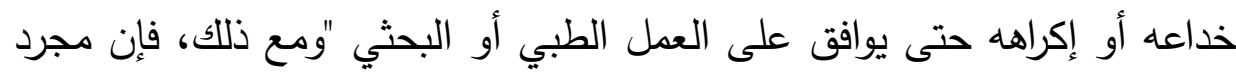

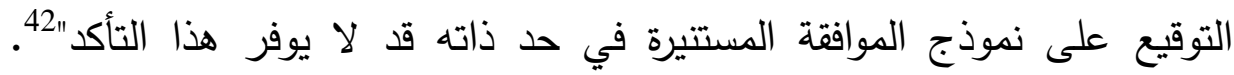

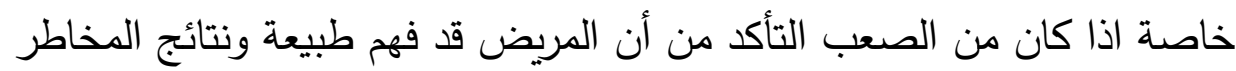
المحتملة مما يصل إلى أن يصبح التأكد من حدوث الموافقة المستنيرة شبه

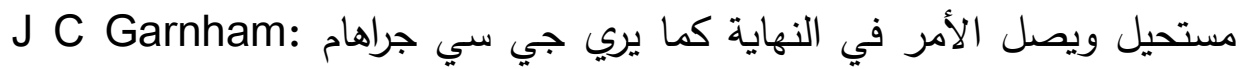
إلى أن يصبح الطبيعي هو "افتراض أن الموافقة المستتيرة قد تم الحصول جلئ عليها

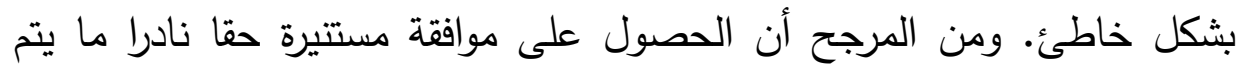

40- Richard A Wagner: informed Consent, in https://www.emedicinehealth.com/informed_consent/article_em.htm. Also What is informed consent and what does it mean? In https://www.cancer.org/treatment/finding-and-paying-fortreatment/understanding-financial-and-legal-matters/informedconsent/what-is-informed-consent.html.

41 -Kenneth Boyd: The impossibility of informed consent?, Journal of Medical Ethics, 2015, vol 41, page 44

42- N G Messer: Professional-patient relationships and informed consent, Medical Journal,2004, vol 80, page277 
الحصول عليها"43. وفي المقابل فإن الأغلبية من المفكرين يرون أهمية الموافقة المستتيرة وأنه من الواجب أن يكون " المريض على علم بالمخاطر الهامة، والآثار الجانبية لأي علاج مقترح، وأن هذه المعلومات يجب أن تشكل جزعًا من علاقة ثقة بين المريض وطبيبه"44، بل أن الموافقة المستتيرة تعد ضمانة أساسية للمرضى والمبحوثين للثقة في مقدمي الرعاية الصحية والمؤسسات البحثية الطبية، وأن أي مخالفة لها تفقد المرضى أو المبحوثين الذين قد يتم خداعهم الثقة في هذه المؤسسات "وقد يصبح فقدان الثقة نهائي. ومن ثم فقد يفقدون الثقة في الأطباء حسني النية، وفي الأدوية التي قد يحتاجونها في المستقبل، بل قد يحصلون لأنفسه على عقاقير أكثر ضررا أو يعلقن آمالهم في الخرافات والبدع"45. وزادت أهمية دراسة الموافقة المستتيرة في ظل عدم كفاية اللوائح والمواثيق الطبية وعدم تتاسبها مع التطورات العلمية الحالية أو وضعها حلول للمشكلات التكنولوجية المستجدة مما يجعل الطبيب وعالم الأحياء عاجزين عن وجود ما يمكن الرجوع إليه للحكم على المواقف التي تواجهوما46. وقد زادت أهمية الموافقة المستتيرة وتطورت عبر الزمن بدءً من كود نورمبرج 1947*، ومرورًا

43- J C Garnham: Some observationsns on iofrmed consent in nontheraeutic research, Journal of Medical Ethics, 1975 , vol1, page 143 44- Grant R Gillett: Informed consent and moral integrity, Journal of medical ethics, vol 15, 1989,page 117

45 -Nir Eyal: Using informed consent to save trust, Jourmal of Medical Ethics 2014, page 437

46 -د حسين على: العلم والقيم الأخلاقية - رؤية معاصرة، مرجع سابق، ص 51

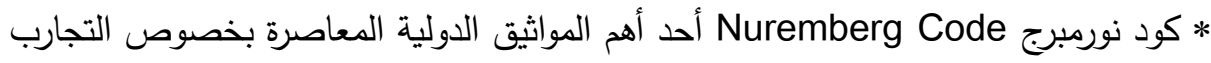

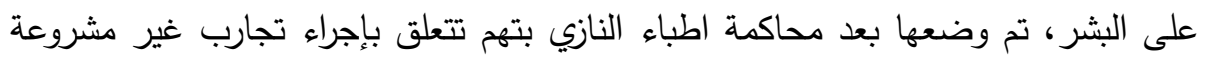
على البشر أثثاء الحرب العالمية الثانية 
بإعلان هلسنكي 1964، تقرير بلمونت 1979، المؤتمر الدولي للموائمة gcp

توجد العديد من الثروط الواجب توافرها حتى تعد الموافقة المستنيرة الصادرة من المريض أو المبحوث صحيحة ومن أهم هذه الثروط:

1- الأهلية: ويقصد بالأهلية هنا صلاحية الشخص لإصدار الموافقة

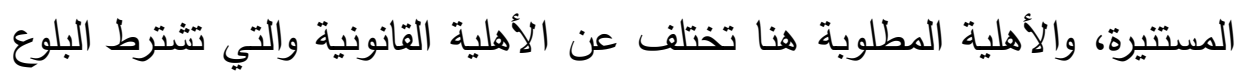
والوصول لسن معين دون وجود مانع أو عارض من عوارض الأهلية، فالأهلية هنا تعني القدرة على اتخاذ القرار من الناحية القانونية والطبية واتخاذ القرارات فيما

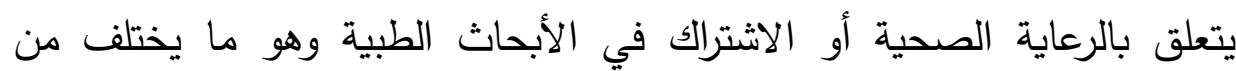
شخص لآخر، وعند نفس الثخص من وقت إلى آخر، ويختلف عن الأهلية

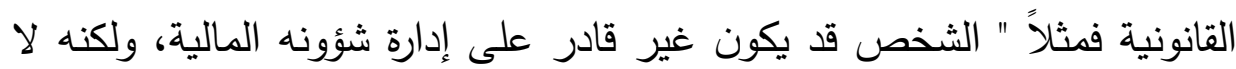

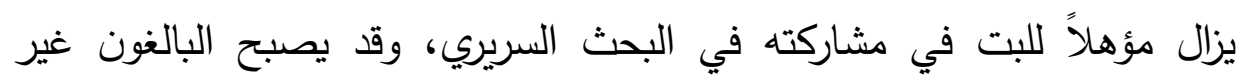

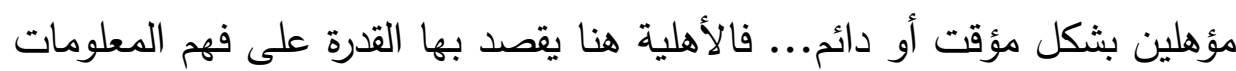

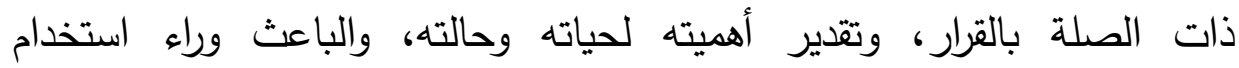

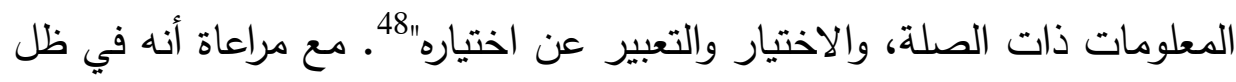

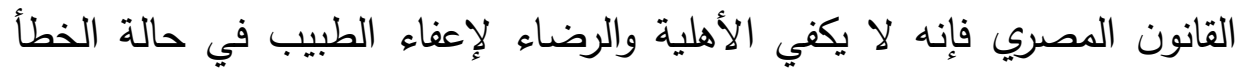

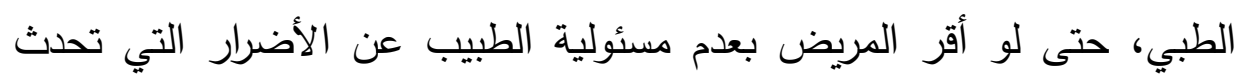

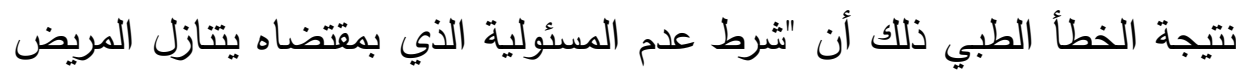

47-Lokesh P. Nijhawan, Manthan D. Janodia, B. S. Muddukrishna, K. M. Bhat, K. L. Bairy, N. Udupa, and Prashant B. Musmade: Informed consent: Issues and challenges, Journal of Advanced Pharmaceutical Technology \& Research, v4 (issue 3), jul-sep 2013, p 135

48 -N G Messer: Professional-patient relationships and informed consent, Medical Journal,2004,80, page2079,280 
عن حقه في التعويض في حالة الأضرار الناتجة عن خطأ الجراح، يعتبر شرطًا باطلاً"

2- تقديم المعلومات الكافية: التزام الباحثين والأطباء بتقديم المعلومات

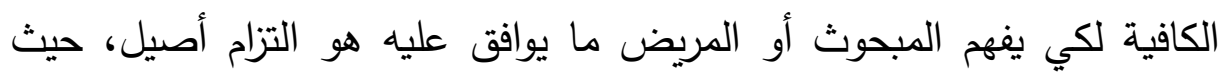

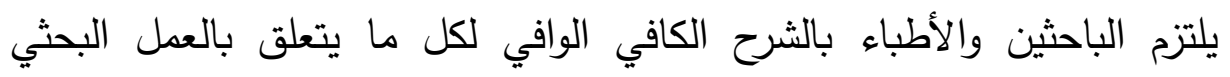

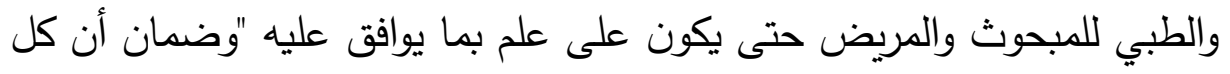

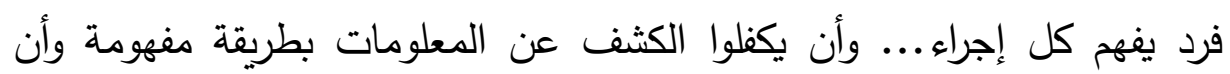
يضمنوا أيضا أن تستند قرارات التسجيل إلى فهم دقيق لتلك المعلومات وأن تكون

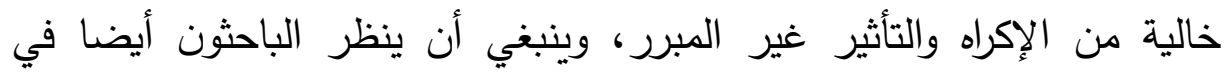

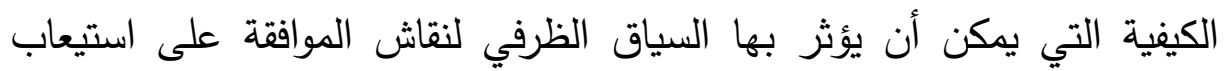

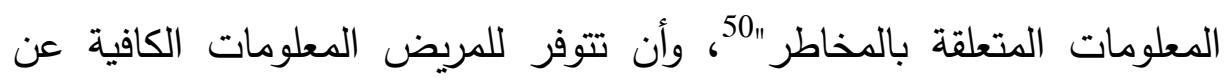

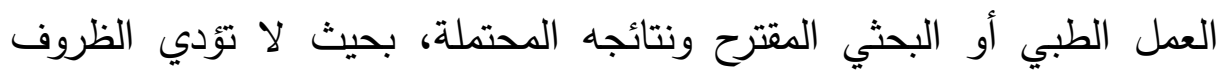

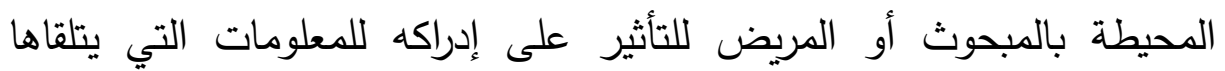

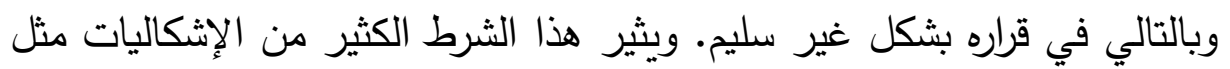

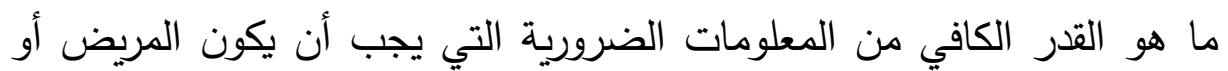

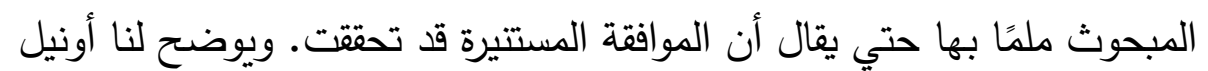
O Neill المريض قد وافق على الإجراءA ، الذي ينطوي منطقيًا على الإجراء B ، ويكون

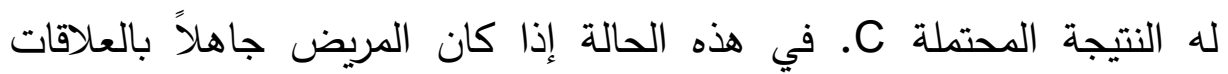

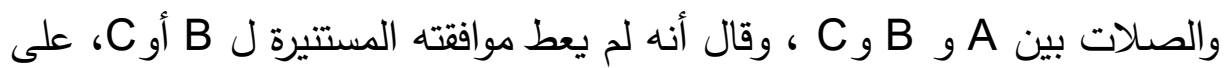

49- د أحمد السعيد شرف الدين: زراعة الأعضاء والقانون، مجلة الحقوق والثريعة، الكويت،

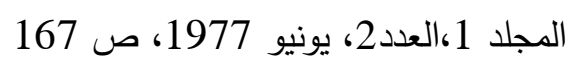

50- Danielle Bromwich, Annette Rid: Can informed consent to research be adapted to risk?, journal of medical ethics, 2015, vol 41, page 521

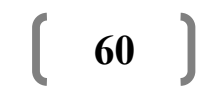


الرغم من أن المختصين يعرفون هذه العلاقات والصلات بشكل بديهي" "51 في هذه الحالة إذا لم يوضح المختصون هذه العلاقات فإن موافقة المريض أو المبحوث تعد موافقة معتمة حيث تمت الموافقة دون توضيح كاف للعلاقات والنتائج المترتبة على الإجراء الأساسي الذي يعرفه المريض أو المبحوث بشكل واضح.

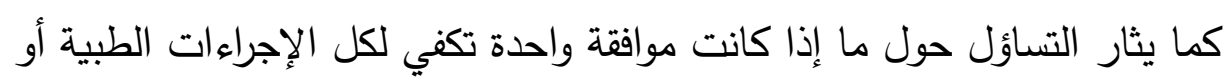
البحثية أم يجب الحصول على موافقة محددة لكل إجراء منفرد، وهنا يشير أونيل إلى ضرورة التمييز بين الموافقة العامة والمحددة، وضرورة مراعاة ما إذا كانت الموافقة العامة "يمكن أن تثير إلى الموافقة الصحيحة على مجموعة من لهن الإجراءات المختلفة، أو ما إذا كان يجب الحصول على موافقة محددة لكل إجراء

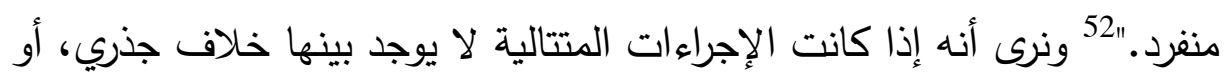
أنها مترتبة على بعضها البعض بطريقة لزومية، وأن المريض أو المبحوث يفهم ذلك فإنه لا يشترط الحصول على موافقة على كل إجراء، وإن كان هنالك خلاف جذري بينها، أو أن هناك تطورات أثناء العلاج أو البحث لم تكن متوقعة في البداية، وتؤثر تأثيرًا جوهريًا في طبيعة العلاج أو البحث فإنه يجب الحصول على موافقة مجددة للإجراءات الجديدة.

3- الإرادة الحرة: يجب أن تتوفر لدى المريض أو المبحوث الإرادة الحرة الكاملة عند اتخاذ القرار وتوقيع الموافقة المستتيرة، والمقصود بحرية الإرادة هو القدرة على القيام بعمل، أو الامتتاع عن عمل، دون الخضوع لأي ضغط خارجي أو تحت تأثير قوى خارجية، بحيث نصمم ونعمل بعد تدبر وروية، وتكون أفعالنا

51- N G Messer: Professional-patient relationships and informed consent, Medical Journal,2004,80, page 280

52- N G Messer: Professional-patient relationships and informed consent, Medical Journal,2004,80, page279 
وليدة معرفة وتأمل 53. وهذه الحرية "ليست مجردة من الضوابط والثوابت والقيود

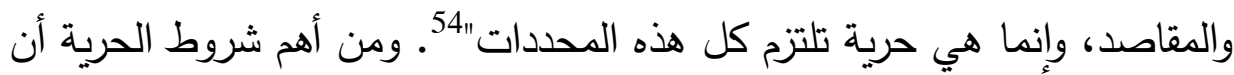
تكون الإرادة مستقلة تفعل كما يشاء صاحبها، وعند كانط ترتبط "فكرة الحرية بتصور الاستقلال الذاتي ارتباطًا لا ينفصل"55 ولهذا يعرف كانط مبدأ الحرية بأنه " قدرة الشخص على التصرف وفقا لقوانين موضوعية التي يتبناها بنفسه"56. والحرية عند كانط إمكانية تحتاج إلى الإرادة لتتحول إلى فعل حر يمارس الإنسان

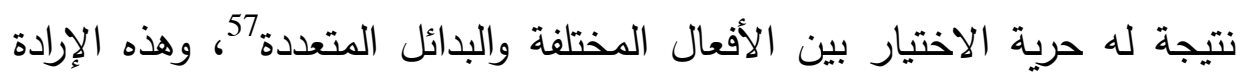
الحرة هي مصدر المسئولية لذا أكد كانط "على المسؤولية المطلقة للإنسان باعتباره كائنًا عاقلاً وحرًا"58، والتي تدخل في نطاق ضمان أن "المريض لديه حرية الاختيار من بين البدائل الطبية دون إكراه أو التلاعب"59. ولكن الحرية لا

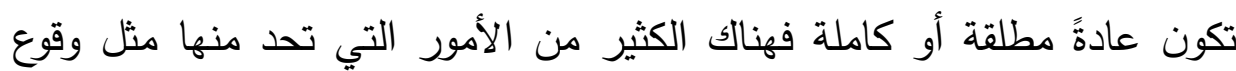

53- د زكريا إبراهيم: مشكلة الحرية، مكتبة مصر ، القاهرة، ط3، 1972، ص 18، 19

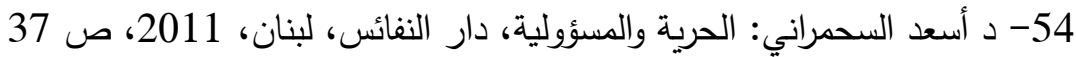

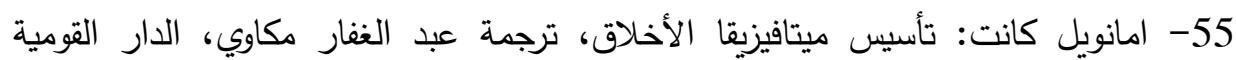
للطباعة والنشر والفنون، 1965، ص 116 56- دليلة جبار:: طبيعة الحرية عند كانط من خلال فلسفته النقدية، رسالة ماجستير غير منشورة، جامعة الجزائر، كلية العلوم الإنسانية والاجتماعية، قسم الفلسفة، 2004، ص 73

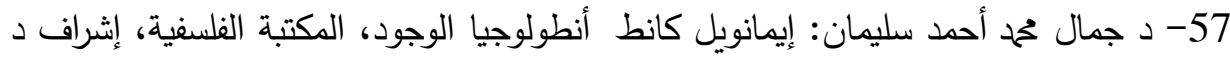
أحد عبد الحليم عطية، دار التتوير للطباعة والنشر والتوزيع، مصر، 2009، صابط صل 423،

58 -عماري خيرة: الإنسان في فلسفة كانط، رسالة ماجستير غير منشورة، جامعة الجزائر، كلية العلوم الإنسانية والإجتماعية، قسم الفلسفة، 2006، ص صل 109

59- Committee on Bioethics: Informed Consent, Parental Permission, and Assent in Pediatric Practice, PEDIATRICS, Volume 95 Number 2, Pages 314-317, February 1995, in http://www.cirp.org/ library/ ethics/AAP 
المريض أو المبحوث تحت سيطرة الطرف الآخر أو تحت الإكراه المادي أو المعنوي، مثل عدم التوازن في المعرفة والسلطة بين المريض والطبيب أو الباحث، أو تأثير أطراف ثالثة على قرار المريض مثل أسرته، أو وجود علاقة تبعية بين المريض والأطباء أو الباحثين مما يؤدي لشعور بعض المرضى بوجوب الالتزام أخلاقيًا بالموافقة على مشروع بحثي، أو التخوف من تأثر الرعاية الطبية سلبًا إذا لهاء رفضوا أو الوقوع تحت إغراء دفع مكافآت سواء نقدية أو عينية كبيرة بما فيه

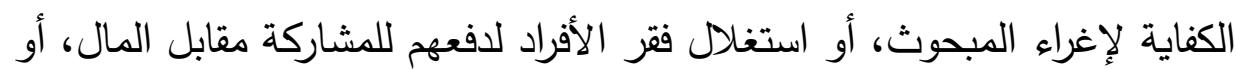
وجود جهات مانحة ذات سلطة مثل السجون، وهو ما سنوضحه تفصيلاً في

$$
\text { التجارب غير المشروعة }
$$

ثالثًا: العوائق التي تشوب الموافقة المستنيرة: توجد العديد من العقبات والعوائق التي تشوب الموافقة المستنيرة وبالتالي تجعلها غير كاملة، أو غير معبرة بشكل حقيقي عن إرادة المريض أو المبحوث،

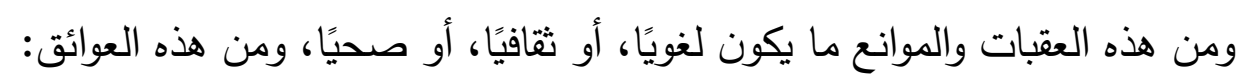
1- عائق اللغة: تمثل اللغة عائقًا ضخمًا يعوق التواصل بين الطبيب والباحث من جهة، وبين المريض والمبحوث من جهة أخرى. وتزداد صعوبة عائق اللغة في المجتمعات ذات اللغات المختلفة، أو المجتمعات المستقبلة للهجرة الكثيفة، فمثلاً "يتعامل مستشفى Elmhurst في ولاية نيويورك في الولايات المتحدة الأمريكية مع أكثر من 100 لغة ولهجة في العام الواحد مما يشكل صعوبة في الحصول على ترجمة فورية في بعض الأحيان. و في كثير من

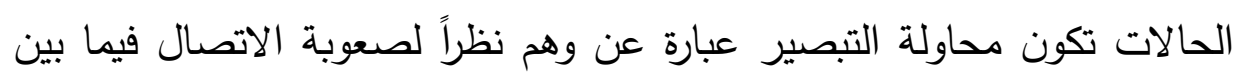

60- N G Messer: Professional-patient relationships and informed consent, Medical Journal,2004,80, page 280, 281 
الطبيب والمريض"61، حيث تئدي لعدم تمكن كل من الطبيب والباحث، أو المريض والمبحوث، من التعرف على المعلومات المطلوبة بشكل واضح مما قد يوجد سوء فهم أو لبس في فهم ما يتم عرضنه، وبالتالي الموافقة المستتيرة عليه. بينما من أهداف الموافقة المستنيرة الأساسية " توفير معلومات كافية للمشارك

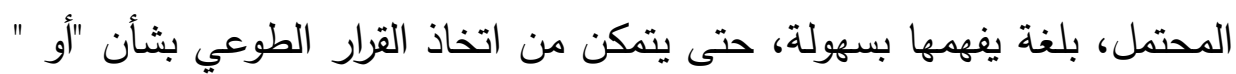

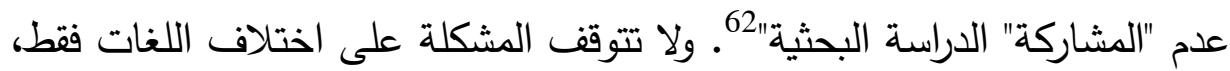
بل أن اختلاف اللهجات يؤدي أحيانًا لنفس المشكلة حين يكون للكلمة الواحدة معاني متعددة في اللهجات المختلفة داخل اللغة الواحدة. 2- العائق الديني: في الوقت الذي يرى فيه البعض أن من أهم سمات الأخلاق الطبية أن تكون علمانية تبتعد عن أي عقيدة دينية أو مذاهب لاهوتية تهتم بالإنسان في الأساس بغض النظر عن العقيدة الدينية وألا تتضمن الأخلاق الطبية أية نزعة فلسفية قبلية63، فإننا نختلف مع هذا الرأي حيث نرى أن الأخلاق كاملة ومنها الأخلاق الطبية قد لا يمكن فصلها عن العقائد الدينية. فالمريض قد يرفض العلاج أو العمليات التي تتعارض مع عقيدته الدينية*. لذلك يجب في

61- أيمن خالد مساعده، نسرين محاسنة: الالتزام القانوني بتبصير المريض بالتدخل العلاجي

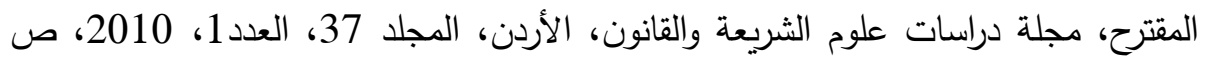

62 - Lokesh P. Nijhawan, Manthan D. Janodia, B. S. Muddukrishna, K. M. Bhat, K. L. Bairy, N. Udupa, and Prashant B. Musmade: Informed consent: Issues and challenges, Journal of Advanced Pharmaceutical Technology \& Research, v4 (3), jul-sep 2013, p 134

63 - د حسين على: العلم والقيم الأخلاقية رؤية معاصرة، مرجع سابق، ص 59، 60 * يرفض شهود يهوه على سبيل المثال أي عمل طبي يتضمن نقل الدم للمريض منهم استنادًا

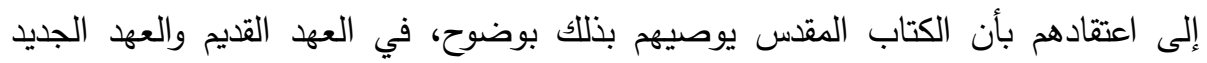

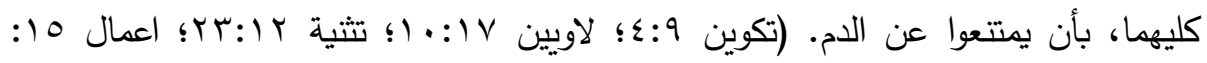


الدراسات المثيرة للجدل سواء لأسباب دينية أو سياسية أو خلافه يجب على

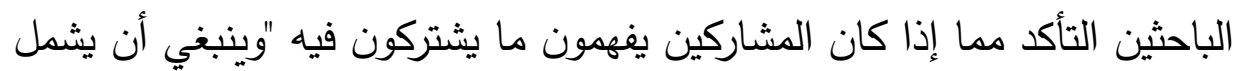

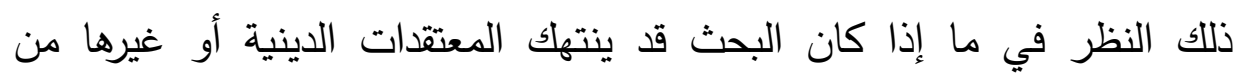

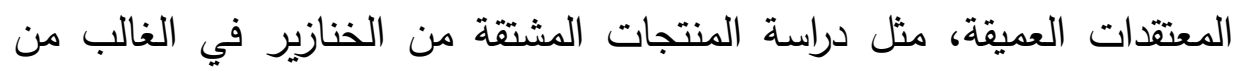

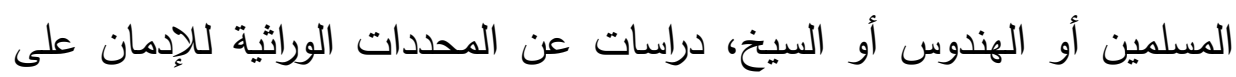

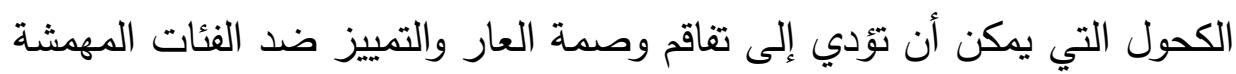
بالفعل"64 3- عائق استمارة الموافقة المستنيرة: ويتمثل في عدم إمكانية شرح كل الاحتمالات المكنة المترتبة على العمل الطبي أو البحثي في استمارة الموافقة

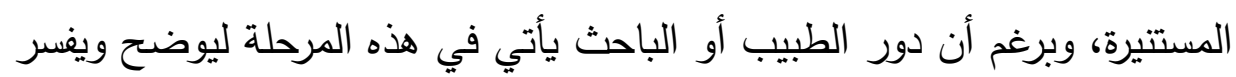
للمريض أو المبحوث ما هو مختصر أو غامض أو دأ ما لم يتم ذكره في الاستمارة،

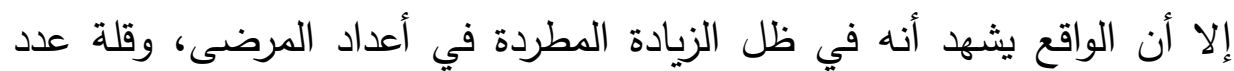

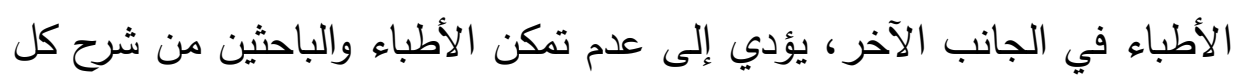

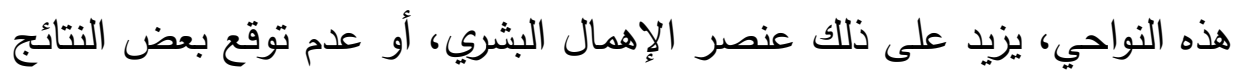

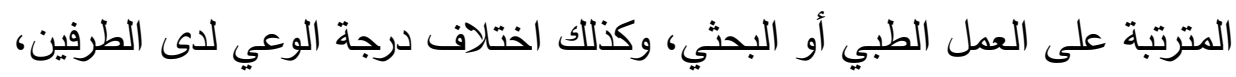

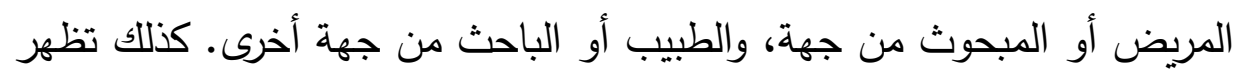

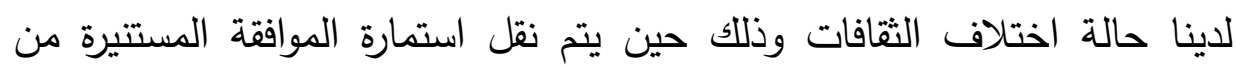

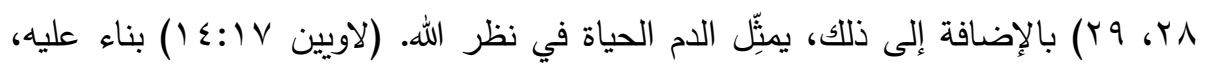

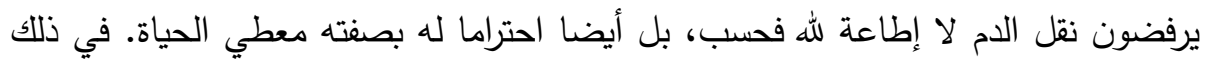

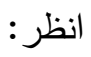
https://www.jw.org/ar/ 64 - Ibid, p 524 


$$
\text { مجتمع إلى مجتمع آخر ذو ثقافة مختلفة دون تغييرها بما يتناسب مع طبيعة المجنم الجديد وهو ما يعرف بالسيناريو الهندي }
$$$$
\text { الموافقة المستنيرة في مجال العمل الطبي }
$$$$
\text { تعد الموافقة المستتيرة في مجال العمل الطبي العلاجي من أهم الخطوات }
$$$$
\text { العلاجية حيث تسبق قرار المريض بالعلاج وطريقته من عدمه، حين يعطي }
$$$$
\text { الأطباء معلومات للمريض حول علاج معين، وتقوم الموافقة المستنيرة على قاعدة }
$$$$
\text { استقلالية المريض } 66 \text { الذي يكون له الحق في اتخاذ القرارات بشأن حالته الصحية }
$$$$
\text { والطبية والموافقة على أي إجراء طبي علاجي يتم اتخاذه معه، والا عد ذلك تعديًا }
$$$$
\text { مجرمًا أخلاقيًا وقانونيًا على سلامة الجسد. ويجب حتى تكون الموافقة سليمة أن }
$$
يكون الحصول على الموافقة المستنيرة من "شخص مطلع، يمتلك القدرة على

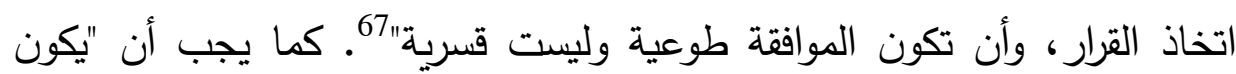
التبصير كاملاً؛ ومن ثم لا يكتفى بتبصير المريض جزئيًا؛ وتطبيقًا لذلك فإن المستشفى العام يخالف الالتزام بالتبصير إذا تم تبصير مريضة بموضوع التدخل الجراحي، وهو عملية تعقيم، دون إخبارها أيضًا بالمضاعفات المحتملة لهذا

65- Lokesh P. Nijhawan, Manthan D. Janodia, B. S. Muddukrishna, K. M. Bhat, K. L. Bairy, N. Udupa, and Prashant B. Musmade: Informed consent: Issues and challenges, Journal of Advanced Pharmaceutical Technology \& Research, v4 (issue 3), jul-sep 2013, p 137, 138 66 -Richard A Wagner: informed Consent, in https://www.emedicinehealth.com/informed_consent/article_em.htm.

67 -The Bioethics of the Circumcision of Male Children in http://www.cirp.org/library/ethics/ 
التتخل"68. ويجب أن يراعي الطبيب في تبصيره للمريض جميع الظروف التي يراها مؤثرة وذات أهمية في تبصير المريض من حيث الحالة الصحية والنفسية، وضرورة أن يكون هذا الإعلام مفهوما وواضحا بعيدا عن التعقيدات أو ون المصطلحات العلمية الدقيقة والمعقدة بأسلوب بسيط وميسر وبلغة مفهومة واضحة. كما ينبغي على الطبيب أن يراعي سن المريض وجنسه وقوة شخصيته ومستوى تعليمه وثقافته ومدى رغبته في معرفة التفاصيل المتعلقة بحالته، ومن ثم يكون واجبًا على الطبيب أن يأخذ في اعتباره درجة ذكاء المريض ودرجة استيعابه 69. ويقع عبه إثبات قيام الطبيب بالتبصير على الطبيب نفسه، ويمكنه إثبات ذلك بكل طرق الإثبات، غير أنه "لا يعتبر دليلاً على تبصير المريض أن يقدم المستشفى شهادة صادرة عن طبيب في وقت لاحق على التتخل الطبي تفيد أنه قد تم تبصير المريض بمخاطر العلاج المقترح"70 لذا جرى العرف على على الاعتماد على استمارة الموافقة المستتيرة وتوقيع المريض عليها. ولا يجوز المساس بجسد المريض بأي شكل دون موافقته حيث أن حرمة الشخص الطبيعي تعني حقه في الاعتراض على أي مساس بسلامة جسده بما في ذللك رفض الخضوع هون

68- حمح محمد عبد اللطيف: مشكلات المسئولية الطبية أمام القضاء الإداري، مجلة البحوث القانونية والاقتصادية، كلية الحقوق جامعة المنصورة، مصر، العدد 36، أكتوبر 2004، ص ص 64، 66

69- مراد ابن صغير: مدى التزام الطبيب بتبصير المريض: دراسة علمية تأصيلية مقارنة، مجلة الحقوق، الكويت، المجلد 34، العدد 4، ديسمبر 2010، ص صل 287، 288، 288، د هيثم

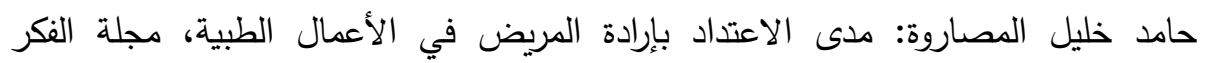

$$
\text { الشرطي، الإمارات، المجلد 24، العدد 93، إبريل 2015، 2015، ص } 239
$$

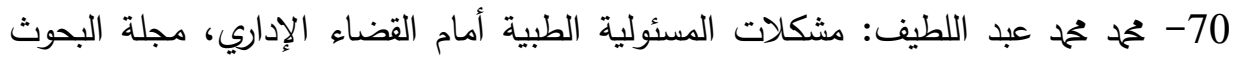
القانونية والاقتصادية، كلية الحقوق جامعة المنصورة، مصر، العدد 36، أكتوبر 2004،

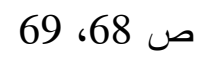


لإجراء العمليات الجراحية أو التحليل الطبي 71. ومن الجدير بالذكر أن وضع شروط في الأعمال الطبية حتى تصبح أخلاقية ليس جديدًا فقد وضعت الثريعة الإسلامية مجموعة من القواعد المستمدة من الأسس الثرعية الإسلامية مثل قاعدة النية، حيث يشترط أن تكون نية الطبيب في العمل الطبي هو العلاج. فمثلا لا يجوز أن يعطي الطبيب للمريض مسكن الهدف منه العلاج ولكن بنية إحداث الموت الرحيم، وكذلك قاعدة اليقين حيث يجب على الطبيب ألا يقوم بأي عمل كل كثل طبي إلا إذا غلب لديه أنه في صالح المريض، وذلك على عكس كثير من المعالجات التي تتم اليوم دون التأكد من نتائجها. كما يجب على الطبيب ألا يحدث ضررًا للمريض من خلال عمله طبقًا لقاعدة لا ضرر ولا ضرار بل وعليه تفادي حدوث الضرر قدر الإمكان، كما يجب عند تحديد العلاج ألا يعالج الضرر بوسيلة تؤدي إلى ضرر آخر يماثل الضرر القديم أو تزيد عنه، مع مراعاة أن هناك بعض الممارسات الطبية المحرمة مثل إعطاء المريض أدوية تغيب العقل قد تصبح مباحة وفقًا لحالة الضرورة فالضرورات تبيح المحظورات، على أن تكون الإباحة مؤقتة تتتهي بانتهاء الضرورة التي فرضتها، ويلتزم الطبيب في ذلك كله بالعرف والعادات العامة والمقبولة في المجال الطبي 72 وفي حالة التزام الطبيب بالحصول على موافقة المريض فإنه ترتفع مسئوليته ولا يحاسب عن العمل الطبي الذي يقوم به. وقد أكدت على هذا العديد من المذاهب الفقهية حيث ذهب الحنفية إلى أن العلة في رفع المسئولية عن الطبيب هي الضرورة الاجتماعية للحاجة

71- منذر عبد الحسين الفضل: التجربة الطبية على الجسم البشري ومدى الحماية التي يكفلها القانون المدني والقوانين العقابية والطبية، مجلة الكوفة للعلوم القانونية والسياسية، العراق،

$$
\text { المجلد 2، العدد 7، أكتوبر 2010، صن صندين } 10
$$

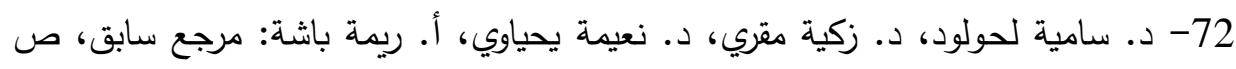




\section{مجلة وادى النيل للاراسات والبحوث الإنسانية والاجتماعية والتربوية}

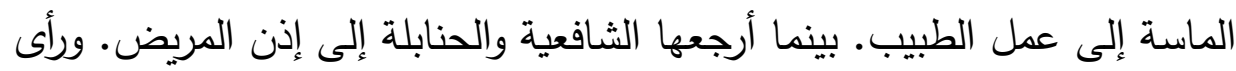

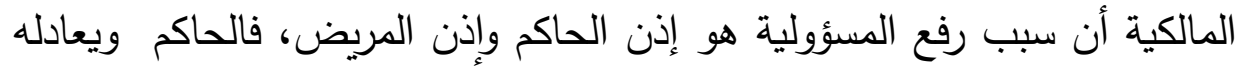

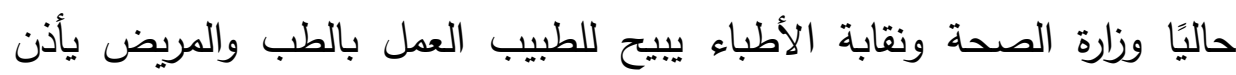

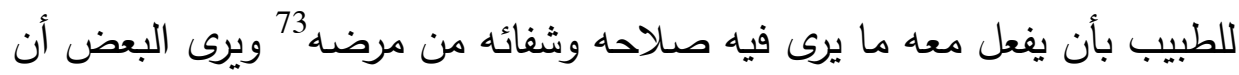

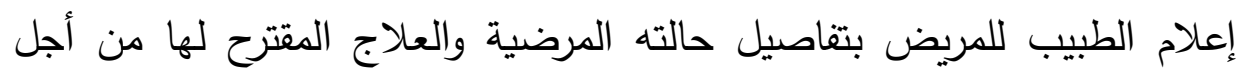

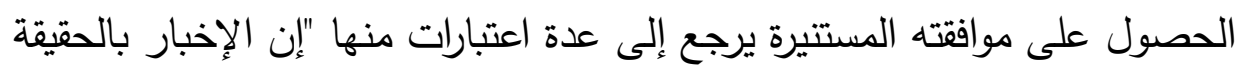
مطلوب في حد ذاته كمبدأ أخلاقي مستقل، كما يعبر عن احترام استقلالية

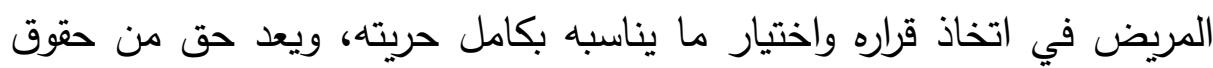
المريض في معرفة تفاصيل الإجراءات الطبية والجراحية، ويعبر عن الوفاء بالعقد

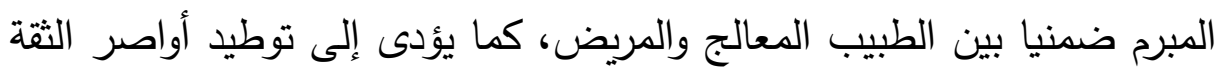
بين الطبيب ومريضه بما يحقق التفاعل والتعاون المثمر، وبناء عليه، فإن

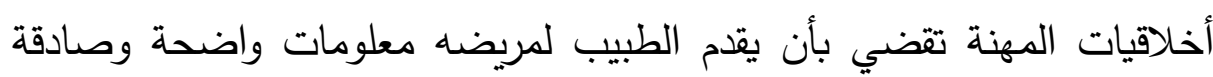

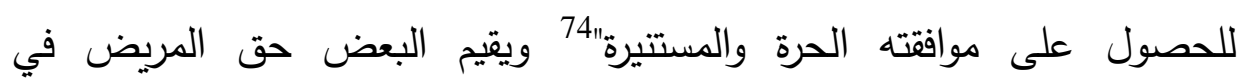

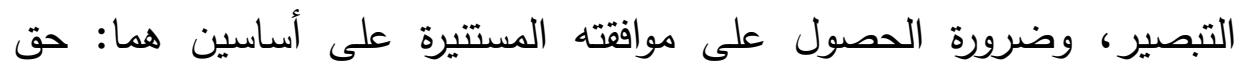
المريض في تقرير مصيره... وبالتالي فإن إجراء عملية جراحية دون أخذ موافقة

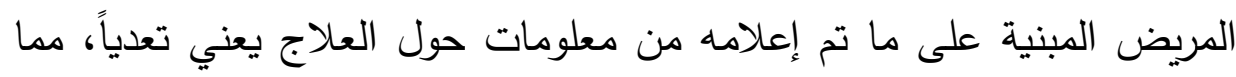

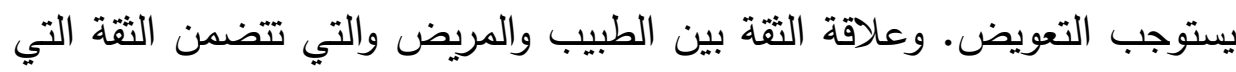
يضعها المريض في شخص الطبيب مما يتوجب على الأخير توضيح الصورة لدى المريض فيما يتعلق بوضعه الصحي ونتائج العلاج المتوقعة ومخاطره

73- عبد الله محمد الجبوري: فقه الطبيب وأدبه في المنظور الإسلامي، مجلة الحكمة، السعودية،

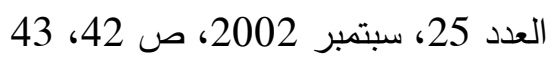

74- مراد ابن صغير: مدى التزام الطبيب بتصير المريض: دراسة علمية تأصيلية مقارنة،

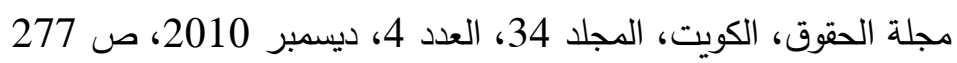


المحتملة"75. ويلاحظ أن تبصير المريض وإعلامه بحالته الصحية والعلاج المزمع القيام به ونتائجه ومضاعفاته والعلاجات البديلة ونتائجها ومضاعفاتها، وأسباب اختيار العلاج المزع القيام به ورفض العلاجات الأخرى يختلف عن الموافقة المستتيرة، فالموافقة المستنيرة هي النتيجة المترتبة على العمليات السابقة عليها والتي تستهدف الوصول إليها. كما يختلفان عن استمارة الموافقة التي هي دليل على اتباع الإجراءات السابقة وموافقة المريض عليها. ويميز كثير من الباحثين بين الموافقة الصريحة والموافقة الضمنية للمريض وذللك على ضوء طبيعة التدخل الطبي، حيث يشترط البعض الموافقة الصريحة بشأن التدخلات الطبية الكبرى فقط دون التخخلات المألوفة، وهو معيار من لن الصعب تطبيقه، حيث يختلف الأطباء فيما بينهم حول ما هي التدخلات الطبية الكبرى هل هي العمليات الجراحية ؟ وهل كل العمليات الجراحية أم العمليات الجراحية الكبرى فقط؟ ومن الذي يحدد ما يعد عملية جراحية كبري ؟ وهل يدخل ضمن التدخلات الكبرى العلاج بأدوية شديدة التأثير أو الخطورة أم يقتصر على يلى العمليات الجراحية فقط؟ ورغم محاولة البعض التفسير بأن معيار تحديد التدخلات الطبية الكبرى هو الطبيب المعتاد أي المتوسط العادي فإن هذا التفسير يعيدنا للمربع الأول حيث يتطلب أن نحدد من هو الطبيب المتوسط العادي وهل تحديده لطبيعة العمل الطبي يدخل ضمن التخخلات الطبية الكبرى أم لا كان صحيحًا أم الم جانبه فيه الصواب، خاصةً في ظل النصوص القانونية التي لا تقصر الموافقة

75- أيمن خالد مساعده، نسرين محاسنة: الالتزام القانوني بتبصير المريض بالتدخل العلاجي

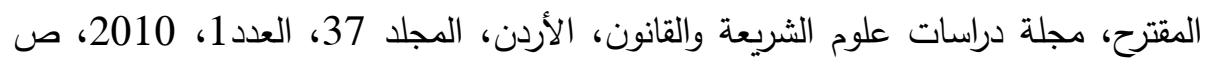


المستتيرة على التخخلات الطبية الكبرى.76 ويذهب آخرين إلى أن اتفاق المريض مع الطبيب أو قبوله العلاج في المستثفى يعتبر قبولاً منه لكل إجراء يتخذه الطبيب من وسائل العلاج العادية ما لم يعترض المريض صراحةً، غير أن هذا الرأي يعيدنا مرة أخرى لإشكالية تحديد ما يعد من وسائل العلاج العادية وما لا يعد كذلك 77

ومع التقدم في المجال الطبي سواء العلاجي أو البحثي ظهرت العديد من

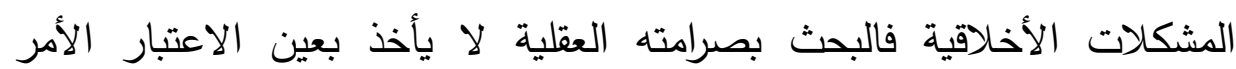
الأخلاقي ومن ناحية أخرى أحيانًا ما يتم إعاقة البحث بسبب التعصب الأخلاقي

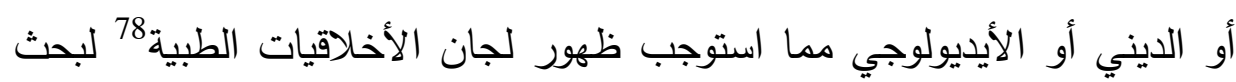
المشكلات الأخلاقية المختلفة الناتجة عن التقدم الطبي ومنها الموافقة المستنيرة للمريض على العمل الطبي المزمع القيام به. ومن الجدير بالذكر أننا لم نصل الى مرحلة الموافقة المستنيرة دفعةً واحدًة، بل مرت العلاقة بين الطبيب والمريض بعدة مراحل، يمكن رصدها على النحو التالي: أولاً: تطور طبيعة العلاقة بين الطبيب والمريض وأثر ذلك في الموافقة المستنيرة: تطورت العلاقة بين الطبيب والمريض على مر العصور حيث أخذت صور مختلفة منها:

76- د هيثم حامد خليل المصاروة: مدى الاعتداد بإرادة المريض في الأعمال الطبية، مجلة

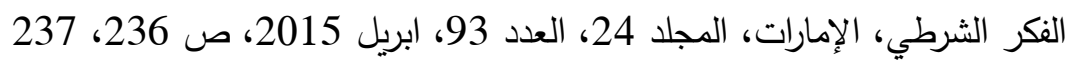
77- منصور مصطفي: حقوق المريض على الطبيب، مجلة الحقوق والثريعة، الكويت، المجلد 5، العدد 2، يونيو 1981، 1981، ص 19 19، 20 78-البشير المؤدب: البيوأثيقا بين العلم والأيديولوجيا، المجلة التونسية للدراسات الفلسفية، الجمعية التونسية للدراسات الفلسفية، تونس، العدد 24، 25، لئن 
1-السلطة الأبوية للطبيب: ساد هذا الاتجاه العلاقة بين الطبيب والمريض

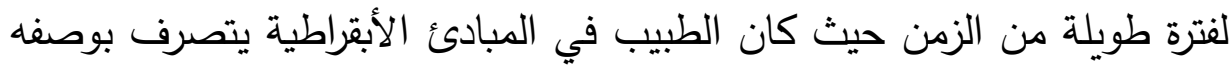

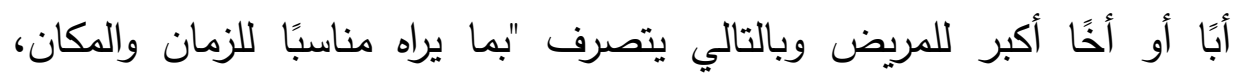

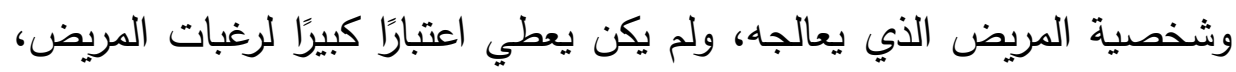

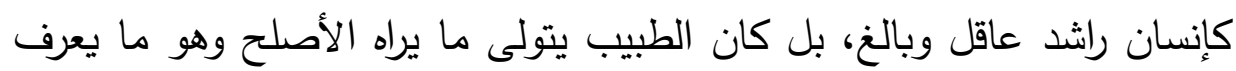

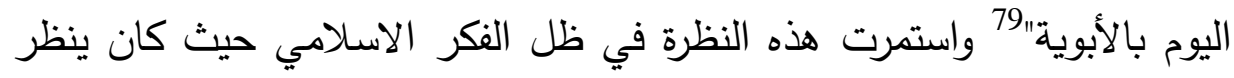

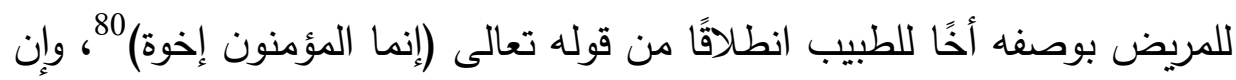
كان المريض امرأة فكان الطبيب ينظر إليها بوصفها في مكانة أمه التي تحتاج

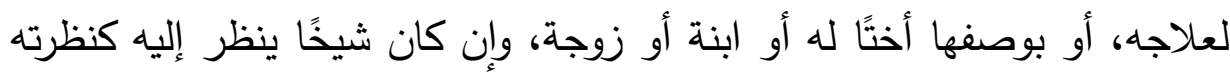

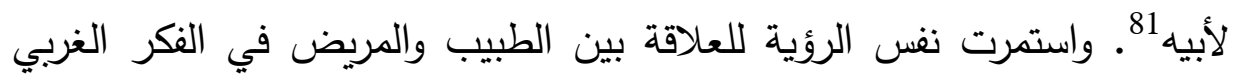

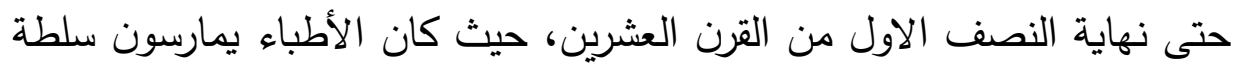

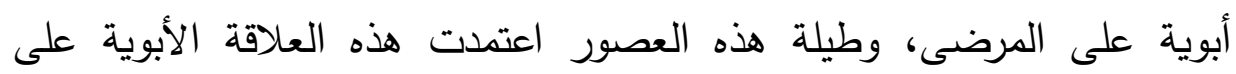

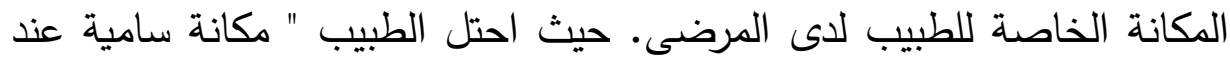

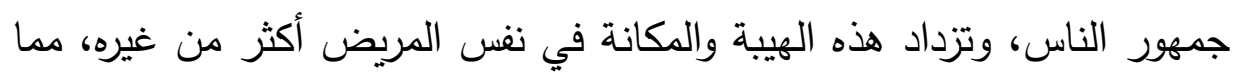

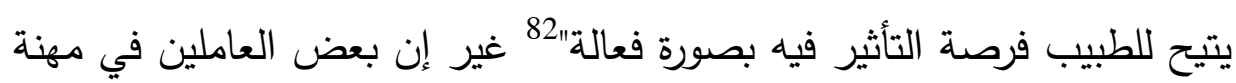

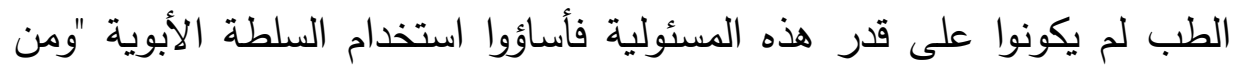

79 -سمية محمود إبراهيم الجربي: فلسفة العلم التطبيقية، مرجع سابق، ص 99

80- سورة الحشر آية 7

81- تحمح أبو بكر أبو عزة: الأخلاق المهنية في العطل الطبي، المجلة الليبية للدراسات، دار

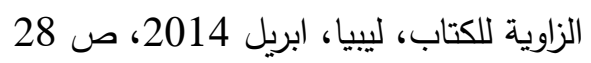

82-سمير إسماعيل الحلو: الطب الإسلامي: نحو تطبيق عملي، مجلة الحكمة، السعودية،

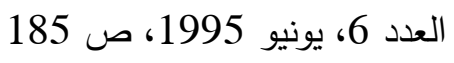


هنا ظهرت محاولات متعددة لوضع قوانين وقواعد تحدد سلوك الأطباء، وتشرع الحقوق الإنسانية للمرضى"

2-تحول العلاقة من السلطة الأبوية إلى علاقة شراكة وثقة متبادلة: نتيجة

التغيرات المختلفة خاصة الاجتماعية والثقافية تغيرت النظرة للعلاقة بين الطبيب والمريض، وظهر تيار ينادي بحق المريض في معرفة كل ما يتعلق بحالته الصحية، ومعرفة الاختيارات والبدائل العلاجية المختلفة، والآثار المتوقعة لكل منها، وأسباب تفضيل طريقة علاجية عن غيرها، وأصبح المجتمع يعترف " بأن المرضى لديهم الحق في أن يقرروا بالتشاور مع الأطباء، التدخلات الطبية التي سيقبلونها أو لن يقبلوها، وأصبح ينظر إلى سلطة اتخاذ القرار على أنها شيء يتم مشاركته من قبل شركاء" "84، ومثل ازدياد التأكيد على مفاهيم جديدة في العلاقة بين الطبيب والمريض مثل " الحقوق الفردية والاستقلال الذاتي وتقرير المصير. أسلحة لازمة للهجوم وخرق قلعة الأبوية الطبية التي هيمنت على العلاقة بين المريض والطبيب حتى منتصف القرن العشرين على الأقل"85، وانتشرت وجهة النظر الجديدة على سبيل المثال في المملكة المتحدة حيث تغير شعار العمل من " الطبيب يعرف أفضل، إلى الشراكة في الرعاية...، وأصبح من المقبول على نطاق واسع أن الأطباء يجب أن يتفاوضوا بدلاً من إملاء ما هو الأفضل"

83

84- Committee on Bioethics: Informed Consent, Parental Permission, and Assent in Pediatric Practice, PEDIATRICS, Volume 95 Number 2, Pages 314-317, February 1995, in http://www.cirp.org/ library/ ethics/ $\underline{\mathrm{AAP}}$

85- M Stirrat, R Gill: Autonomy in medical ethics after O'Neill, journal of medical ethics, 2005, 31, p 127

86- L Doyal: Good clinical practice and informed consent are inseparable, Hear, t2002, VOL 87, P 103 
للمرضى والاستحواذ على سلطة اتخاذ القرار لأنفسهم. وبالتالي أصبحت سلطة اتخاذ القرار العلاجي مشتركة بين الطبيب والمريض. 3- العلاقة العلاجية هي أساس العلاقة بين الطبيب والمريض: في ظل التطور الطبي وظهور نظم التأمينات الطبية المختلفة لم يعد بإمكان المريض دومًا اختيار طبيبه، بل أصبح مجبرًا على الطبيب الذي يفرضه عليه التأمين الطبي أو المؤسسة العلاجية دونما اختيار من جانبه ومن هنا اصبح الأساس في العلاقة بين الطبيب والمريض هو العلاقة العلاجية، وهنا ذهب البعض إلى أن المريض يفصح للطبيب عن علته وشكواه "والطبيب يقوم باتخاذ بالإجراءات العلاجية اللازمة. كما يعتبر مسئولاً مسئولية تامة عن جميع ما يترتب على هذه الإجراءات من نتائج"87، وبذلك استبعد هؤلاء إرادة المريض وحصروا مرة أخرى سلطة اتخاذ القرار العلاجي وبالتالي المسئولية عنه في يد الطبيب، واستبعدوا الموافقة المستتيرة تمامًا من الخريطة العلاجية. وتزامن ذلك مع تغير أكبر في طبيعة العلاقة بين المريض والطبيب عند بعض الأطباء نتيجة المتغيرات الاقتصادية حيث أصبح الطبيب " إذا كان في عيادة خاصة، فإنه يستقبل "عميلاً" (أو زبونا) ولا يستقبل "مريضاً"! وبعض الأطباء عندما يكون في مستشفى، ويستقبل مريضاً، فإنه يستقبل "عبئًا" ولا يستقبل "مريضاً"! وهذا التتاقض الظاهر ليضاء بين توقعات المريض، وبين الطريقة أو الأسلوب الذي يعامله به الطبيب، هو لب

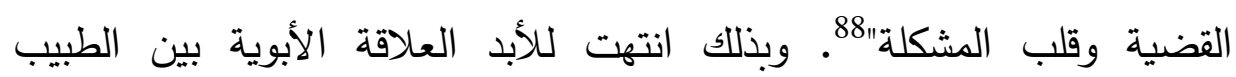

87 - 87 سوف الكيلاني: سر المهنة الطبية، مجلة الحقوق والثريعة، الكويت، المجلد 5، العدد

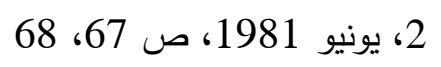

88 عبد الرحمن عبد اللطيف النمر: الأطباء ليسوا ملائكة، مجلة الوعي الإسلامي، وزارة

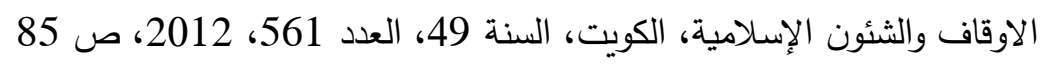


والمريض، وسادت النزعة المادية في العلاقة بينهما. وأصبحت الحقوق والواجبات متبادلة بين الطبيب والمريض وعلى رأسها الحق في الإفصاح عن المعلومات. ثانيًا: الحق المتبادل في الإفصاح عن المعلومات: ساد لفترة طويلة من الزمن الاعتقاد بأن الإفصاح عن المعلومات يكون من الإن المعاح جانب واحد هو الطبيب حيث يفصح للمريض عن كل ما يتعلق بحالته الصحية

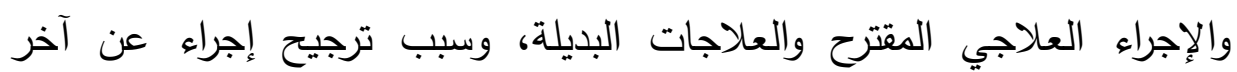

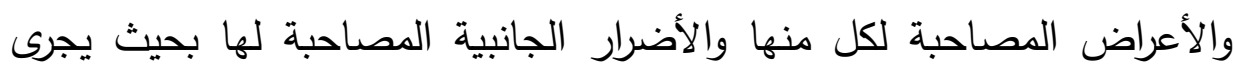

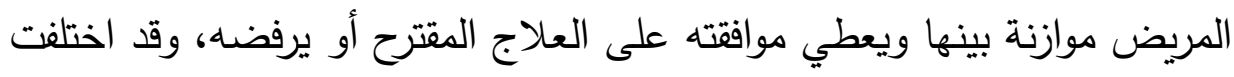

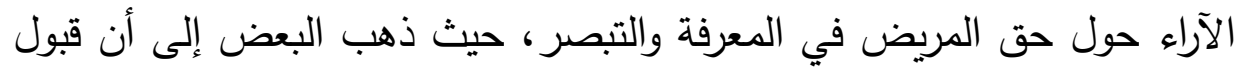

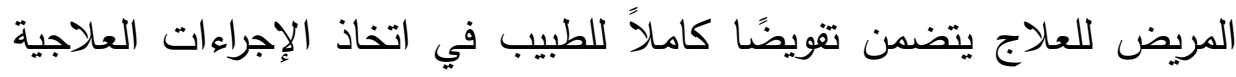

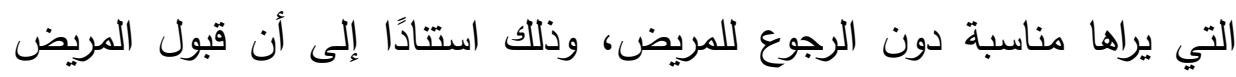

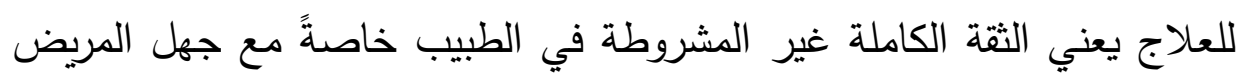
بالمسائل الطبية، ومحاولة الطبيب تبصير المريض تعوقه عن القيام بعطله

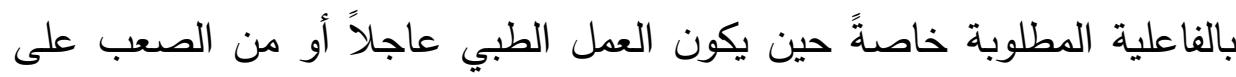

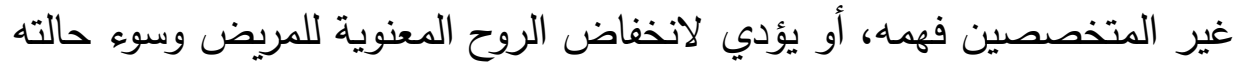

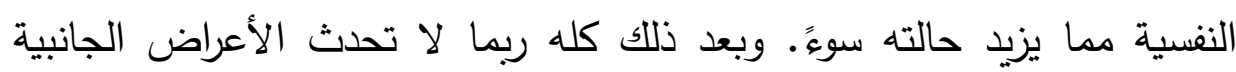

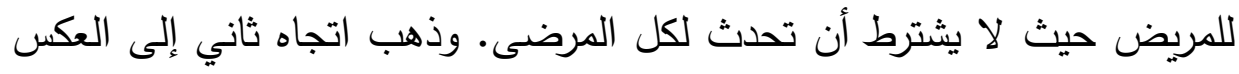
حيث يرون أن من واجب الطبيب تبصير المريض بحقيقة مرضه تفصيلاً

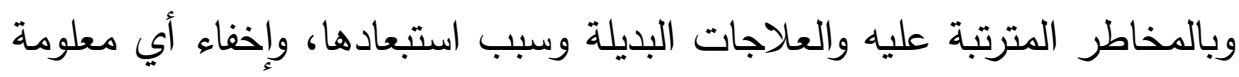
يعتبر كذب وخطأ يستوجب مسئولية الطبيب، وذللك استنادًا إلى أن حق الإنسان في سلامة الجسد يتطلب عدم المساس به بدون رضاء المريض حتى على سبيل

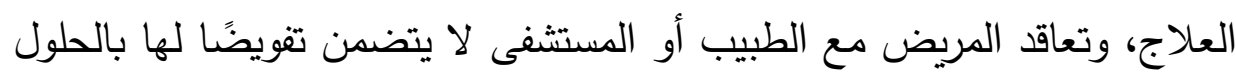
محله وفقدانه لأهليته وإرادته الحرة، وإخفاء الطبيب أي معلومات عن المريض لإضيض 
يقضي على علاقة الثقة الواجب توافرها بين الطبيب والمريض، ولا يجوز الاستناد لجهل المريض بالأمور الطبية لادعاء عدم مقدرته على الموازنة بين مزايا وعيوب وسائل العلاج المختلفة. وظهر رأي ثالث يتوسط بين الرأيين السابقين يرى أنصاره أن من واجب الطبيب تبصير المريض بحالته وطبيعة العمل الطبي المزمع إجرائه حتى يتخذ المريض قراره بالموافقة أو الرفض عن بينة ومعرفة، وذلك مع مراعاة العوامل الأخرى مثل الحالة النفسية للمريض حيث يكون الكذب عليه أحيانًا في مصلحته، بشرط عدم استخدام وسائل احتيالية لإقناع المريض بصحة المعلومات التي يعطيها له الطبيب 89. بل وصل الأمر إلى التزام الطبيب بتبصير المريض له له بحالته الصحية وخبرته العملية إن كانت ذات أهمية في العلاج "فعلى سبيل المثال، في القضية الأمريكية Faya v. Almaraz ألزمت المحكمة الطبيب بدفع تعويضات إلى مريضتين قام بإجراء عمليات جراحية لهما دون إعلامهما بأنه يحمل فيروس نقص المناعة المكتسبة HIV، فعلى الرغم من عدم انتقال الفيروس إلى المريضتين، إلا أن المحكمة قضت بالتعويض عن الارتباك النفسي الذي أصابهما من لحظة علمهما بالوضع الصحي للطبيب لحين ظهور نتائج فحوصاتهما المخبرية

89- منصور مصطفي: حقوق المريض على الطبيب، مجلة الحقوق والثريعة، الكويت،

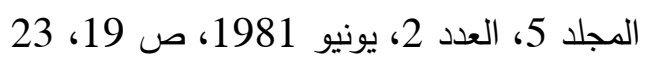

* يلاحظ بالطبع أن المقصود هنا إلزام الطبيب بالإفصاح عن الحئ لعالة الصحية له إذا كانت

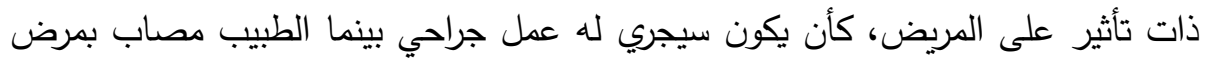

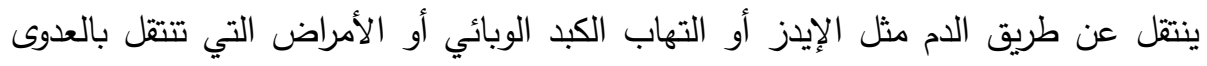

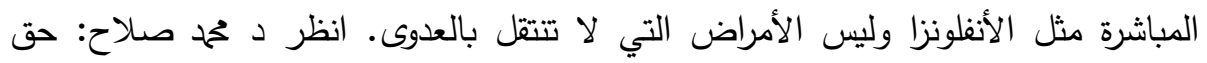
المريض في الحصول على المعلومات الطبية: دراسة تحليلية مقارنة، المجلة القانونية

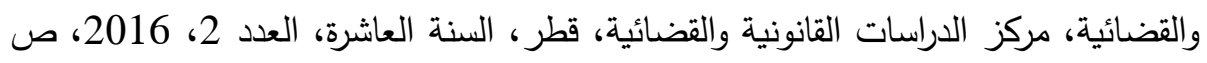




\section{مجلة وادى النيل للاراسات والبحوث الإنسانية والاجتماعية والتربوية}

وفي المقابل نشأ حق أخر مقابل هو حق الطبيب في إفصاح المريض له عن الهن

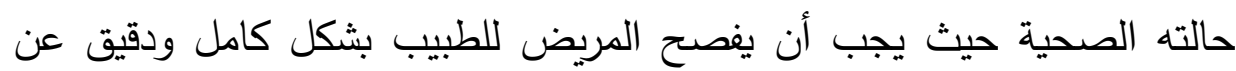

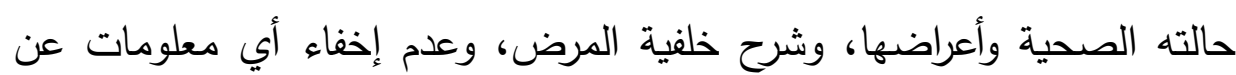

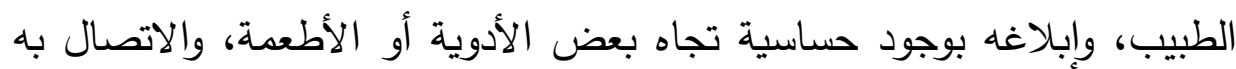

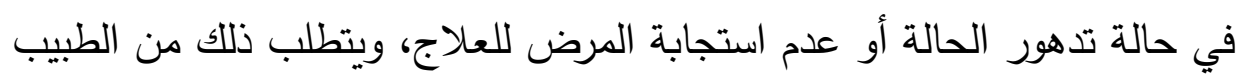

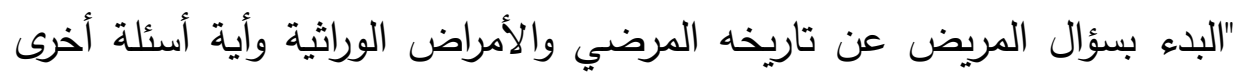

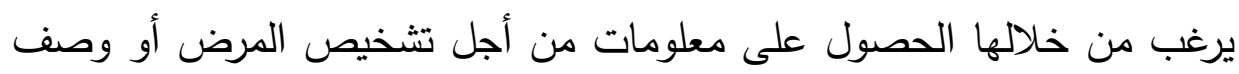

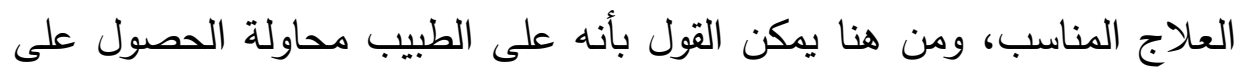

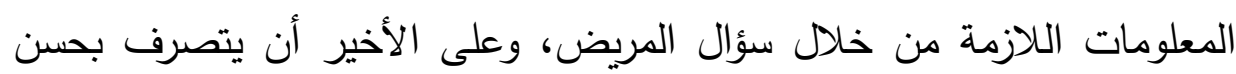

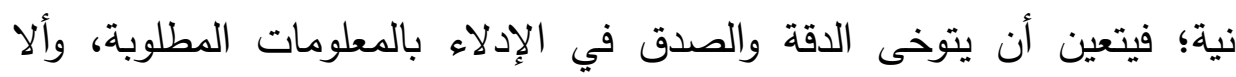

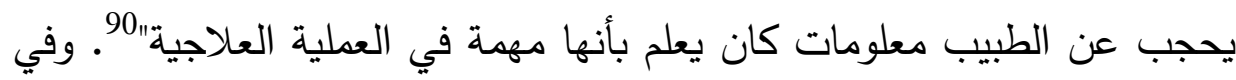

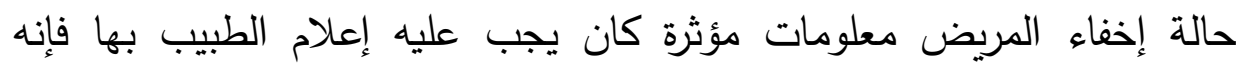
يتحمل المسئولية إذا ساهم ذلك في تضليل الطبيب واختياره علاجًا غير صحيداً

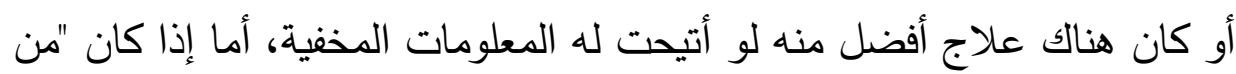
الطبيعي في مثل هذه الظروف أن يتبين الطبيب المعلومات الحقيقية المتعلقة

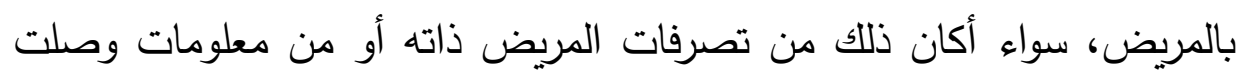

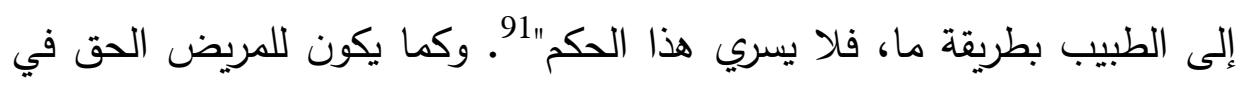
رفض العلاج المقترح من الطبيب وعدم إعطاء موافقته المستتيرة فإن الطبيب أيضًا

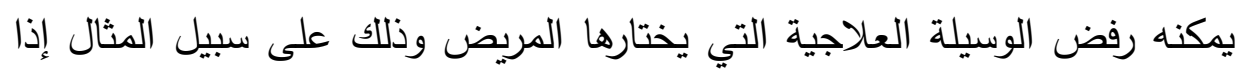
كان الإجراء المطلوب غير قانوني كالموت الرحيم، أو أن يترتب على الإنبل العراء

90- د محمد صلاح: مرجع سابق، ص 173، 174 91- أيمن خالد مساعده، نسرين محاسنة: مرجع سابق، ص صل 189 
استهلالك مسرف لموارد نادرة يحتاجها مرضى أخرين أكثر احتياجًا لها، أو الإجهاض غير الثرعي أو غير القانوني 92

ثالثًا: المعلومات التي يجب الإفصاح عنها للمريض حتى تكون الموافقة المستنيرة صحيحة

بازدياد التقدم العلمي، وابتكار طرق علاجية جديدة، زادت المعلومات التي يجب على الطبيب الإفصاح عنها للمريض حتى تتحقق الموافقة المستنيرة، وقد

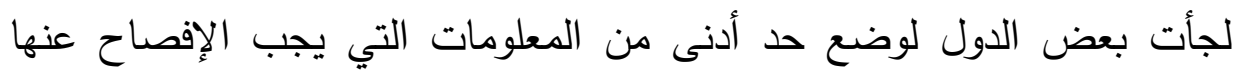
للمريض*، ولتحديد المعيار الذي يجب اللجوء إليه لتحديد طبيعة المعلومات التي لإلي

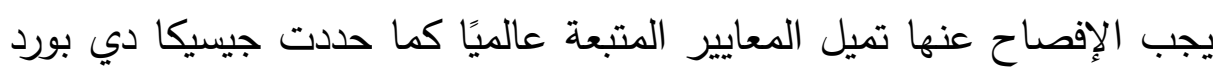
Jessica De Bord المعلومات بما يعطيه طبيب بمستوى الطبيب المعالج وفي نفس الظروف بحيث يعد الطبيب مقصرًا لو لم يقم بتعريفها للمريض ويعفى من المسئولية من ذكر

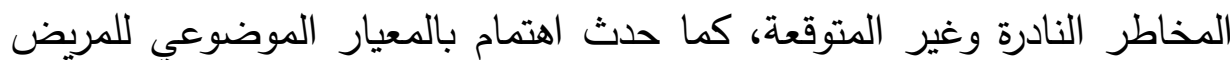
حيث يتم تحديد حجم المعلومات المطلوبة بالنظر للمريض العادي، وكذلك المعيار الذاتي لتحديد ما الذي يحتاجه هذا المريض بالذات لمعرفة وفهم حالته المرضية

92- M Stirrat, R Gill: Autonomy in medical ethics after O’Neill, journal of medical ethics, 2005, 31, page 130 * حددت م 5 من الدعاهدة الأوروبية لحقوق الإنسان والطب البيولوجي تضع الحد الأدنى من هذه الدعلومات وهي أربع: أهية العلاج وطبيعته ونتائجه الدتوخاة والدخاطر الناتجة عنده. كما أن قانون القبول الطبي لولاية فلوريدا (Florida Medical Consent Law) قد أشار

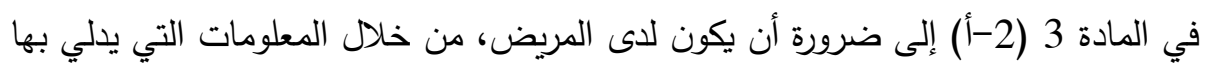

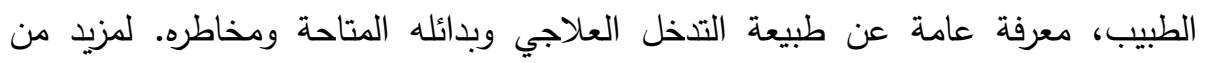
التفاصيل انظر أيمن خالد مساعده، نسرين محاسنة: الالتزام القانوني بتبصير المريض الفرانة

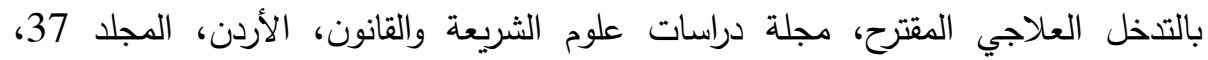

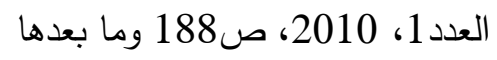


من أجل اتخاذ القرار بالموافقة المستتيرة من عدمه 93 وذهب ريتشارد واجنر Richard A Wagner يمنح الموافقة المستتيرة بأنها القدرة على فهم الخيارات، وفهم عواقب كل اختيار، والمقدرة على تقييم التكلفة والعائد من كل اختيار ونتائجه ومدى تتاسبه مع قيمه الخاصة، ووفي حالة عدم توفر القدرة على صنع القرار من المريض فإنه يتم اللجوء لأفراد العائلة أو الأوصياء المعينين قضائيًا 94.

$$
\text { وأهم المعلومات التي يجب توفيرها للمريض هي: }
$$

1- بيان الحالة الصحية للمريض والتطورات المتوقعة لها وتشخيص المرض

بشكل واضح مع الاستعانة بكل الوسائل الممكنة من أشعة وتحاليل وقياسات 95

2- توضيح طبيعة العلاج المقترح للمريض، والعلاجات البديلة، وسبب تفضيل طريقة علاجية على الطرق الأخرى، والهدف من العلاج والنتائج المترتبة

93- أيمن خالد مساعده، نسرين محاسنة: الالتزام القانوني بتبصير المريض بالتدخل العلاجي

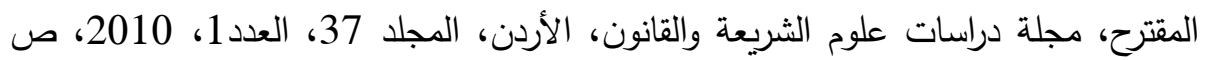
189: 191، 191، انظر كذلك:

Jessica De Bord: Informed Consent, march 2014, University of Washington, in https: depts.washington.edu/bioethx/topics/ consent. html

94- Richard A Wagner: informed Consent, in https://www. emedicinehealth.com/informed_consent/article_em.htm.

95- مراد ابن صغير: مدى التزام الطبيب بتبصير المريض: دراسة علمية تأصيلية مقارنة،

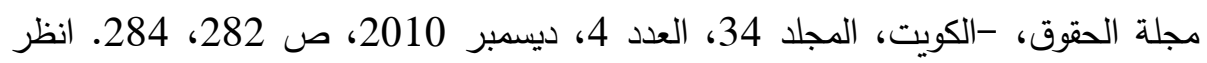
Sichard A Wagner: informed Consent, in https://www.emedicinehealth.com/informed_consent/article_em.htm 
عليه والأعراض الجانبية له، مما يساعد المريض على تفهم حالته ويرفع روحه النفسية

3- إبلاغ المريض بالاحتياطات الواجب اتخاذها لضمان تحقيق أفضل نتيجة علاجية ممكنة من الطريقة العلاجية المتبعة، وبيان المسموح به والممنوع للمريض، مثل عدم التعرض للهواء البارد، وضرورة تجنب أطعمة أو أدوية معينة، أو ضرورة القيام بعلاجات أخرى مكملة مثل العلاج الطبيعي 97 4- توضيح خطورة الامتناع عن العلاج المقترح والأضرار المترتبة على ذلك للمريض، حتي يمكن للمريض اتخاذ قراره بالموافقة من عدمه على العلاج، وفي حالة الرفض يكون على بينة من النتائج المترتبة على ذلك 98 5- إخبار المريض بتخزين معلوماته ضمن النظام الالكتروني للمنشأة الصحية، ويشمل ذلك جميع البيانات التي يدلي بها المريض، وجميع مراحل علاجه، مع الالتزام بسرية المعلومات والبيانات التي يوصي المريض بعدم

96- مراد ابن صغير : مدى التزام الطبيب بتبصير المريض: دراسة علمية تأصيلية مقارنة،

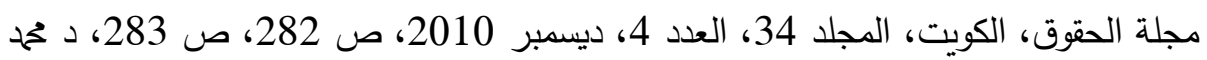
صلاح: حق المريض في الحصول على المعلومات الطبية: دراسة تحليلية مقارنة، المجلة القانونية والقضائية، مركز الدراسات القانونية والقضائية، قطر، السنة العاشرة، العدد 2، 2016، ص 165، 169

97- مراد ابن صغير : مدى التزام الطبيب بتبصير المريض: دراسة علمية تأصيلية مقارنة،

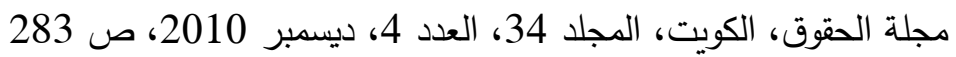
98- مراد ابن صغير : مدى التزام الطبيب بتبصير المريض: دراسة علمية تأصيلية مقارنة، مجلة الحقوق، الكويت، المجلد 34، العدد 4، ديسمبر 2010، صنير صلطير 284 
إدخالها أو بالحفاظ على سريتها، مع تعريف المريض بالأشخاص والجهات الذين يمكنهم الوصول لهذه المعلومات 99

وفي المقابل لا يلتزم الطبيب بالحصول على موافقة المريض أو إخطاره بالوسائل الفنية التي سيتبعها في العمل الطبي أو الجراحي، فاختيار الوسيلة المناسبة أمر يخص الطبيب الأكثر قدرة على تحديد الوسيلة الفنية الأفضل، كما لا يلتزم الطبيب بتبصير المريض بالمعلومات الفنية الدقيقة، وإن كان يلتزم بتبسيطها للمريض 100

رابعًا: الحالات التي لا يشترط فيها الموافقة المستنيرة من المريض

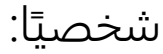

القاعدة العامة ان الموافقة المستنيرة تكون من المريض، لكن في بعض الحالات لا يمكن الحصول على الموافقة المستتيرة من المرضى. حيث يشترط دويال L Doyal في المريض حتى يكون لديه الأهلية للحصول على الموافقة المستتيرة منه أن يكون قادرًا على فهم وتذكر المعلومات التي يشرحها له الطبيب والا لا يعود كفوًاً للموافقة المستنيرة، وفي بعض الحالات تختلف الثروط الواجب توافرها في الشخص فثثلاً يكون الطفل مختصًا بالموافقة على إجراء فحص الدم لكن لا تتوافر لديه أهلية الموافقة على العلاج الكيماوي 101. أما في حالة عدم قدرة المريض على إعطاء الموافقة المستنيرة لأي سبب ففي هذه الحالة يثور التساؤل

99- الشهابي إبراهيم الشهابي: التزام الطبيب حفظ أسرار المرضى "الأصل والاستثناء"، مجلة

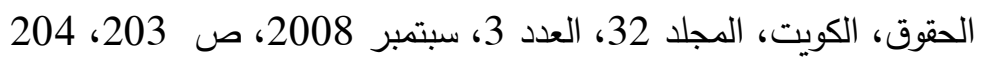
100 -منصور مصطفي: حقوق المريض على الطبيب، مجلة الحقوق والثريعة، الكويت، المجلد 5، العدد 2، يونيو 1981، صنور صعرف 25 101-L Doyal: Good clinical practice and informed consent are inseparable, Hear, t2002, VOL 87, PAGE 103 
من الذي يحل محل المريض؟ وما المعايير التي يتم على أساسها اتخاذ الآخرين

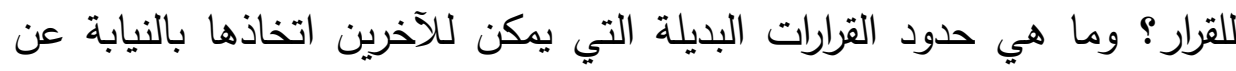

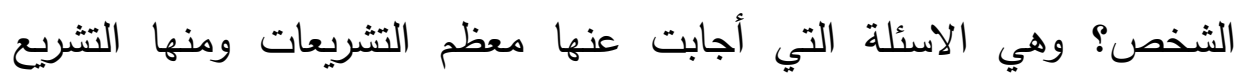

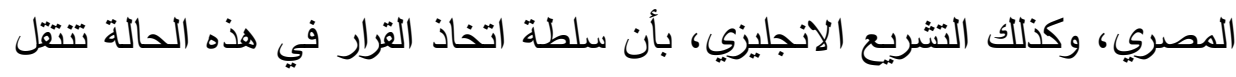

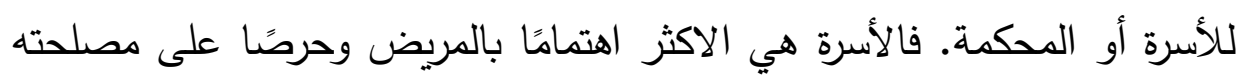

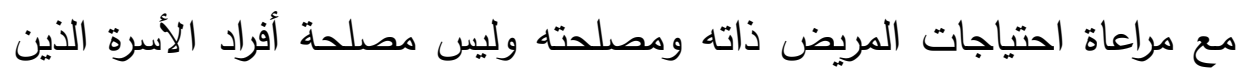

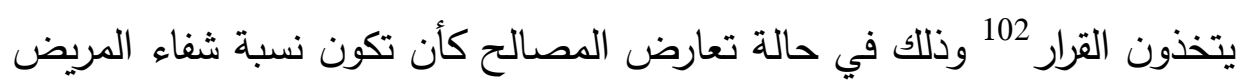

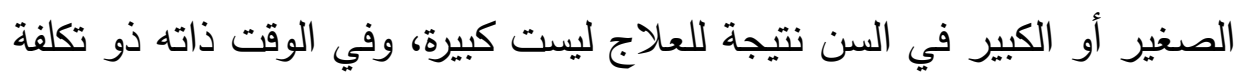

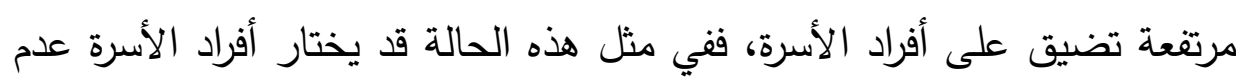

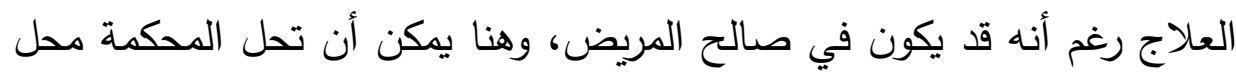
الأسرة، كذلك ففي بعض المجتمعات ذات الثقافة المنخفضة يفضل فل فئل أفراد الأسرة

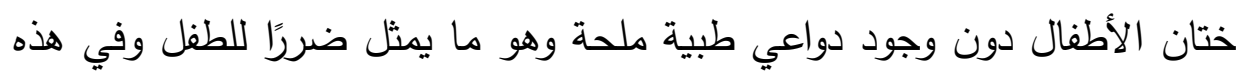

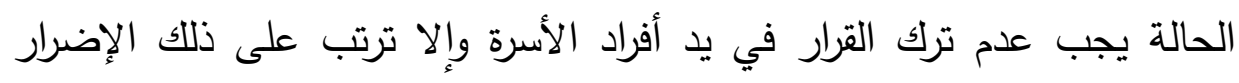
بالمريض.

وأهم الحالات التي يتم فيها الحصول على الموافقة من غير المريض هي:

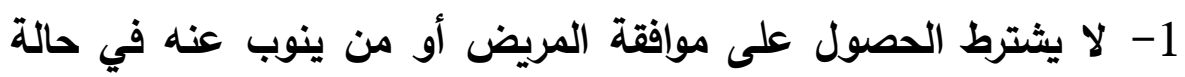
الاستعجال والضرورة: وفي هذا الإطار يتم التمييز بين حالتين هما حالة العلاج

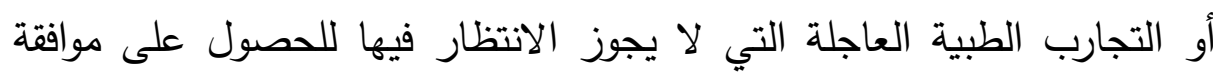

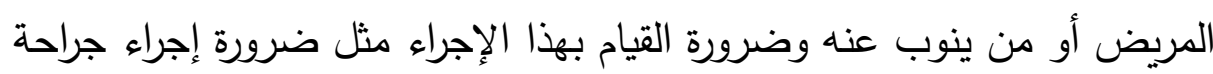
فورية للصاب في حادث وعدم وعيه وعدم القدرة على الوصول لذويه، وحالة الذاه

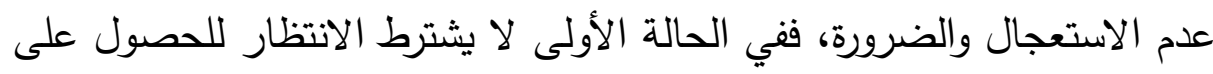

102-N G Messer: Professional-patient relationships and informed consent, Medical Journal,2004,volume 80,issue 943, page 281 
موافقة المريض أو من ينوب عنه حيث تكون أضرار ذلك أكبر من أضرار

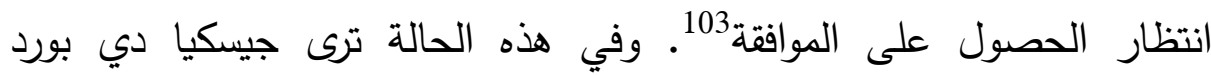
Jessica De Bord

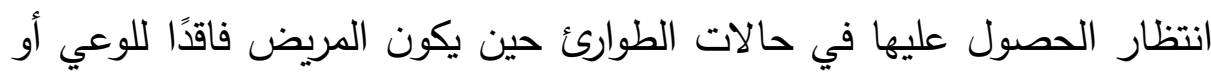

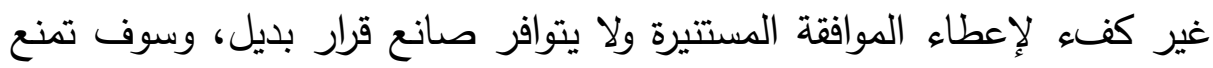

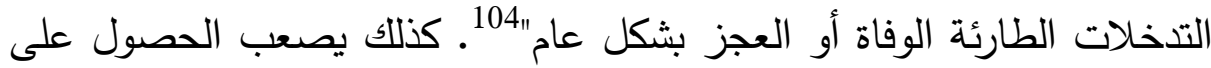

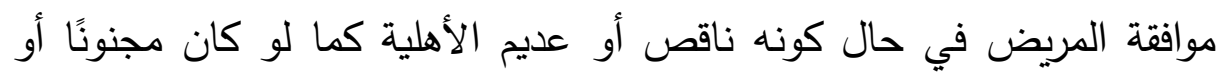

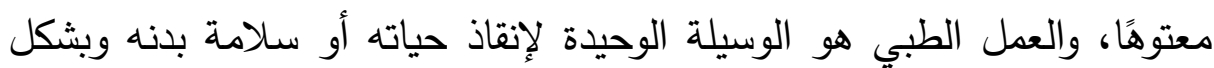

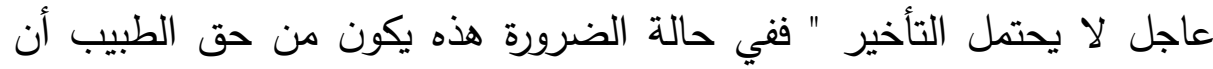
يقوم بالعمل الطبي أو الجراحي، مع ما فيه من قدر من الخطورة، دون رضاء المريض أو ذويه، بل إن قيامه بهذا العمل يعتبر واجبًا عليه" 105.

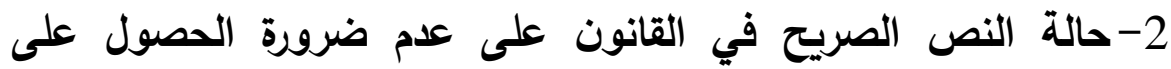

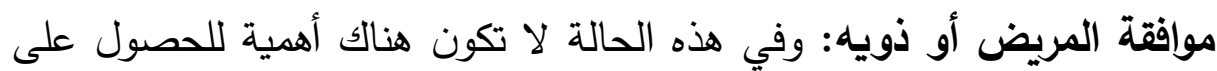

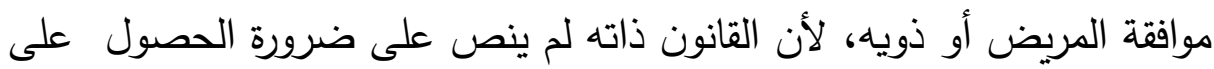

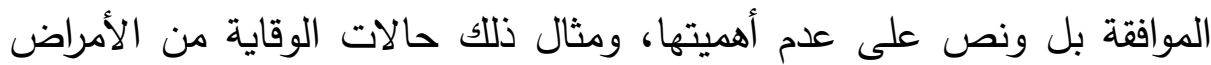

103- فاطيمة الزهرة بومدين: مضمون التجارب العلمية والطبية والضوابط الأخلاقية والقانونية

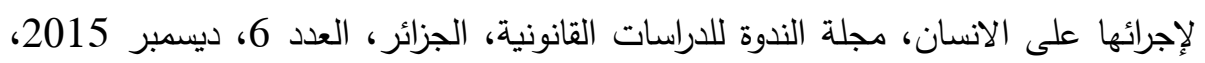

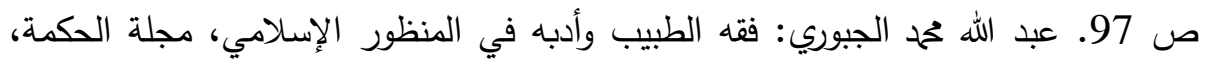

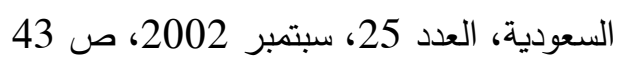

104-Jessica De Bord: Informed Consent, march 2014, University of Washington, in https://depts.washington.edu/bioethx/topics/consent.html 105- منصور مصطفي: حقوق المريض على الطبيب، مجلة الحقوق والثريعة، الكويت،

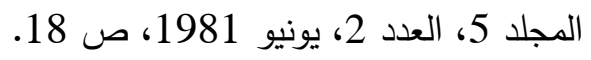




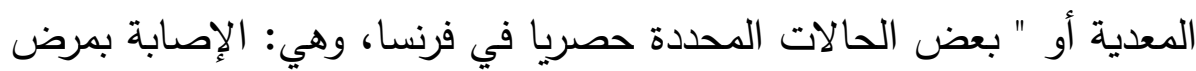

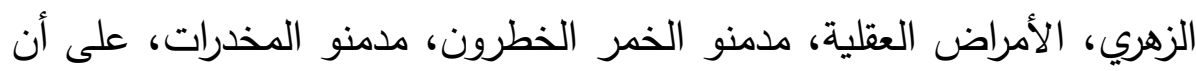

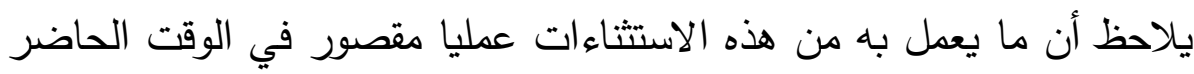
على مدمني المخدرات" (106.

3- إثكالية الأطفال والموافقة المستنيرة: تغيرت قواعد الموافقة المستنيرة في

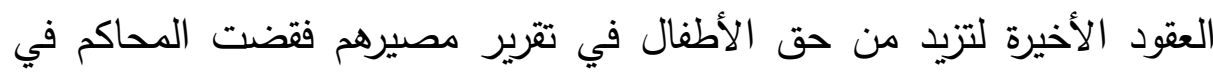
Gillick v West Norfolk and Wisbech Area Health قضية بuthority

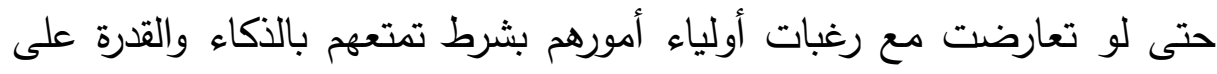

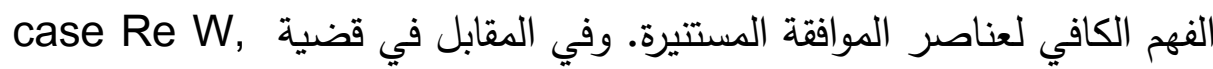
an orphaned girl يتيمة تعيش في ملجأ تتاول الطعام فتم تغذيتها بالقوة حتي أصبح عمرها 16 عام

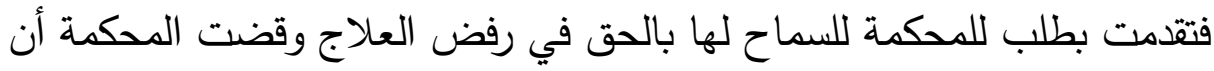
من يقل عمرهم عن 18 عام ليس لهم الحق المطلق في اتخاذ قرارات خاصة لهات

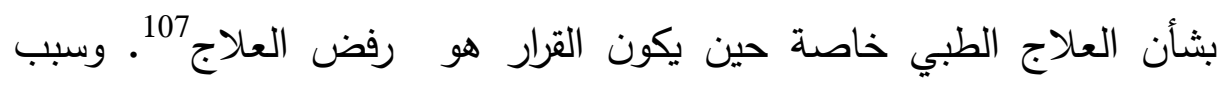
ظهور هذه الإشكالية أن الأطفال لا تتوافر لايهم القدرة على التخاذ القان القرار

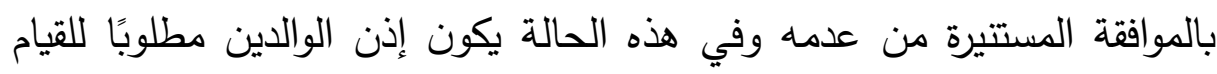
بالعمل الطبي، بينما بالنسبة للمراهقين والقصر الناضجين فئهي فإنه ينبغي دائما

106- مراد ابن صغير : مدى التزام الطبيب بتبصير المريض: دراسة علمية تأصيلية مقارنة،

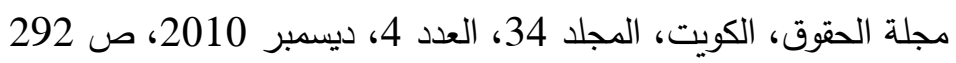
107 - J P H Shield: Children's Consent to Treatment, British Medical Journal, 7 May 1994, Vol 308, Pages 1182, in http://www.cirp.org/library/ethics/shield. 
السعي للحصول على موافقتهم بالإضافة إلى إذن الوالدين 108، وفي بعض الحالات يجب استبعاد أولياء الأمور إن كان هناك تعارض واضح في المصلحة مثلما في حالة الاعتداء على الأطفال المشتبه بهم، أو حالة الاختلاف بين الأبوين فيما يجب القيام به، وفي هذه الحالة تحل المحكمة أو من تعينه محل الأبوين. وفي كل الأحوال يجب شرح الإجراء الطبي الذي سيتم القيام به للطفل

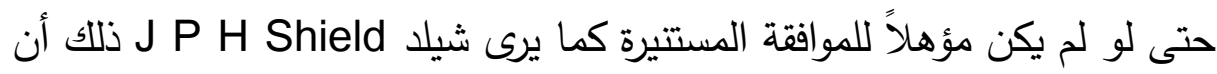
الطفل هو الذي سيعيش مع نتائج العمل الطبي وبالتالي يجب أن يكون مهيئا له 109 نموذجًا لذلك حالة ختان الأولاد والتي لا تعد إجراء تشخيصي كما لا تعد علاج لمرضًا ما، هنا لا تكون رغبات الوالدين العامل الحاسم ولا يكون الأطباء ملزمين بالقيام بإجراءات غير ملائمة على المرضى ويكون عليهم رفض إجراء عملية الختان غير العلاجية غير الضرورية، ويكون قرار ما إذا كان الختان في مصلحة الطفل أم لا قرار الطبيب ويتحمل مسئوليته وحده، فإن أجراءه دون

108 - Jessica De Bord: Informed Consent, march 2014, University of Washington, in https://depts.washington.edu/ bioethx/ topics/ consent.html. Also

Committee on Bioethics: Informed Consent, Parental Permission, and Assent in Pediatric Practice, PEDIATRICS, Volume 95 Number 2, Pages 314-317, February 1995, in http://www.cirp.org/library/ ethics/AAP

109- J P H Shield: Children's Consent to Treatment, British Medical Journal, 7 May 1994, Vol 308, Pages 1183, in http://www.cirp.org/ library/ethics/shield. 
ضرورة علاجية كان تصرفه غير أخلاقي وغير قانوني، وإن كان ضروريًا من الناحية العلاجية كان عليه استخدام التخدير المسكن للطفل 110.

4- التشدد في الموافقة المستنيرة في حالة تغيير الجنس: من ضمن العمليات الطبية الناتجة عن التقدم الطبي في القرن العشرين إمكانية تغيير الجنس من ذكر إلى أنثى والعكس. وهي جراحات يتداخل فيها الطبي والنفسي والثرعي والقانوني والاجتماعي والاعلامي مما يتطلب شروط مختلفة في الموافقة المستنيرة التي تصدر عن المريض محل الجراحة بعد التيقن من صحتها من الناحية القانونية والشرعية، لذلك ترى كريستين ويت " على التخخلات المتغيرة للهوية اختلافا هاما عن الموافقة المستتيرة على التذخلات العادية"111. 5- الموافقة المستنيرة من الأثخاص الذين تتغير قدراتهم وآرائهم من يوم لآخر: الكثير من الأشخاص تختلف آرائهم من يوم لآخر نتيجة تغير المعارف المتاحة لهم وازدياد خبراتهم وبالتالي اختلاف قراراتهم، ومن هنا ذهب كانط إلى أن "ما يظهر أمامنا في كل لحظة هو وجود مختلف تمامًا عما يظهر أمامنا في لحظة أخرى. وهكذا، فمما وقع الآن، ومما وقع في الماضي، لا يوجد ما يمكن أن نستدله عما سيحدث في لحظات المستقبل، أو حتى في اللحظة التالية مباشرةً، وبالتالي فإن خبرتتا تتحدد في الزمن..بمعنى أن خبراتنا تقع خلال فترات من الزمن"112. وبالتالي يثور التساؤل عن المريض الذي تختلف قدراته على اتخاذ القرار من يوم لآخر، بل ويختلف رأيه من يوم لآخر وفي هذه الحالة ترى

110- The Bioethics of the Circumcision of Male Children in http:// www.cirp.org/library/ethics/

111- Karsten Witt: Identity change and informed consent, journal of medicl ethics, 2017, 43, page 384 112- آلن و. وود: كانط فيلسوف النقد، ترجمة بدوي عبد الفتاح، المركز القومي للترجمة، مصر ، ط1، 2014، ص 
جيسيكا دي بورد Jessica De Bord ضرورة فعل ما نستطيع للحصول على موافقة المريضة الواضحة على فترات مختلفة ثابتة مما يجعل قراره معبرًا عن بردان رأيه الغالب لديه 113

خامسًا: حق المريض في رفض رفض العلاج، والعلاج الإجباري بدون

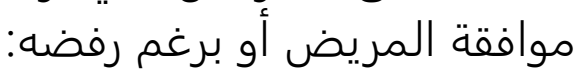

القاعدة العامة هي حق المريض في رفض العلاج، وضرورة احترام ذلك من

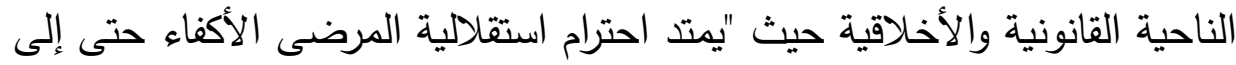

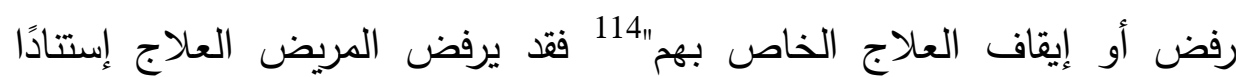

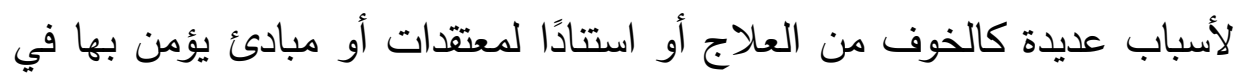

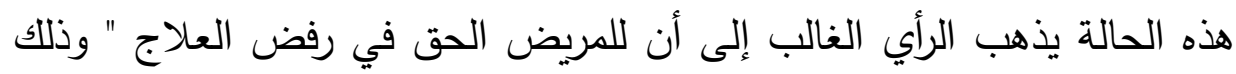

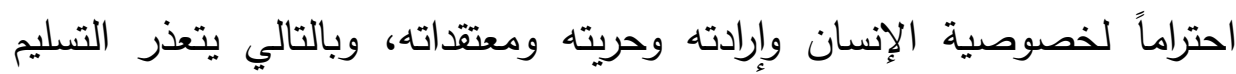

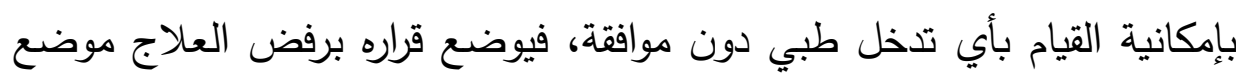

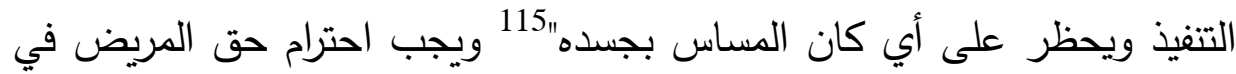

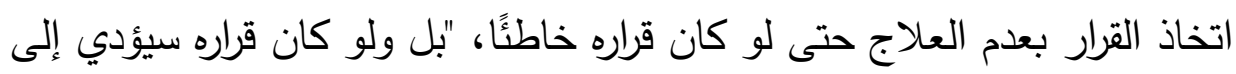

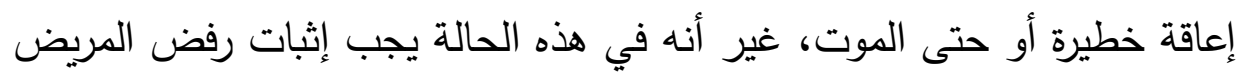

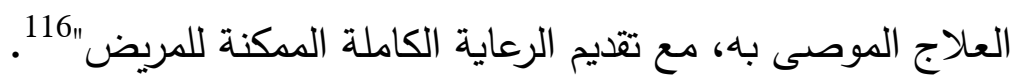

113 -Jessica De Bord: Informed Consent, march 2014, University of Washington, in

https://depts.washington.edu/bioethx/topics/consent.html

114 -Committee on Bioethics: Informed Consent, Parental Permission, and Assent in Pediatric Practice, PEDIATRICS, Volume 95 Number 2, Pages 314-317, February 1995, in http://www.cirp.org/ library/ ethics/AAP

115- الدكتور • هيثم حامد خليل المصاروة: مدى الاعتداد بإرادة المريض في الأعمال الطبية،

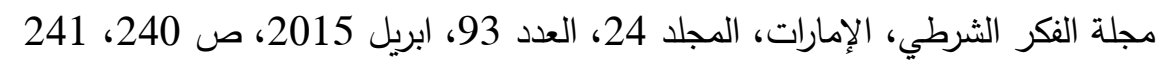

116- Richard A Wagner: informed Consent, in https://www.emedicinehealth.com/informed_consent/article_em.htm. 
ومع ذلك فإنه يمكن علاج المريض علاجًا إجباريًا أي بدون موافقته بل وبرغم معارضته مثل المرضى المصابين بالأمراض المعدية أو الوبائية المؤثرة في صحة بقية أفراد المجتمع أو الأمراض النفسية، أو الإدمان على المخدرات، حيث تتعارض في هذه الحالة مصلحتين هما مصلحة المريض من ناحية ومصلحة المجتمع من ناحيةً أخرى فيتم ترجيح المصلحة العامة. ورغم أن العلاج في هذه هئ الحالة يكون إجباريًا فإن التساؤل يثور هل يلتزم الطبيب في مثل هذه الحالات

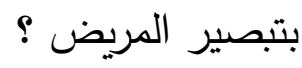

من الصعب التسليم بوجود حكم واحد على الحالات المختلفة أو وضع قاعدة عامة تطبق في كل الحالات، لهذا يرى البعض أن "ثمة حالات يتوجب فيها على لتى الطبيب تبصير المريض بحالته وما يتوجب اتخاذه من إجراءات بشأن العلاج حتى وإن كان جبرياً- كما في الحالات التي يكون فيها المريض بكامل وعيه، ليس بقصد احترام إنسانية وكرامة ذلك المريض فحسب، بل ولأن ذلك قد يفضي إلى تجاوب المريض مع الطبيب وعدم رفضه ومقاومته للعلاج وحسن السير في مراحل العلاج وانتظامه"117. وفي المقابل فإن هناك حالات أخرى يعفى فيها الطبيب من الالتزام بالحصول على الموافقة المستتيرة من المريض مثل حالة فقد المريض الوعي أو العقل، وحتى في هذه الحالات يلتزم الطبيب بإبلاغ أهل المريض بحالته الصحية وما سيتم اتخاذه معه حتى يكونوا على علم بالإجراءات

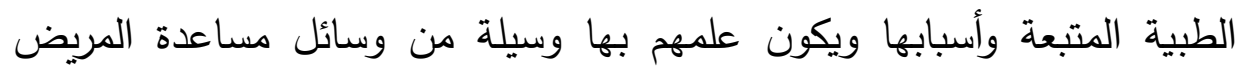
للشفاء، وكذلك لمساعدة المريض إن احتاج لمساعدة أهله في استكمال العلاج بعد

$$
\text { انتهاء العلاج الإجباري } 118 .
$$

117- الدكتور • هيثم حامد خليل المصاروة: مدى الاعتداد بإرادة المريض في الأعمال الطبية،

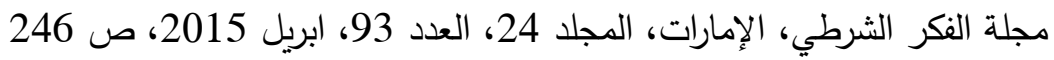




\section{المبحث الثالث}

الموافقة المستنيرة في الأبحاث الطبية على البشر

مع التقدم العلمي والتكنولوجي بشكل عام وفي المجال الطبي بشكل خاص زاد الاهتمام بالأبحاث الطبية خاصة حين تتناول العنصر البشري كمحل له، وظهرت العديد من الواجبات تجاه المبحوثين في البحث الطبي مثل "احترام شخصية الأفراد المشاركين في البحث، واحترام الحياة الخاصة للمبحوثين وعدم الكثف عما لا يريدون الكثف عنه أو خصوصيتهم، كذلك الاهتمام بتقليص العيوب في البحث والظروف المحيطة به، والصدق والإيجابية في التعامل مع أعضاء المجموعة البحثية، وتحمل المسئولية كعالم، مع احترام القوانين المهنية والمبادئ الأخلاقية للمهنة"119 وتداخلت في القواعد الأخلاقية المتعلقة بالأبحاث على البشر تلك الخاصة بالقواعد الأخلاقية بشكل عام بجانب الأخلاق الطبية والأخلاق البحثية وكلها فروع في الأخلاق. وظهرت مجموعة من القواعد الأخلاقية والمتطلبات البحثية التي يجب على الباحث الالتزام بها ومنها " أن يكون البحث ضروريًا لخدمة المجتمع، وألا تكون هناك أمكانية للحصول على المعلومات المتوقعة عن غير طريق إجراء البحث، وتوقع تفوق المتوقع من فوائد منظورة للأشخاص الذين تجرى عليهم التجربة على أية أخطار يحتمل أن تصيبهم، مع اعتبار أن لا تكون هذه الأخطار جسيمة. وختامًا أن يتولى الدراسة باحثون مؤهلون، وأن يكون بروتوكول الدراسة صحيحًا من الناحية العلمية" أولآ: تعريف البحث العلمي الطبي والتجارب الطبية وأهميتها:

119- د جحنيط حمزة: المبادئ الأساسية والأخلاقية للبحث العلمي، الملتقي المشترك حول الأمانة العلمية، مركز جيل البحث العلمي، الجزائر، 2017/7/11

120- د حسين على: فلسفة الطب، مرجع سابق، صانه 82 
تعددت تعريفات البحث العلمي الطبي والتجارب الطبية حيث يعرف بأنه " الاختبارات والتجارب والتحويرات والتطويرات والتطبيقات العلمية الطبية على المادة البيولوجية الحية للإنسان (أي البحوث الطبية على الانسان) بغية الوصول إلى نتائج علمية محددة متوقعة بعد دراسة نظرية، أو إلى اكتشافات علمية غير متوقعة جديدة، شريطة أن تجرى هذه البحوث في مخابر بحوث طبية علمية معتمدة ومراقبة وتخضع للقوانين المنظمة للبحث الطبي العلمي"121 وهو تعريف يعيبه أنه يركز على العملية البحثية في حد ذاتها دون أن يتطرق لأطراف العلاقة البحثية بدءً من الباحث مرورًا بالمبحوث وانتهاءً بالجهة الراعية للبحث. كما يعرف البعض التجارب الطبية بأنها تجارب يتم إجرائها على الإنسان " تجرى التجارب السريرية Clinical Trials على الانسان بهدف اختبار فاعلية ومأمونية معالجة ما، سواء كانت تلك المعالجة بالأدوية أم بغيرها، ونتيجة هذه التجارب قد تكون ذات فائدة مباشرة للفرد المشارك في التجربة أو ذات فائدة غير مباشرة تُشخر فيها ولهاء مصلحة الفرد لصالح المجتم"122 ويعاب على هذا التعريف أنه كذلك لم يهنم بأطراف العلاقة البحثية كما لم يوضح كيفية إجراء التجربة الطبية على عكس سابقه. ويعرف أخرين التجارب الطبية بأنها " الأعمال العلمية أو الفنية الطبية التي تعمل دون ضرورة تمليها من حالة المريض ذاته لإشباع شهوة علمية أو

121- مختار عيواج: حرية البحث الطبي العلمي في ظل إشتراطات الحق بالسلامة الجسدية: دراسة حالة البحوث الطبية العلمية الخاصة بالاستساخ البشري، مجلة جيل حقوق الانسان،

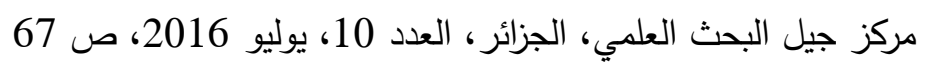

122- عبد الله محم جواد: الجوانب الأخلاقية لإجراء التجارب الطبية على الانسان، المجلة

الثقافية، الأردن، العدد 50، أغسطس 2000، صود: ص 212 
حتى لخدمة علم الطب أو لخدمة الإنسانية المعذبة"123 وهو تعريف تنطبق عليه نفس الانتقادات السابقة، إضافة إلى حصره الدافع لإجراء التجارب الطبية في مجرد الشهوة العلمية والسخرية من أهميتها لخدمة البشرية. وتركز بعض التعريفات على القيم التي تتوافر عليها التجارب الطبية وأهمها قيمة إثراء المعرفة العلمية واحترام حرية العالم في القيام بأبحاثه المفيدة في التقدم الطبي، مع احترام الإنسان وحمايته وعدم المساس بشخصه وكرامته في الوقت ذاته 124

تعددت الاتجاهات بشأن التجارب الطبية على البشر وتتوعت ما بين مؤيد ومعارض، فمن رفضوا التجارب الطبية على البشر استندوا إلى أنها من الأعمال الضارة بجسم الإنسان بينما الحفاظ على الحياة والحق في سلامة الجسد من الحقوق الشخصية الثابتة التي لا يجوز الإضرار بها، كما لا يجوز للإنسان التنازل عن هذه الحقوق فلا يجوز أن يكون الجسم محلاً للتصرفات الضارة به. وفي المقابل يعدد لنا مؤيدي التجارب الطبية على البشر أسباب أهميتها وأنها مباحة ما دام الهدف منها الوصول لغاية علمية وأجريت طبقًا للأصول والقواعد الطبية والقانونية.125.

وقد أجاز الإسلام التجارب الطبية بشرط ألا تؤدي للإضرار بالإنسان لقوله

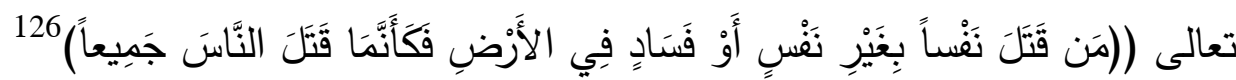

123- منذر عبد الحسين الفضل: التجربة الطبية على الجسم البشري ومدى الحماية التي يكفلها القانون المدني والقوانين العقابية والطبية، مجلة الكوفة للعلوم القانونية والسياسية،

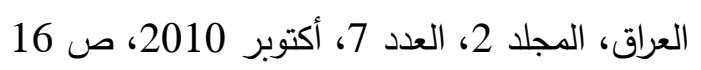

124- عبد اللطيف بربيش: أخلاقيات البحث والتجريب الطبي على الانسان، الأكاديمية،

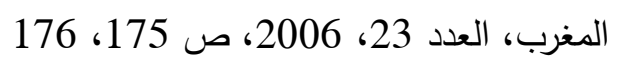

$$
125 \text {-منذر عبد الحسين الفضل: مرجع سابق صد 23، 23، } 126
$$


وبالتالي لا يجوز على سبيل المثال إجهاض الجنين لإجراء تجارب طبية عليه، وهو ما ذهب إليه المشرع المصري حيث لا يجيز إجهاض الأجنة من أجل الجل الجراه

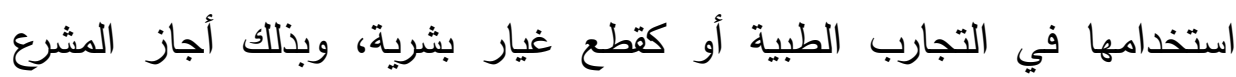

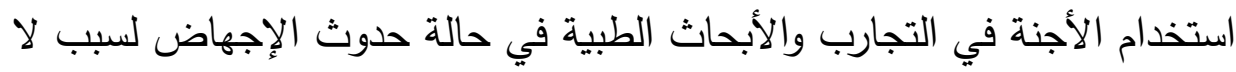
علاقة له بالرغبة في إجراء التجارب الطبية كأن يكون الإجهاض قد تم لإبل لإنقاذ حياة الأم وذلك بشرط موافقة الأب والأم على ذلك. كما لا يجوز إجراء الأبحاث الطبية

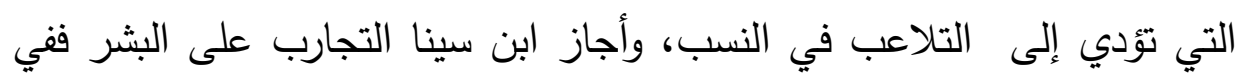

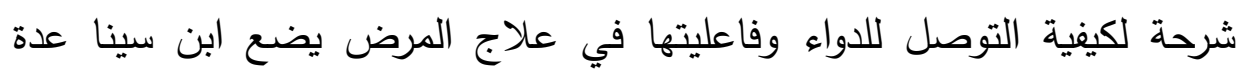

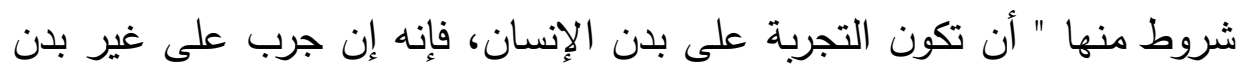

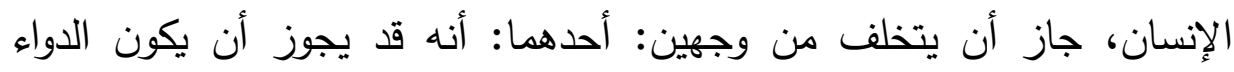

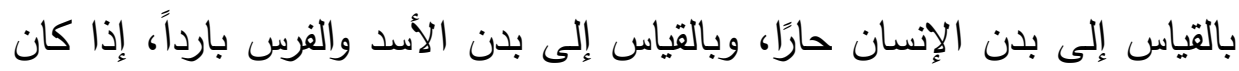

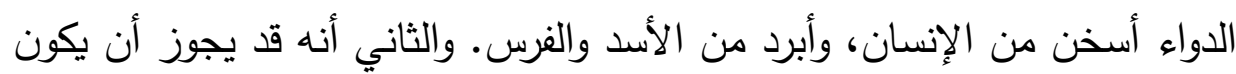

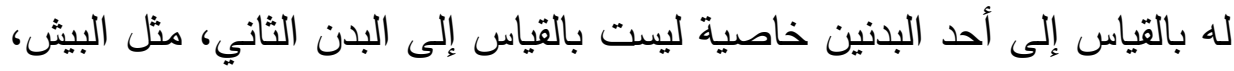

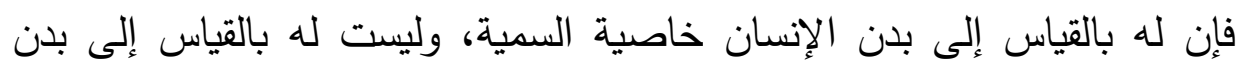

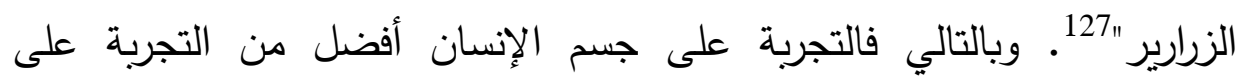
الحيوانات ثم إعطاء الإنسان الدواء الذي أفاد في شفاء الحيوان.

وتوجد أنواع متعددة من التجارب الطبية وأهمها التجارب العلمية غير العلاجية ويكون الهدف منها معرفة تأثير عقار ما على الإنسان السليم دون ضرورة تمليها

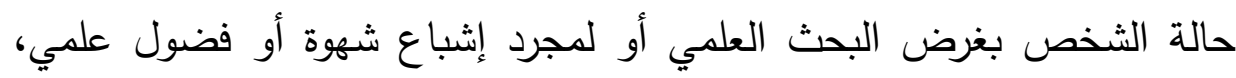

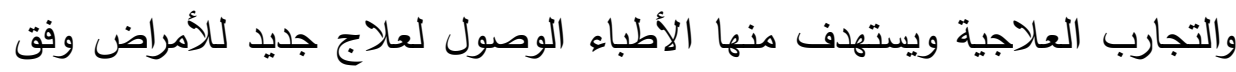

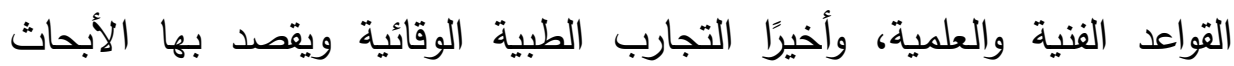

127- بن سينا: القانون في الطب، ج1، دار الكتب العلمية، بيروت، ط1، 1999، ص 319 
والتجارب التي يقوم بها الأطباء على أشخاص من أجل معرفة درجة نجاح علاج أو طريقة علاجية معينة في الوقاية من الإصابة بمرض معين في المستقبل 128 أهمية التجارب البثرية: تتميز التجارب الطبية بكثير من الفوائد والمزايا منها

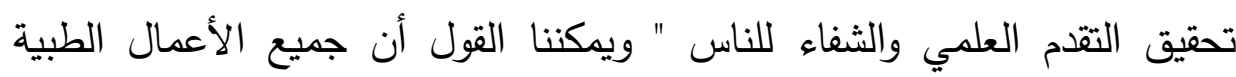

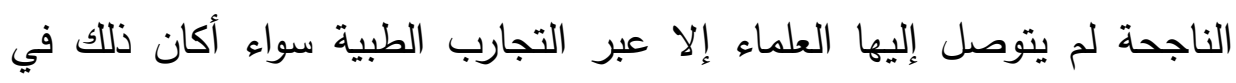

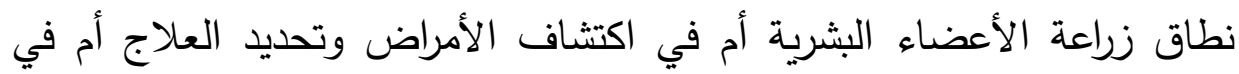

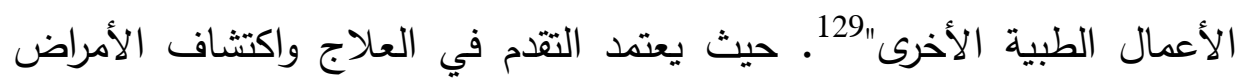
ومحاربة الأوبئة على البحث العلمي الطبي والتجارب التي تجرى على الإنسان

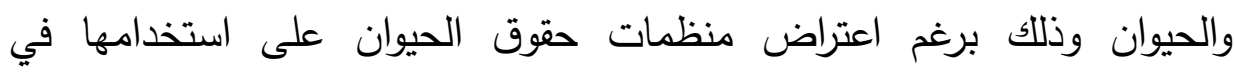

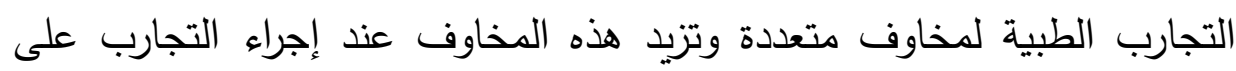
البشر لذلك " ظهرت مواقف تزداد تصلبا تجاهها وخاصة بعد الحرب العالمية الثانية حين تم فضح مساوئ مثل هذه التجارب في محاكمات نورمبرج

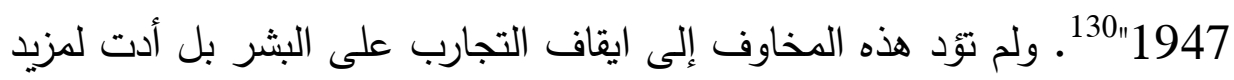

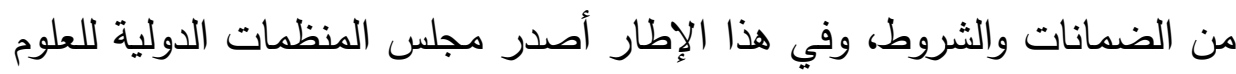

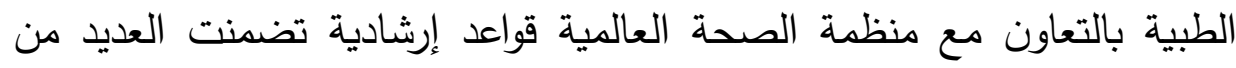

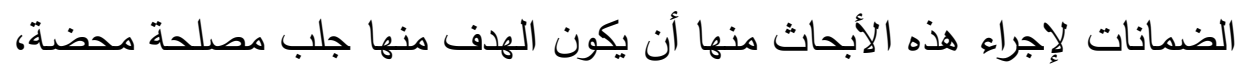

128- فاطيمة الزهرة بومدين: مضمون التجارب العلمية والطبية والضوابط الأخلاقية والقانونية

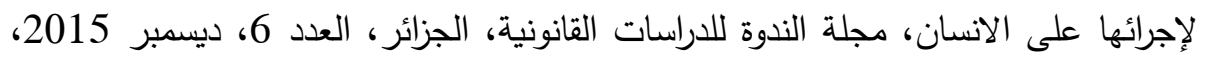
ص 92، 93، 93 129- منذر عبد الحسين الفضل: التجربة الطبية على الجسم البشري ومدى الحماية التي

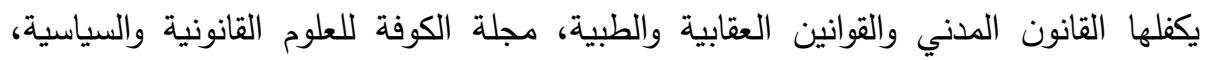

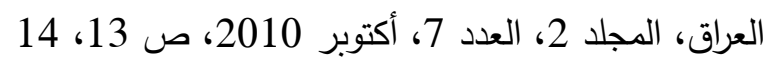

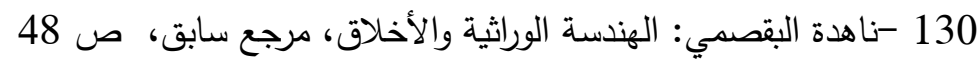


تعود على البشرية بالنفع، أو بدرو مفسدة محضة تعود على البشرية بالضرر • وأن

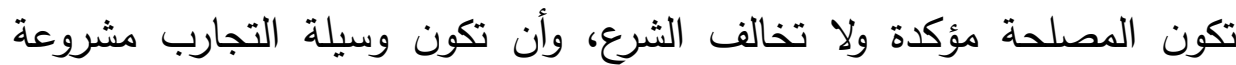
فالغاية لا تبرر الوسيلة والهدف النبيل لا يبرر الوسيلة غير المشروعة، وأن يحاط الهان

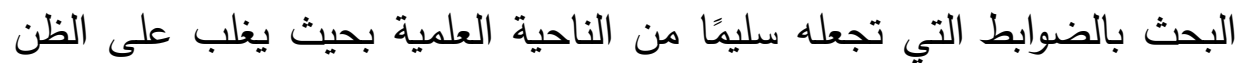

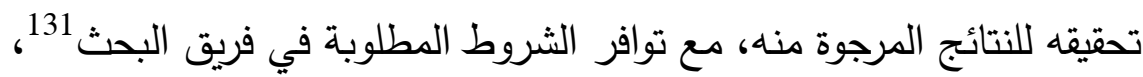
ثانيًا: مراحل العلاقة بين الباحث والشخص موضوع التجربة: تمر العلاقة بين الباحث والمشارك في البحث بعدة مراحل قسهها العلماء إلى

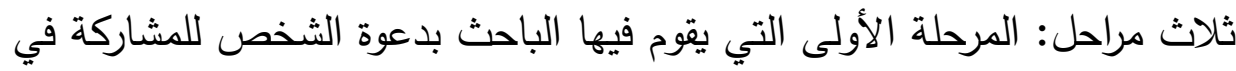

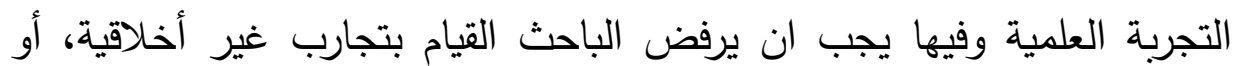

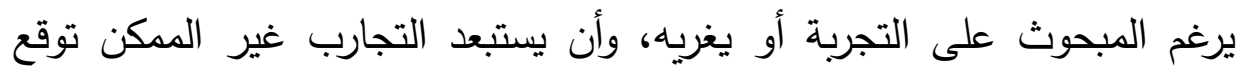
نجاحها، مع اشتراك فريق من الباحثين في صياغة التجربة لضمان أفضل بروتوكول لها، وبعد موافقة الثخص على المشاركة في التجربة العلمية يتم

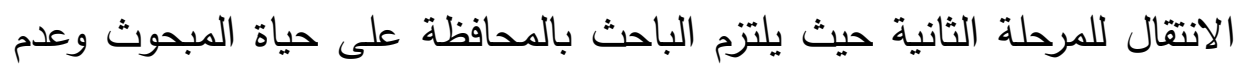

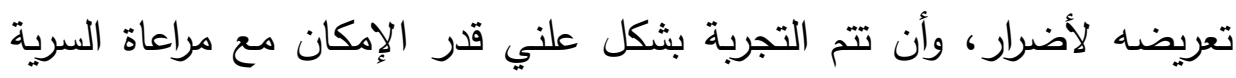

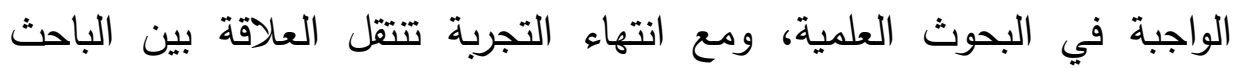
والمبحوث إلى المرحلة الثالثة حيث يجب أن يلتزم الباحث بمتابعة المشاركين في لئه

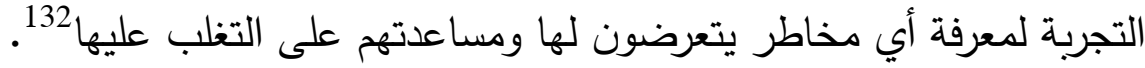
ثالثًا: خطوات الموافقة المستنيرة في التجارب الطبية:

131- القواعد الإششادية الدولية لآداب المهنة فى مجال بحوث الطب الإحيائي المتضمنة

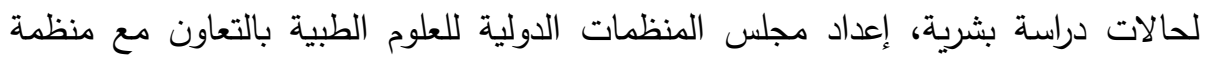

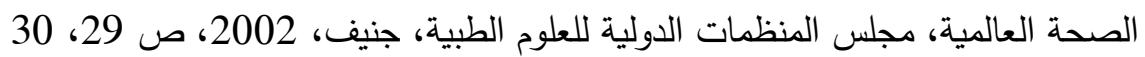
132- أحمد صبحي، محمود فهمي زيدان: في فلسفة الطب، مرجع سابق، ص صلئ، 130: 132 
لا يمكن القول بوجود نموذج ثابت يجب أن يتم اتباعه من قبل كل العلماء

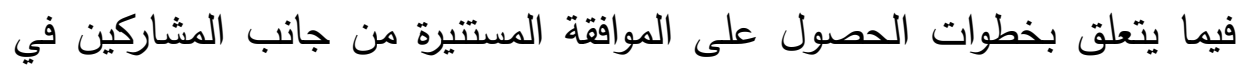

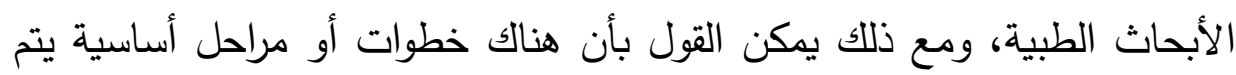
المرور بها للوصول للحصول على الموافقة المستتيرة وهي: 1- الاجتماع الأول والذي يشارك فيه متخصصين من كافة الفروع العلمية المتعلقة بالبحث مع المشحين المحتملين للمشاركة في البحث مثل أحد ممثلي فريق البحث وأخصائي الاورام إن كان البحث متعلق بها، وطبيب من الرئين الرعاية

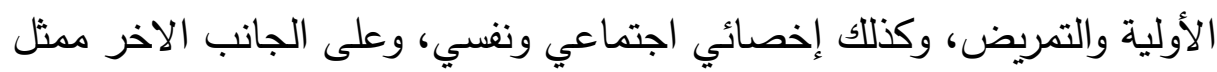
المشارك في البحث القانوني والطبي. ويتم في هذا الاجتماع تقديم كافة التهية المعلومات المكنة مع السماح بطرح الأسئلة من جانب المشارك في البحث وممثليه والإجابة عليها.

2- الجلسات التالية: وفيها يتم منح وقت كاف للمشارك في البحث للتفكير في كل ما يتعلق بالبحث وموافقته على المشاركة فيه والتحدث مع من يمكنهم

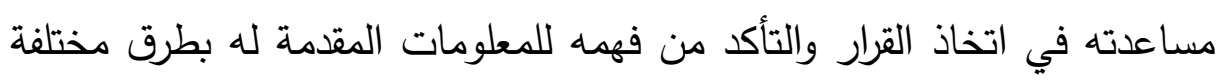
مثل استبيانات الرأي واستمارات الأسئلة والمقابلات

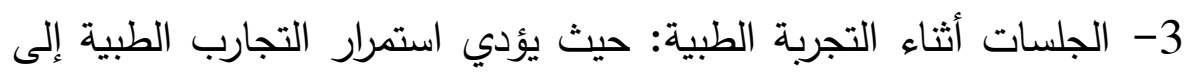
التوصل لاكتشافات جديدة متعلقة بالتجربة بما قد يؤثر على المشارك في البحث

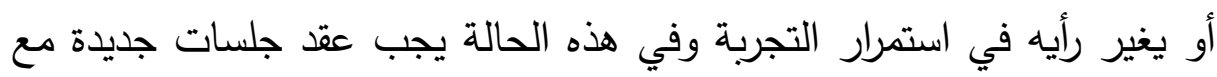

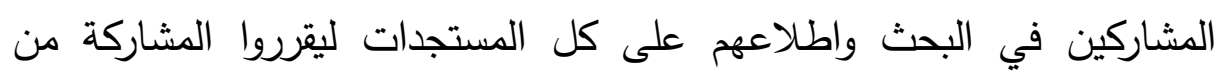
عدمه، ويمكن أن يطلب الباحثين من المشاركين في البحث استمارة موافقة

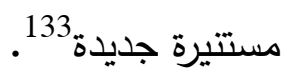

133 -How is informed consent for a clinical trial or research study different from consent for standard treatment? In https://www.cancer.org/treatment/finding-and-paying-for- 
اهم العناصر الواجب توافرها في استمارة الموافقة المستتيرة كما يوضحها لنا لوكيتش نجهاوان Lokesh P. Nijhawan وأخرين هي شرح الغرض من البحث ومدته المتوقعة، وصف الإجراءات المتبعة والمخاطر المتوقعة واحتمالاتها والتعويضات المقررة عنها، بيان الفائدة التي تعود على المبحوث والأخرين من البحث، والكثف عن سرية السجلات ومن يمكنه الاطلاع عليها، معلومات عن عن التعويضات المقررة للمشاركين في البحث، ومن يمكنه الاتصال بهم للحصول على المساعدة واجابات عن أي تساؤلات تراودهم، والتأكيد على طوعية المشاركة وإمكانية التوقف والانسحاب في أي وقت دون أدنى مسئولية على المشارك في البحث 134 رابعًا: شروط الأبحاث الطبية والتجارب على البشر: استهداف التجارب الطبية على البشر فائدة البشرية لا يعني إجرائها دونما شروط أو ضمانات كافية سواء للمبحوثين أو الباحثين، ومن هنا كان وضع مجموع من الضوابط والقواعد التي يجب على الباحثين الالتزام بها لتفادي المخاطر التي قد تتتج عن الأبحاث الطبية على البشر والحد منها لأقصى درجة. لهذا فمن الضروري أن يستوفى البحث العديد من المتطلبات منها أن يكون البحث البث ضروريًا للوصول لهدف عام يخص مصلحة المجتمع، وألا تكون هنالك وسيلة للحصول على المعلومات غير عن طريق إجراء البحث على البشر، وأن تفوق الفوائد المتوقعة أية أخطار يمكن أن تصيب الأشخاص الذين تجرى عليهم التجربة، وأخيرًا أن يتولى الدراسة باحثون مؤهلون، وإتباع بروتوكول صحيح

treatment/understanding-financial-and-legal-matters/informedconsent/clinical-trial-consent.html

134 -Lokesh P. Nijhawan, Manthan D. Janodia, B. S. Muddukrishna, K. M. Bhat, K. L. Bairy, N. Udupa, and Prashant B. Musmade: Informed consent: Issues and challenges, Journal of Advanced Pharmaceutical Technology \& Research, v4 (issue 3), jul-sep 2013, p 1356 
للدراسة من الناحية العلمية135. ويبدأ التجريب على البشر بعد انتهاء التجارب المعطلية والتجارب على الحيوانات حيث يمر الدواء بمرحلة التجارب المبدئية قبل السريرية وفيها يتم إجراء الدراسات الكيماوية والسمومية والصيدلية في الخختبرات،

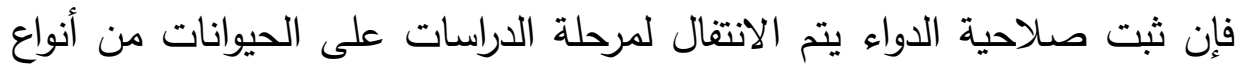

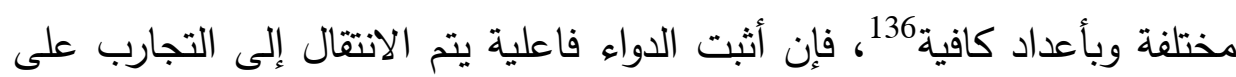

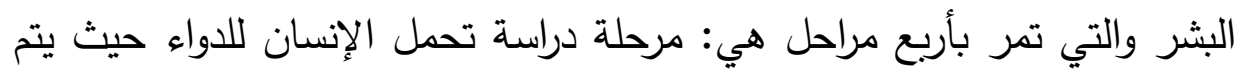
معرفة الآثار الجانبية للدواء خاصة المضرة بالإنسان، فإذا كانت النتائج المبدئية

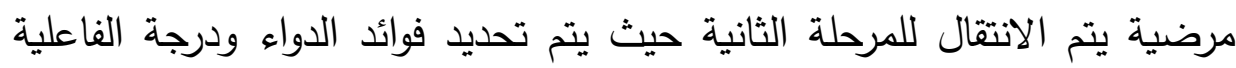
ونسب الاستعمال والتخفيف من الآثار الجانبية الضارة، فإذا كانت النتائج

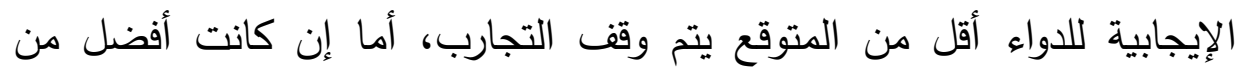

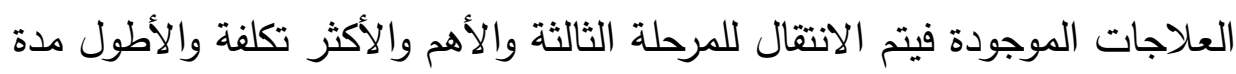
حيث تتم التجارب على عدد كبير من المرضى يتم تقسيمهم لثلاث مجموعات

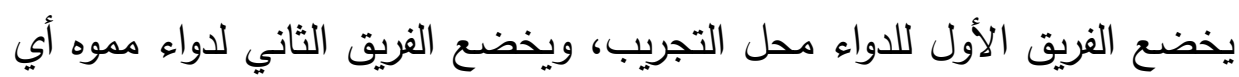

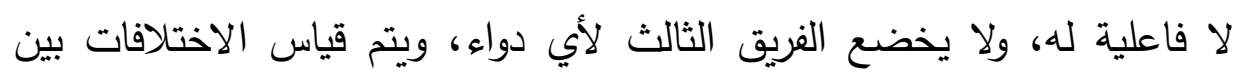

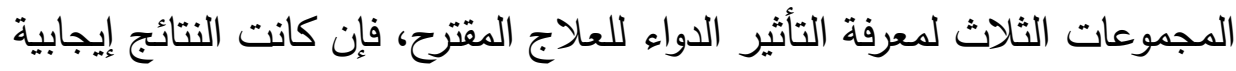

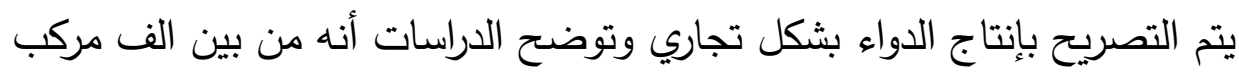

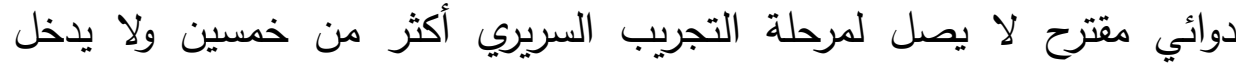

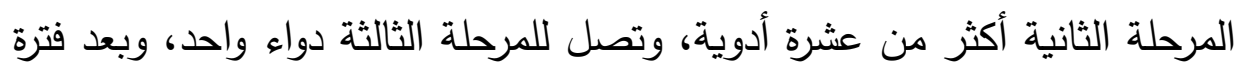

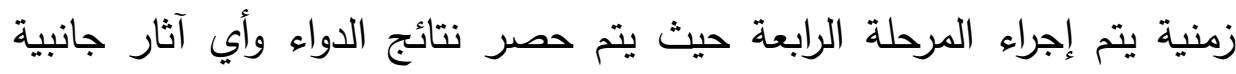

135- د حسين على: فلسفة الطب، مرجع سابق، ص 82

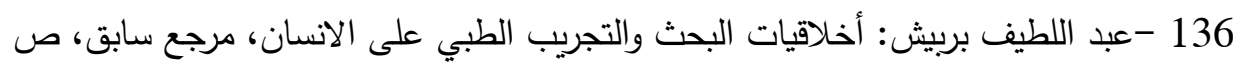


تظهر بعد فترة زمنية طويلة من استخدام الدواء ${ }^{137}$ ويضع لنا تقرير بلمونت المبادئ الأخلاقية الأساسية لاستخدام أي إنسان للبحوث وهي": 1- الاستقلالية واحترام الأشخاص: ويقوم على حماية استقلال جميع الأفراد المشاركين في البحث ومعاملتهم باحترام، والسماح بالموافقة المستنيرة. كما يجب على الباحثين أن يكونوا صادقين ولا يقومون بأي خداع للمبحوثين. 2- الفوائد: فيجب أن يعتمد البحث فلسفة "لا ضرر" للمبحوثين، مع تعظيم الفوائد لمشروع البحث والتقليل من المخاطر على المواضيع البحثية. 3- العدالة: فيجب أن تدار إجراءات البحث بشكل معقول وغير استغلالي للمبحوثين ومدروسة بشكل عادل - بالتوزيع العادل للتكاليف والمنافع للمشاركين المحتملين في البحث - وعلى قدم المساواة"138

وتفسر ليزابيث آدم Lizbeth A. Adams ما جاء بالتقرير بأن المقصود بالاستقلالية هو حق الفرد في تحديد الأنشطة التي يشارك فيها من عدمه، حيث يتضمن الاستقلال الذاتي قدرة الفرد الكاملة على فهم ما يطلب منه القيام به وإصدار قراره المسبب بالاختيار بحرية كاملة دونما قسر، وإتاحة الفرصة الكاملة لهح لطرح كافة الأسئلة التي يريدون إجابات عليها، وبالتالي استبعاد الأشخاص لهاص ضعيفي الإدراك كالأطفال والمعاقين عقليا والمسنين والسجناء أو اتباع شروط الها مشددة إن كان البحث لا يمكن القيام به إلا عليهم، أما الفوائد فالمقصود منه التزام

137- عبد اللطيف بربيش: أخلاقيات البحث والتجريب الطبي على الإنسان، مرجع سابق، ص 185:182. عبد الله محح جواد: الجوانب الأخلاقية لإجراء التجارب الطبية على الانسان، المجلة الثقافية، الأردن، العدد 50، أغسطس 2000، ص صدانب 214، 215. منذر عبد الحسين الفضل: التجربة الطبية على الجسم البشري ومدى الحماية التي يكفلها القانون المدني والقوانين العقابية والطبية، مجلة الكوفة للعلوم القانونية والسياسية، العراق، المجلد 2، العددي العديه

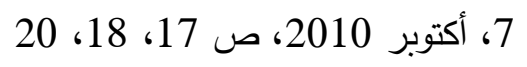

138- Belmont Report: https://en.wikipedia.org/wiki/Belmont_Report 
الباحث بتحقيق أكبر قدر من الفوائد من البحث مع أقل قدر من الأضرار

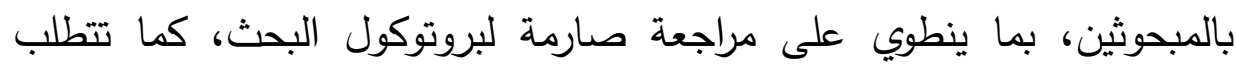

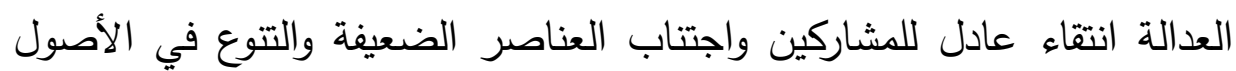
العرقية للمبحوثين، ويفضل أن يكون الشاركين في البحث ومن يتحملون أعبائه

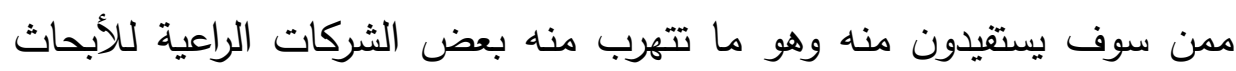

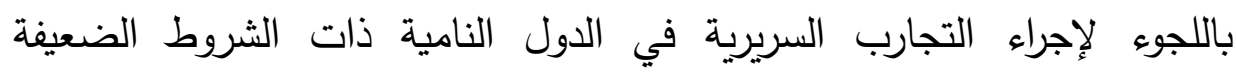
للأبحاث على البشر تصميم الدراسات البحثية الأخلاقية 139. كما توجد شروط يجب توافرها في الباحث والمبحوث والجهة الراعية للبحث

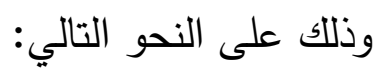

1- الثروط الواجب توافرها في الباحث في البحوث الطبية: من أهم

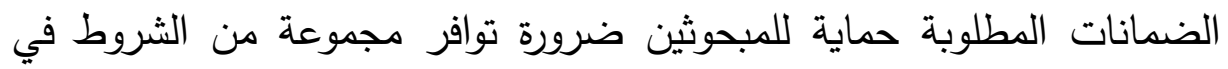

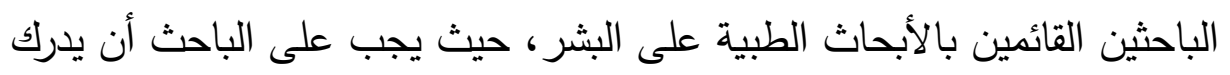

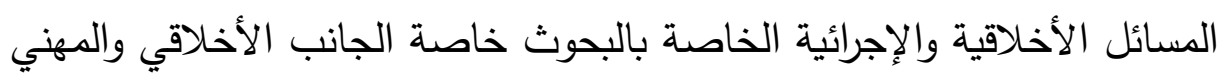

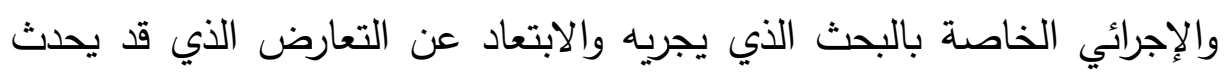

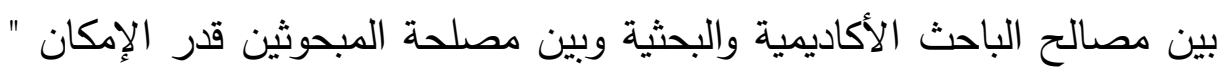

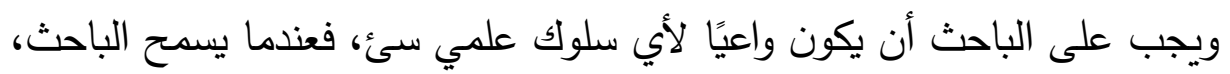

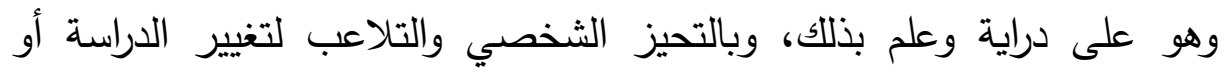

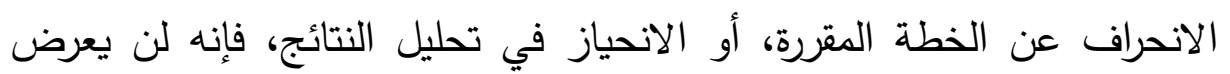

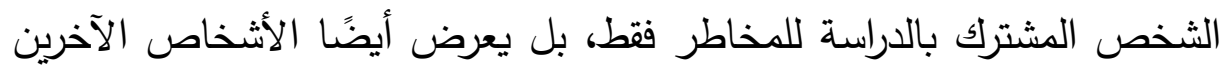
للضرر عن طريق نتائجه غير الدقيقة"140.

139-Lizbeth A. Adams, Timothy Callahan, Research Ethics, in https://depts.washington.edu/bioethx/topics/resrch.html 140- عبد الله محمد جواد: الجوانب الأخلاقية لإجراء التجارب الطبية على الإنسان، المجلة

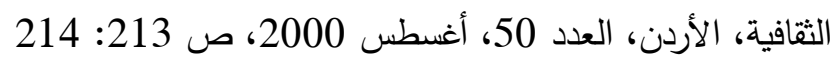


وتثير دانييلا برومويتش Danielle Bromwich إلى ضرورة تجنب

الباحث أي عمل يقلل من طوعية قرار المشارك المحتمل في البحث "وتجنب لئب كافة أعمال الإكراه والخداع وأي أشكال من التلاعب، وهو ما يتطلب من الباحثين الكثف المناسب عن جميع الحقائق التي يعرفونها عن البحث، ولديهخ سبب للاعتقاد بأنها ستكون ذات صلة بقرار تسجيل المشارك"141. والتزام الباحث بالكثف عن الأضرار والأعراض الجانبية المتوقعة الناتجة عن التجربة البحثية هو التزام بما هو معلوم، فالباحث ملزم بالكشف عما يعرفه ويتوقع إمكانية حدوثه، وليس الكثف عما لا يعلمه، والمعيار هنا معيار موضوعي وشخصي في الوقت ذاته في رأينا، حيث يتم القياس بما يجب أن يعلمه الباحث من نفس مستوى الباحث المشارك في البحث، كما يتم القياس على شخص الباحث ذاته، لمعرفة ما إذا كان في إمكانه توقع هذه الأضرار والأعراض من عدمه. وهو ما يثير تساؤل هام حول مدى أخلاقية قيام الباحث بخداع المبحوثين عند إجراء البحث بما يتعارض مع عملية الموافقة المستتيرة ويؤدي لضعف علاقة الثقة المفترض وجودها بين الباحث والمبحوثين كما يقلل مصداقية الأبحاث الطبية أمام المجتمع، وتجيز ليزابيت ادامز خداع المبحوثين إذا كان الخداع ضروريًا لإجراء البحث كما في حالة الدواء الغفل، غير أنه لا يجوز استخدام الخداع إذا أدي لانتهاك الباحث شروط الموافقة المستنيرة كما إذا وافق شخص على تقديم عينة من الدم لمؤشرات مرض السكري واستخدمه الباحث لأغراض أخرى لا لا لإن علاقة لها ببحوث مرض السكري 142 . ونرى من جانبنا أن الخداع يكون مرفوضًا في حالة ما إذا كان جوهريًا أو يعرض المبحوثين لمخاطر جسيمة، أما إذا كان هرئ هرئ هرئ

141 -Danielle Bromwich, Annette Rid: Can informed consent to research be adapted to risk?, journal of medical ethics, 2015, vol 41, page 523 142-Lizbeth A. Adams, Timothy Callahan, Research Ethics, in https://depts.washington.edu/bioethx/topics/resrch.html 
الخداع لا يؤثر على المبحوث بشكل جوهري وكان ضروريًا لإجراء البحث فإنه

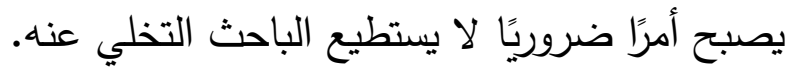

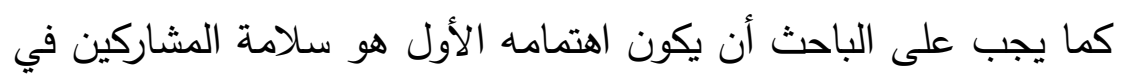

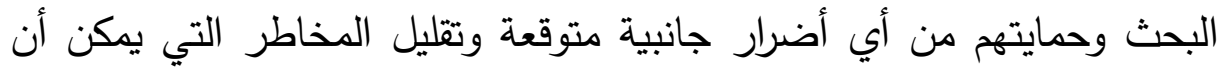

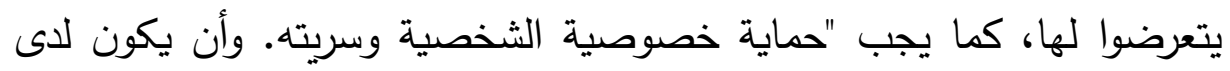

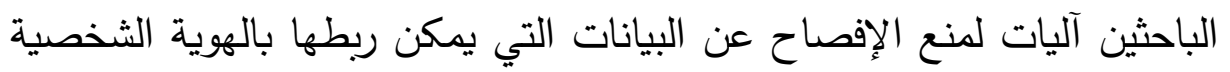

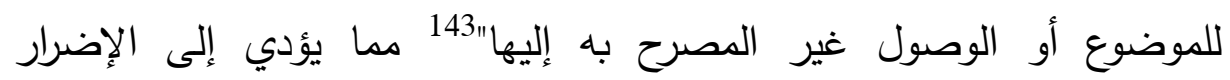

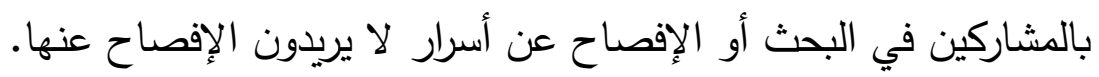

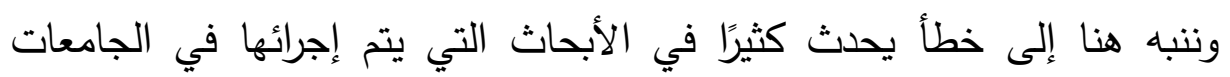
المصرية حيث لا يتم الاحتفاظ بشكل دقيق وتقصيلي للبيانات المتعلقة بالبحث

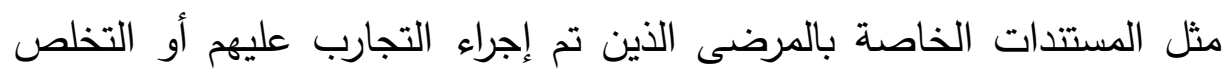

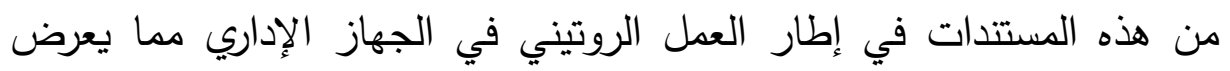
الباحثين لمشكلات خطيرة قد تؤدي إلى عدم الاعتراف بأبحاثهم أو توجيه اتهامات لهم مثل فبركة الأبحاث وهو ما يؤدي إلى تثويه سمعة البـات الباحثين ويتطلب إجراءات كثيرة لإثبات عدم وجود خطأ من جانبهم وهي إجراءات بعيدًا عن كونها تتطلب فترة طويلة من الزمن تستمر فيها سمعة الباحث مشوهة فئإنه

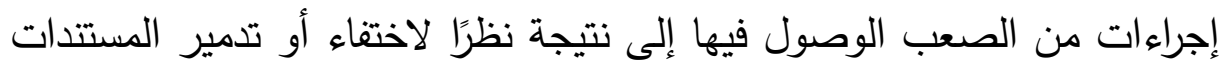

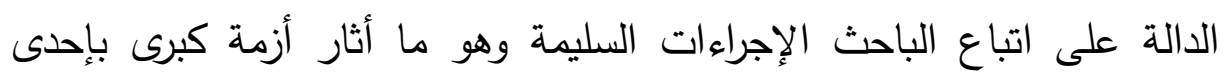

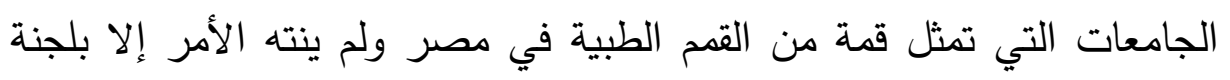

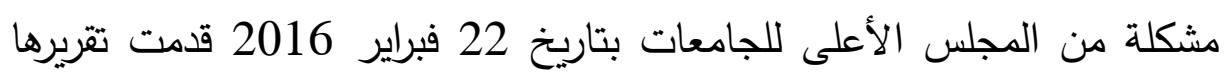
بتبرئة الباحثين من الفبركة وكان من أهم توصياتها ضرورة الاحتفاظ بكل ما لألئ يتعلق بالأبحاث الطبية.

143 -Lizbeth A. Adams, Timothy Callahan, Research Ethics, in https://depts.washington.edu/bioethx/topics/resrch.html 


\section{2- الثروط الواجب توافرها في المشارك في البحوث الطبية: يجب أن}

تتوافر في المشارك في البحوث الطبية العديد من الثروط التي سبق ذكر بعض فئها

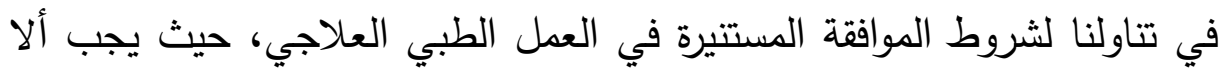

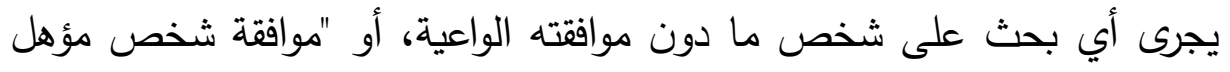

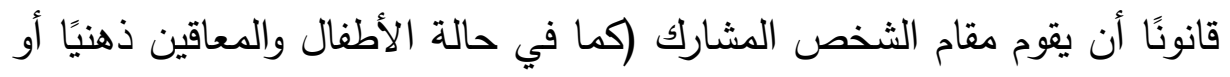

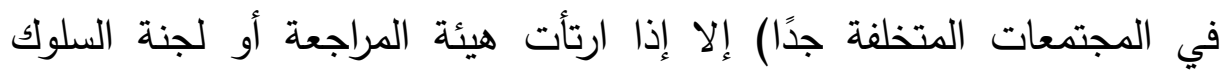

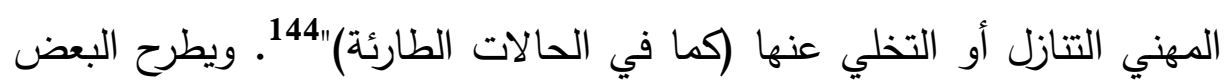

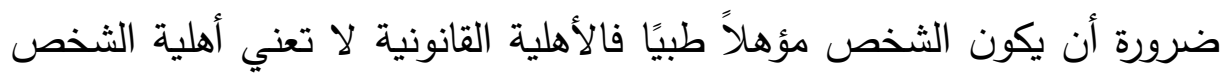

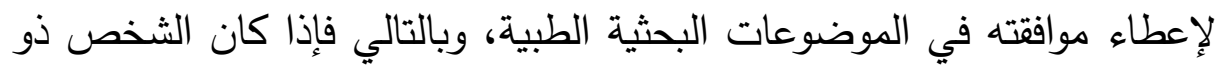

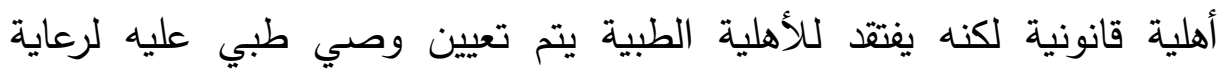

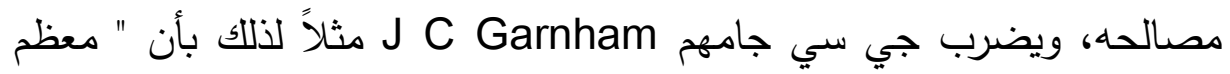
سكان بريطانيا مؤهلين قانونيًا من وجهة نظر الأبحاث السريرية غير العلاجية،

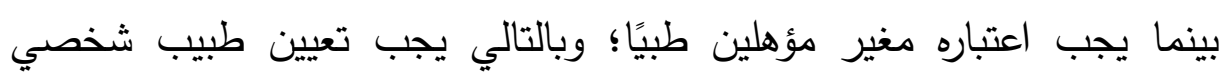

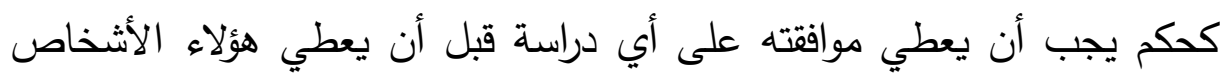

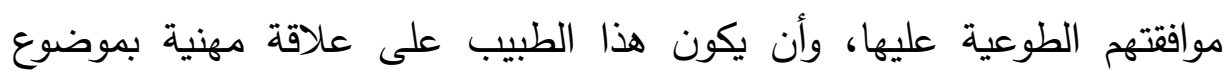

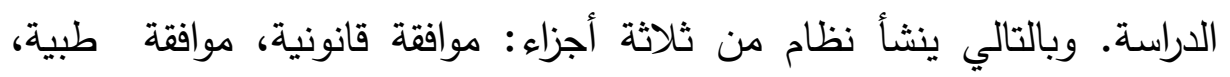

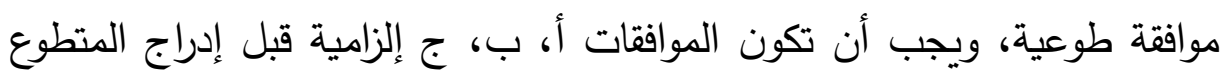

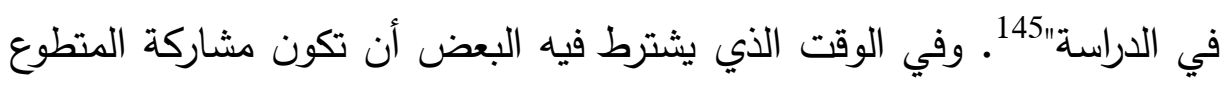

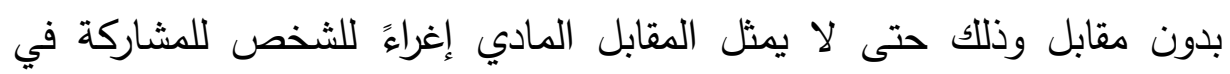

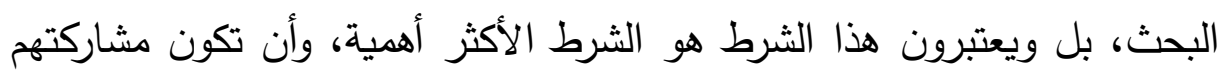

144- عبد الله محم جواد: مرجع سابق، ص 214

145-J C Garnham: Some observationsns on iofrmed consent in nontheraeutic research, Journal of Medical Ethics, 1975, vol1, page 143,144 


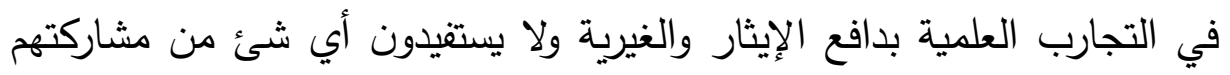

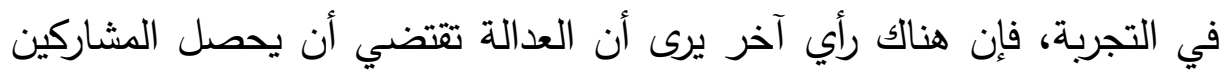

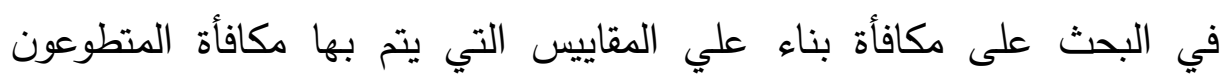

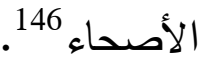

وهناك فئات يرى الكثيرين أنه لا يجوز التجريب عليها أو يجوز التجريب عليها

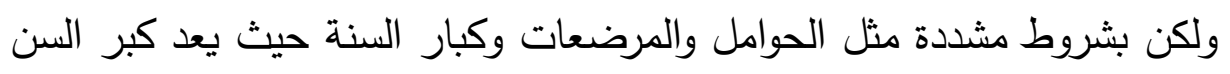

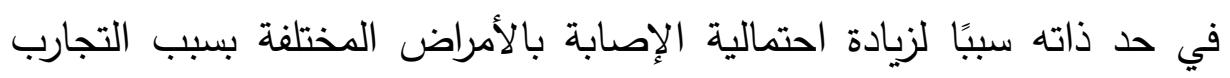

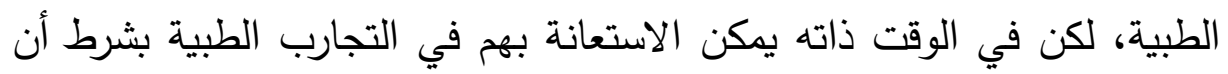

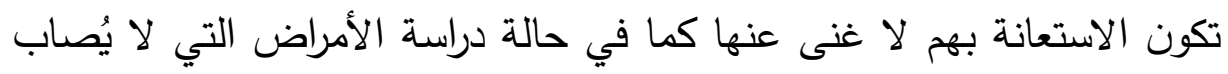

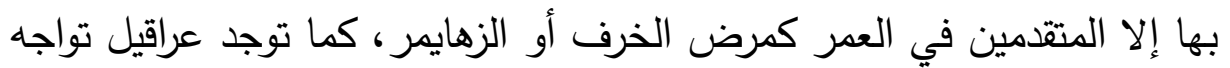

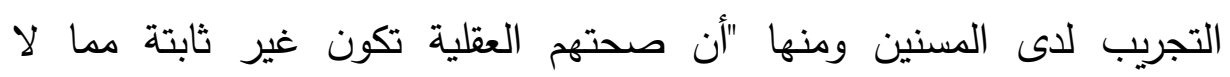

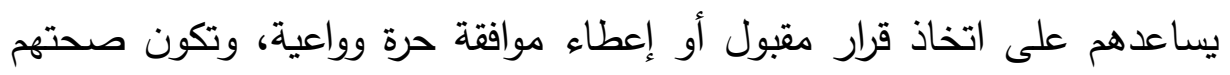

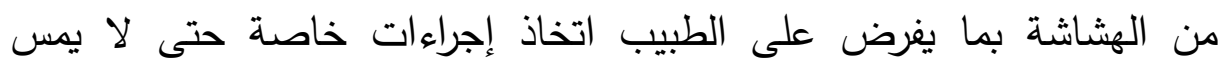
بحياتهم أو صحتهم، وضعف مقدرتهم لفهم التجريب والإدلاء بتقييم صحيح لنتائجه"147. نفس الأمر يجب مراعاته في الأبحاث التي يكون محل الدراسة فيها

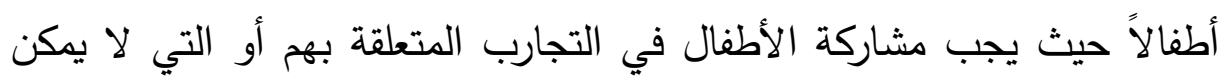

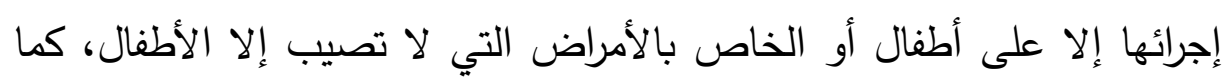

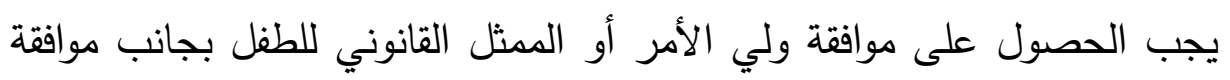

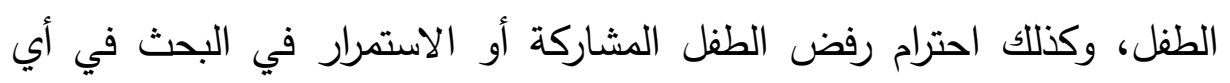

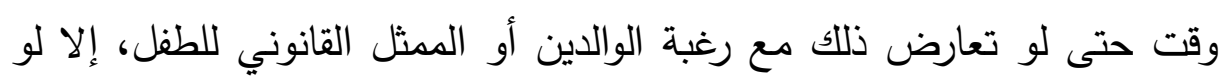

146- د أحمد عبد الحليم عطية: الأخلاقيات الحيوية الطبية، دفاتر فلسفية، العدد 9، 2015، ص 118

147- عبد اللطيف بربش: مرجع سابق، ص 180:182 
كان الطفل محتاجًا لعلاج غير موجود خارج نطاق البحث وكانت هناك احتمالية كبيرة أن تفيده التجربة في العلاج، وفي كل الأحوال يجب أن يتم مراقبة البحث عن طريق أحد الوالدين أو الممثل القانوني للطفل ليستطيع سحب الطفل في أي وقت يرى استمرار التجربة يتعارض مع مصلحة الطفل، وعلى فريق البحث تقديم الرعاية والدعم النفسي والطبي بشكل دائم للأطفال المشاركين في التجربة قبل وأثناء وبعد انتهاء التجربة أو انتهاء مشاركتهم فيهاب14. أما الذين لا يستطيعون التعبير عن إرادتهم سواء بسبب الغيبوبة الدائمة أو بسبب بعض الاضطرابات العقلية فيجب أن يكون البحث متعلق بالحالة المرضية لهم والحصول على موافقة أحد أفراد أسرته المسؤول عنه أو الممثل القانوني لهم, ويراعى دومًا أنه يجب تخفيف الشروط الواجب توافرها في الثخص الخاضع للتجربة الطبية في حالة Danielle الأبحاث ذات المخاطر المنخفضة وتضرب لنا دانييلا برومويتشي Bromwich الحصول على أنسجة متجددة بشكل دوري مثل الشعر والأظافر، وتؤكد أن "معايير الحصول على الموافقة المستتيرة ينبغي أن تتكيف مع صورة المخاطر والمنافع في البحث...وعلى العكس فإن هناك حاجة إلى عملية موافقة أكثر

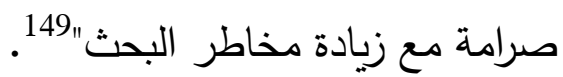
3- التزامات الجهات الراعية للأبحاث: يجب على الجهات الراعية للأبحاث الطبية تقديم كافة المساعدات الممكنة والمطلوبة من أجل الوصول إلى النتائج الحقيقية للأبحاث، ويتطلب ذلك من الجهات الراعية عدم التذخل أو محاولة التأثير في البحث الطبي أوالنتائج التي تتتج عنها حتى لو تعارضت مع التزامات الجهة الراعية، كما عليها التزام بالتأكد من اتباع الباحثين لكافة الإجراءات

148-http://www.islamset.com/arabic/alwseka/nazeh/word/

149- Danielle Bromwich, Annette Rid: Can informed consent to research be adapted to risk?, journal of medical ethics, 2015, vol 41, page 521 
المطلوبة واتباع البروتوكول البحثي وعدم مخالفته، وهو ما خالفه بعض الرعاة ففي الفترة بين عامي 1994- 1997 أجريت تجربة سريرية لدراسة فاعلية مضادات للاكتئاب على المراهقين بينت أن مستحضر الباروكستين يزيد نسبة

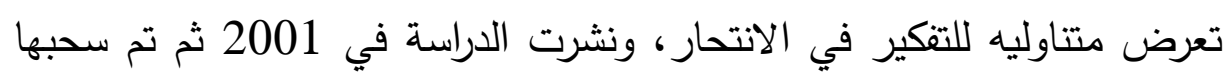

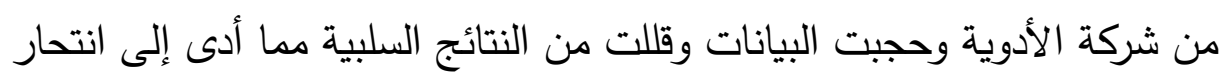
بعض المراهتين وغرمت وزارة العدل الأمريكية شركة غلاسكو سميث كلاين

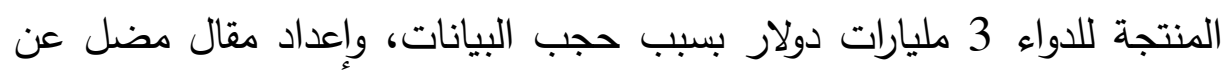
الدراسة، وتشجيعها بشكل غير مشروع المراهقين على تتاول الدواء، كما أدينت

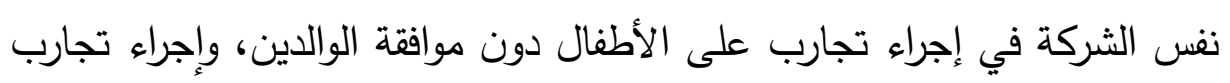
على جنود من الجيش النيبالي 150

خامسًا: نماذج للتجارب الطبية غير الأخلاقية:

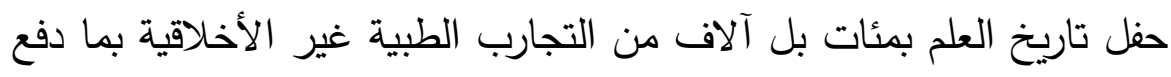

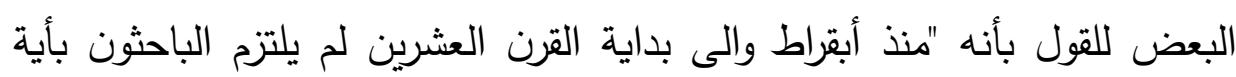

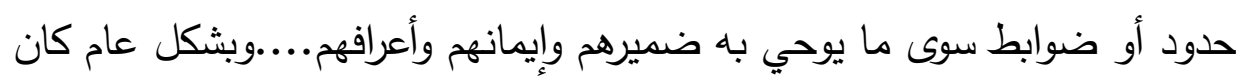

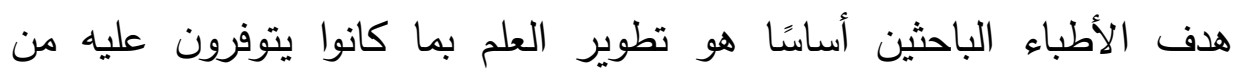

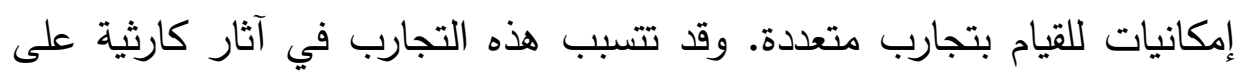

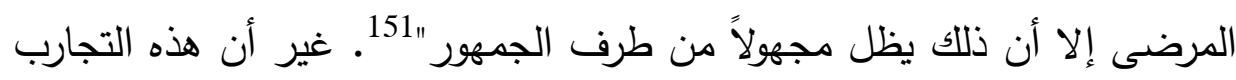

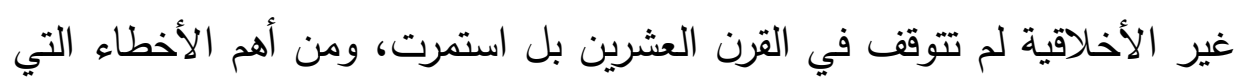

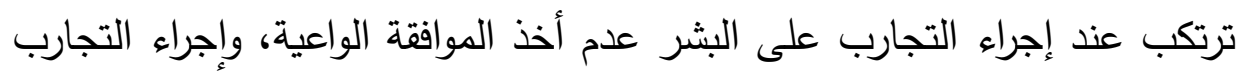

150 -List of medical ethics cases: https://en.wikipedia.org/ wiki/ List_of_medical_ethics_cases

151-عبد اللطيف بربيش: أخلاقيات البحث والتجريب الطبي على الانسان، الأكاديمية، الدغرب، العدد 23، 2006، ص بل 156، 176، 177 
على الأطفال والحوامل والمسنين دونما مبرر بحثي، وإجراء التجارب على الإنسان

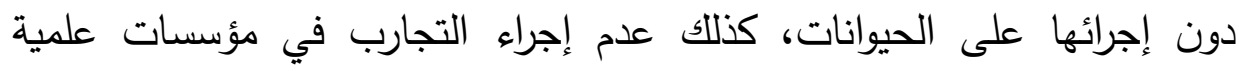

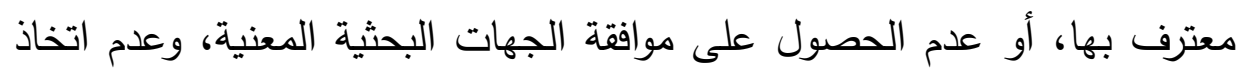

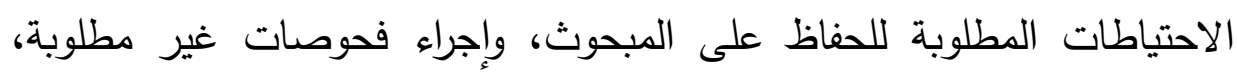

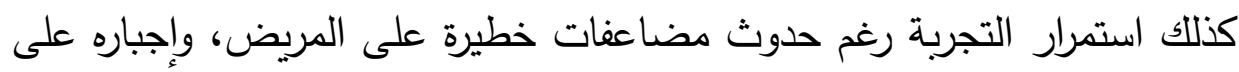

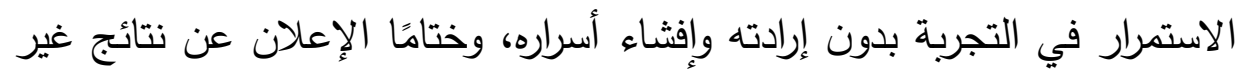

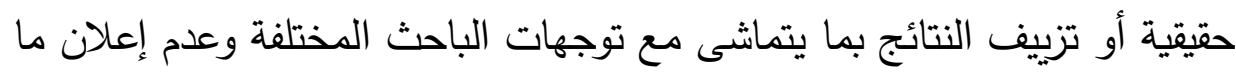

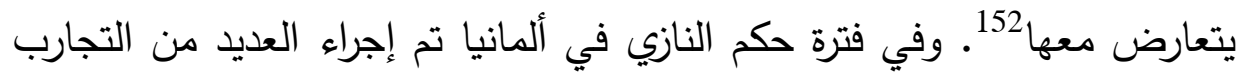

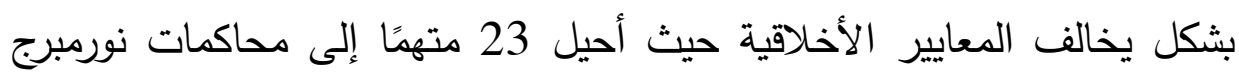
العسكرية بتهم إجراء تجارب طبية على الأسرى دون الالتزام بالشروط القانونية

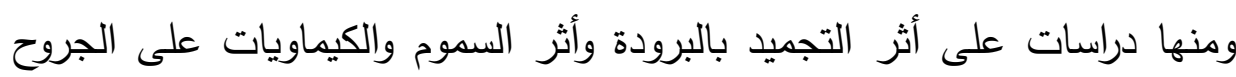

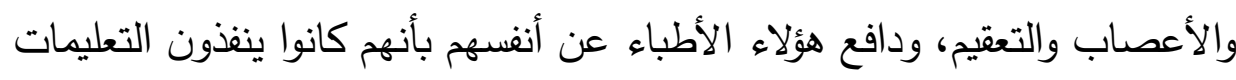

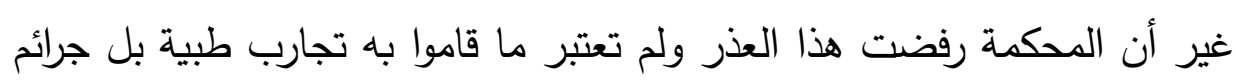

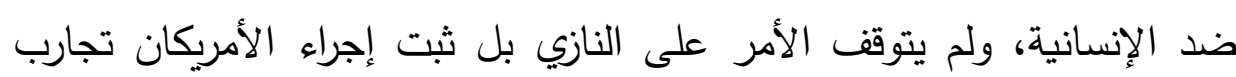

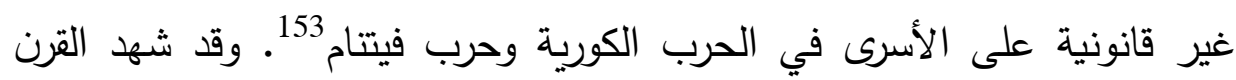

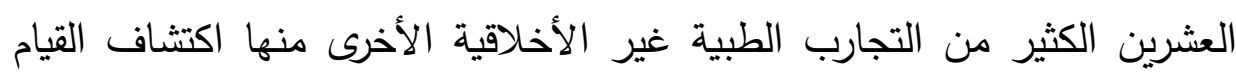

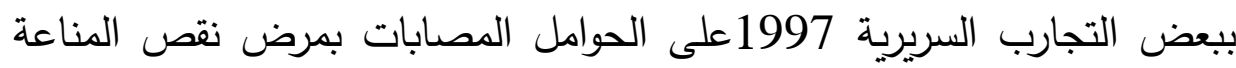

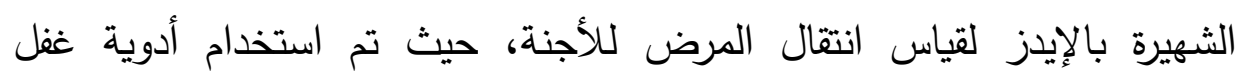

152- عبد الله محمد جواد: الجوانب الأخلاقية لإجراء التجارب الطبية على الانسان، المجلة

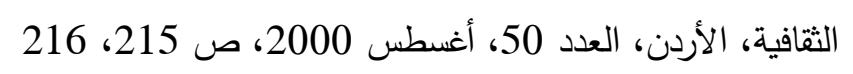

153- منذر عبد الحسين الفضل: التجربة الطبية على الجسم البشري ومدى الحماية التي يكفلها القانون المدني والقوانين العقابية والطبية، مجلة الكوفة للعلوم القانونية والسياسية، العراق، المجلد 2، العدد 7، أكتوبر 2010، ص 14، 15 
للحوامل في تايلاند وبعض دول إفريقيا بينما تم استخدام دواء حقيقي مع الحوامل

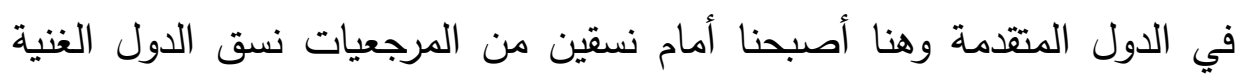

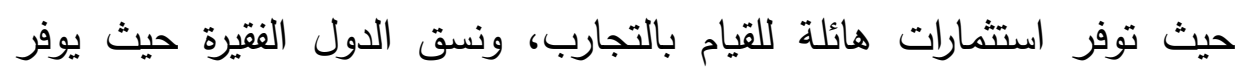
Kenneth الأشخاص الذين تجرى عليهم التجارب

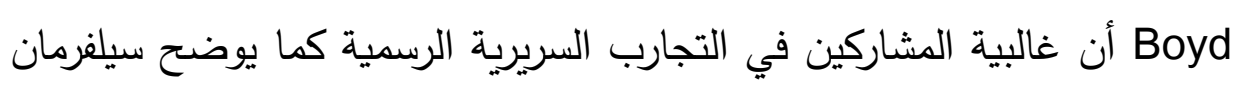

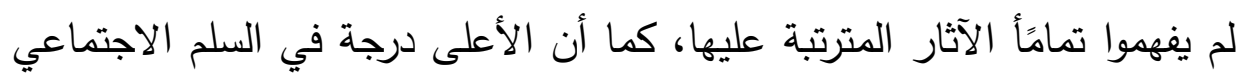

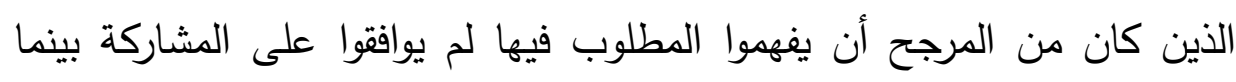

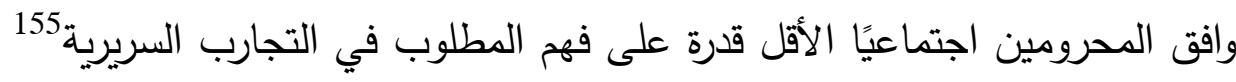

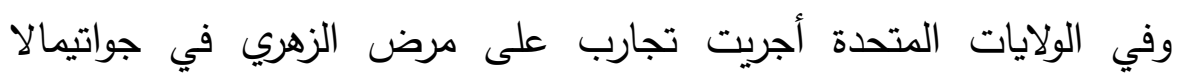

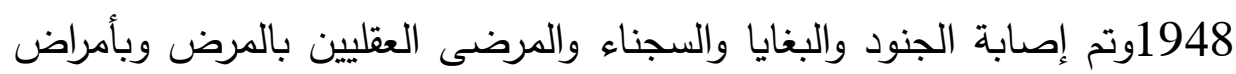
أخرى دون علمه ومعالجة الأمراض بالمضادات الحيوية مما أدى إلى وفاة 82

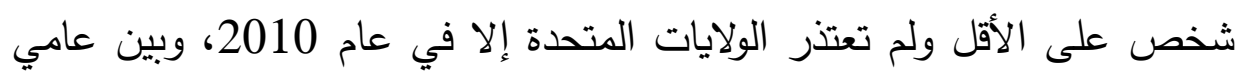

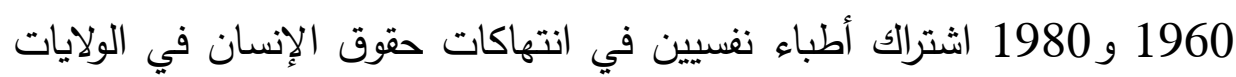
المتحدة والاتحاد السوفييتي والصين، كما تم إعطاء مواد مشعة للحوامل والأطفال

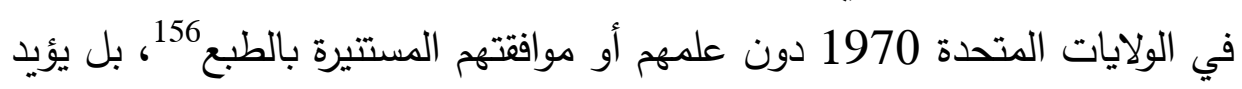

154- عبد اللطيف بربيش: أخلاقيات البحث والتجريب الطبي على الانسان، الأكاديمية،

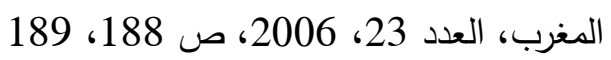

155 -Kenneth Boyd: The impossibility of informed consent?, Journal of Medical Ethics, 2015, vol 41, page 445

156 -List of medical ethics cases: in https://en.wikipedia.org/ wiki/List_of_medical_ethics_cases 


\section{مجلة وادي النيل للاراسات والبحوث الإنسانية والاجتماعية ـ مجلة علمية محكمة}

(ISSN: 2536 - 9555)

البعض إجراء التجارب الطبية على الدحكوم عليهم بالإعدام مقابل تخفيض العقوبة للسجن المؤبد وهو المطبق في ولاية أوهايو 157 النتائج والتوصيات 1- ما زالت العلاقة الأبوية هي السائدة في العلاقة بين الطبيب والمريض في مصر، حيث يتعامل المريض مع الطبيب باعتباره من يعرف مصلحته وعليه

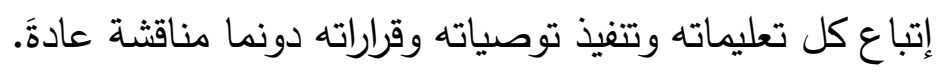
2- ينخف الوعي بالموافقة المستتيرة بين العاملين في المجال الطبي

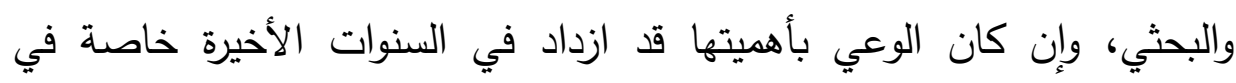

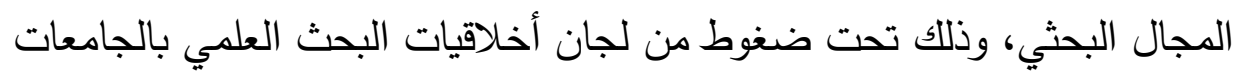
والمراكز البحثية في ضرورة الحصول على الموافقة المستيرة من المبحوثين.

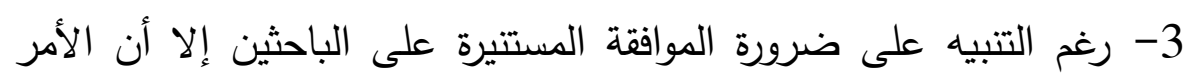

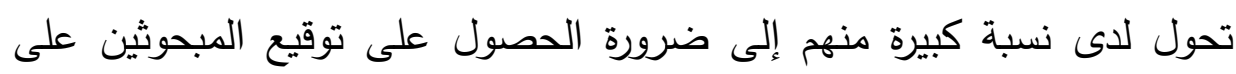

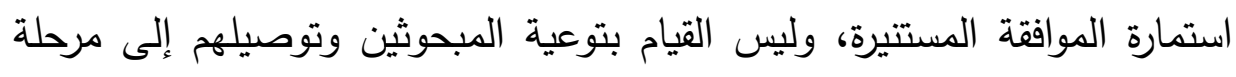

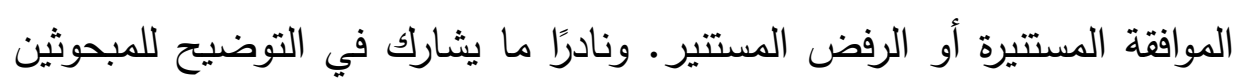
أكثر من عضو من الفريق البحثي. 4- تلاحظ وجود حالات للأبحاث الطبية خارج النطاق القانوني حيث يتم التح

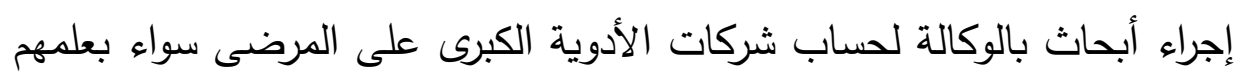

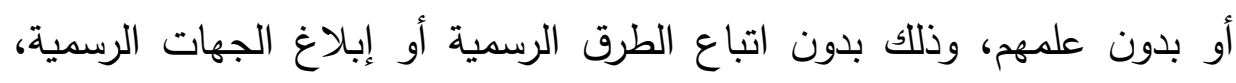

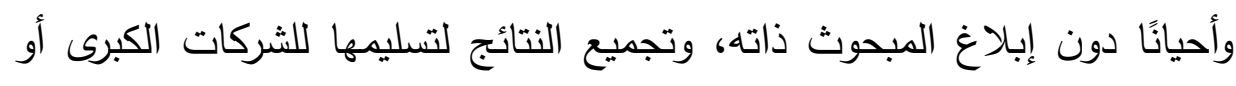
مندوبيها والحصول على المقابل المجزي لإجراء هذه الحالات خارج نطاق القانون

157-منذر عبد الحسين الفضل: التجربة الطبية على الجسم البثري ومدى الحماية التي

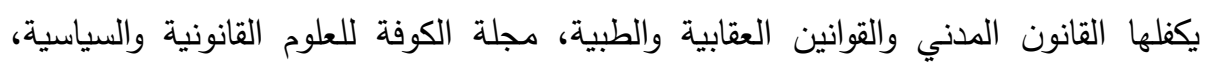
العراق، المجلد 2، العدد 7، أكتوبر 2010، ص العن 24، 25 
وذلك لعدم إمكانية إجرائها بشكل قانوني مثل إجراء التجارب على البشر قبل انتهاء مرحلة التجارب على الحيوانات في الخارج. 5- يزداد إهمال الموافقة المستيرة في المجال الطبي حيث نلاحظ انخفاض في الناض

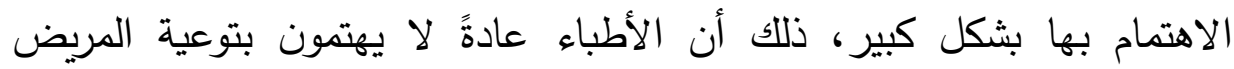

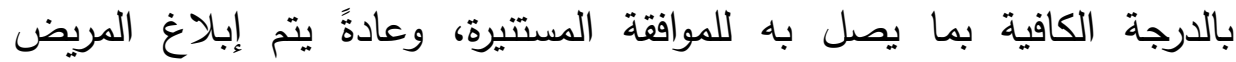
بمعلومات قليلة عن حالته المرضية والطريقة العلاجية المتبعة، ونادرًا ما يتم إعلام المريض بالطرق العلاجية الأخرى الممكنة لحالته وسبب تفضيل الطريقة المتبعة، ويندر إبلاغ المريض بالتطورات التي يمكن أن تحصل لحالته بعد مغادرته لمستشفي أو المركز العلاجي. 6- يعتبر كثير من الأطباء إعلام المريض بكل تفاصيل حالته وأهمية وعيه

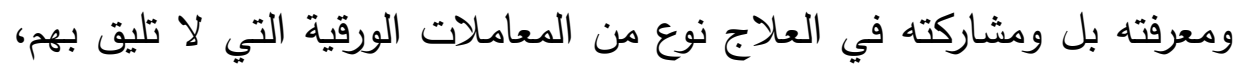
فيلقون عبء القيام بها على المعاونين في العمل الطبي خاصة من التمريض وهو

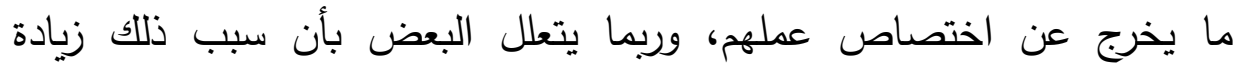
الحالات التي يتعامل معها الطبيب، إلا أن ذلك ليس مبررًا لإهمال الطبيب عنصر هام من عناصر العلاج. 7- نتترح ضرورة تشكيل لجنة طبية في المستشفيات الجامعية والكبرى،

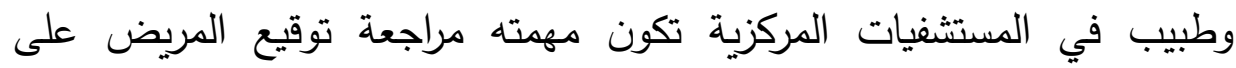

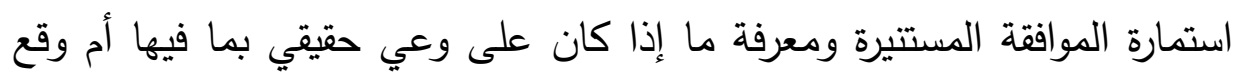
عليها كجزء من الإجراءات الروتينية للقيام بالعمل الطبي أو لخروجه. 8- نرى ضرورة توقيع عقوبات حقيقية وصارمة ضد كل من يخالف الموافقة

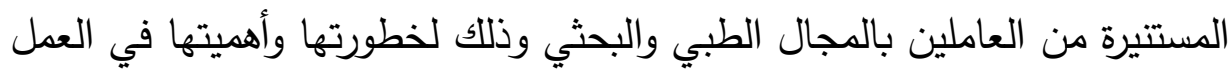

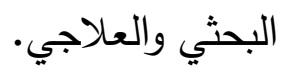


9- يرجع جزء كبير من عدم الوعي بأهمية الموافقة المستنيرة وغيرها من الموضوعات الطبية من الناحية الأخلاقية إما إلى عدم تدريس الأخلاق المهنية والطبية لطلبة القطاع الطبي بشكل عام، أو تدريسها لهم من خلا غير إلى المختصين في الأخلاق التطبيقية مما يجعلهم أقل وعيًا بخطورة المشكلات الطبية من المنظور الأخلاقي، لهذا نوصى بإدراج هذا المقرر في كليات القطاع الطبي وأن يتولى تدريسه المختصين في الأخلاق التطبيقية بأقسام الفلسفة في الجامعات المصرية. 10- زيادة الاهتمام بالأخلاق التطبيقية في أقسام الفلسفة بالجامعات المصرية لضرورتها في الوقت الحالي، باعتبارها تخصصًا أساسيًا في الفلسفة في العقود الأخيرة وتتوع موضوعاتها والمشكلات التي تبحث عن حلول لها.

قائمة المراجع

1. د إبراهيم مدكور وآخرين:المعجم الفلسفي، الهيئة العامة لشئون المطابع

الأميرية، مصر ، 1983

2. أحمد بن حنبل: مسند أحمد بشرح بلوغ الأماني، دار إحياء التراث

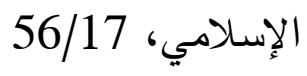

3. د أحمد السعيد شرف الدين: زراعة الأعضاء والقانون، مجلة الحقوق

$$
\text { والشريعة، الكويت، المجلد 1، العدد2، يونيو } 1977
$$

4. د أحمد السعيد شرف الدين: الحدود الإنسانية والثرعية والقانونية للإنعاش

الصناعي، مجلة الحقوق والثريعة، الكويت، المجلد 5، العدد2، يونيو 1981 5. د أحمد عبد الحليم عطية: الأخلاقيات الحيوية الطبية، دفاتر فلسفية، كرسي اليونسكو للفلسفة فرع جامعة الزقازيق بالاشتراك مع جمعية الفنون والآداب، 
6. أحمد محمود صبحي، محمود فهمي زيدان: في فلسفة الطب، دار

النهضة العربية، بيروت، 1993

7. د أسعد السحمراني: الحرية والمسؤولية، دار النفائس، لبنان، 2011

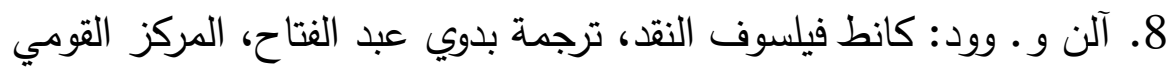

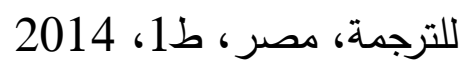

9. امانويل كانت: تأسيس ميتافيزيقا الأخلاق، ترجمة عبد الغفار مكاوي،

الدار القومية للطباعة والنشر والفنون، 1965

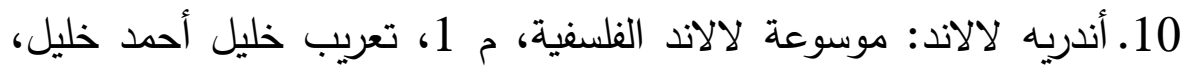

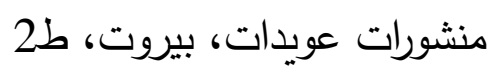

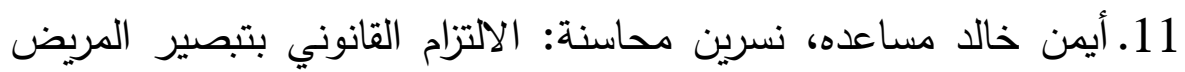

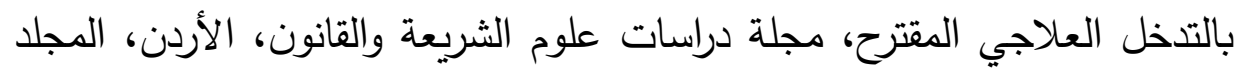

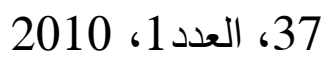

12. البشير المؤدب: البيوأثثيا بين العلم والأيديولوجيا، المجلة التونسية للدراسات الفلسفية، الجمعية التونسية للدراسات الفلسفية، تونس، العدد 24، 25، 2000

13.بن سينا: القانون في الطب، ج1، دار الكتب العلمية، بيروت، ط1،

14.د جحنيط حمزة: المبادئ الأساسية والأخلاقية للبحث العلمي، الملتقي المشترك حول الأمانة العلمية، مركز جيل البحث العلمي، الجزائر، 2017/7/11

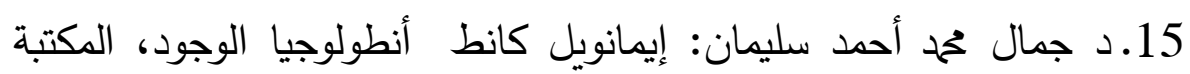

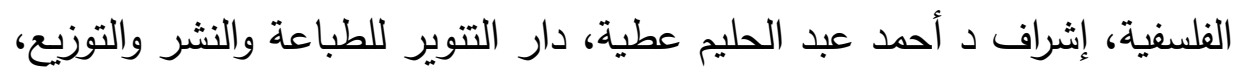
مصر، 2009 
16. د حسين على: العلم والتعاليم الأخلاقية رؤية معاصرة، الفلسفة التطبيقية، تحرير د مصطفي النشار ، الدار المصرية السعودية، القاهرة، 2000

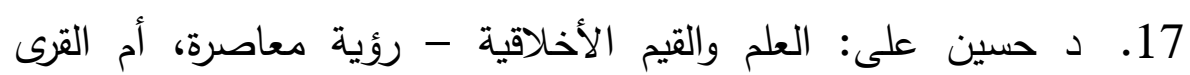
للطباعة والنشر والتوزيع، 2008 18.د حسين على: فلسفة الطب، الدار المصرية السعودية للطباعة والنشر ولر والتوزيع، القاهرة، 2009 19.دليلة جبار: طبيعة الحرية عند كانط من خلال فلسفته النقدية، رسالة ماجستير غير منشورة، جامعة الجزائر، كلية العلوم الإنسانية والاجتماعية، قسم الفلسفة، ماجسير 2004

20. د زكريا إبراهيم: مشكلة الحرية، مكتبة مصر ، القاهرة، ط3، 1972 21. د. سامية لحولود، د. زكية دقري، د. نعيمة يحياوي، أ. ريمة باشة: دور الأخلاقيات الطبية في حماية حقوق المريض من خلال الالتزام بالضوابط الشرعية، المجلة العالمية للتسويق الإسلامي، بريطانيا، المجلد 4، العدد3، سبتمبر 2015 22. دكتور سفيان حمودة: أخلاقيات مزاولة المهنة الطبية من وجهة نظر المقاصد الشرعية الإسلامية، المؤتمر العلمي العالمي، جمعية العلوم الطبية الإسلامية ونقابة الأطباء الأردنيين والاتحاد العالمي للجمعيات الطبية الإسلامية، عمان، 17 تموز من عام 2004 م. 23.سمير إسماعيل الحلو: الطب الإسلامي: نحو تطبيق عملي، مجلة الحكمة، السعودية، العدد 6، يونيو 1995 24.سمية محمود إبراهيم الجربي: فلسفة العلم التطبيقية (الأخلاق الحيوية والطبية نموذجًا)، مجلة الجامعي، النقابة العامة لأعضاء هيئة التدريس الجامعي، ليبيا، العدد 25، ربيع 2017 
25. الثهابي إبراهيم الثهابي: التزام الطبيب حفظ أسرار المرضى "الأصل والاستثناء"، مجلة الحقوق، الكويت، المجلد 32، العدد 3، سبتمبر 2008

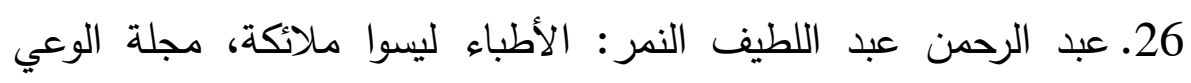

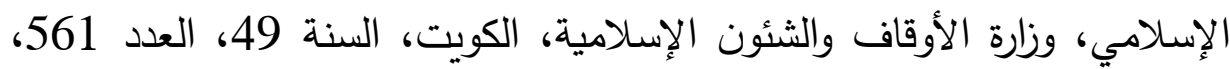

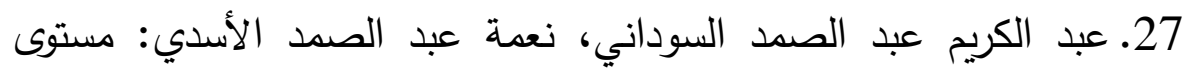

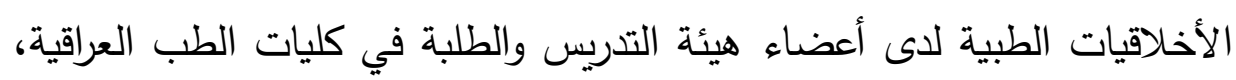
مجلة العلوم الإنسانية، العراق، العدد 15، 2013 28. عبد اللطيف بربيش: تأملات في المظاهر التقنية والخلقية الناجمة عن التطاتية، تطور العلوم الطبية، الأكاديمية، الدغرب، العدد 8، ديسمبر 1999 29. عبد اللطيف بربيش: أخلاقيات البحث والتجريب الطبي على الانية، الانسان، الأكاديمية، المغرب، العدد 23، 2006

30. عبد الله محمد الجبوري: فقه الطبيب وأدبه في المنظور الإنسلامي، مجلة الحكمة، السعودية، العدد 25، سبتمبر 2002 31. عبد الله محح جواد: الجوانب الأخلاقية لإجراء التجارب الطبية على الطي

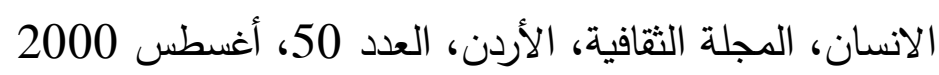

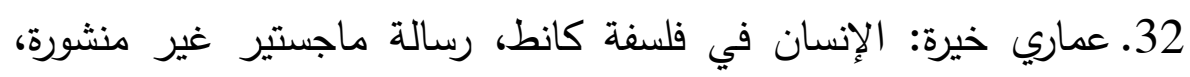
جامعة الجزائر ، كلية العلوم الإنسانية والإجتماعية، قسم الفلسفة، 2006

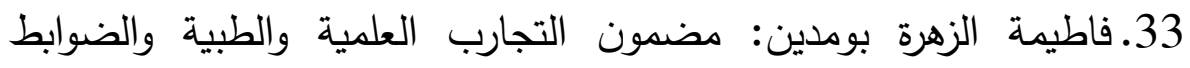

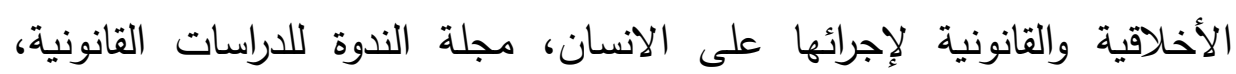
الجزائر ، العدد 6، ديسمبر 2015

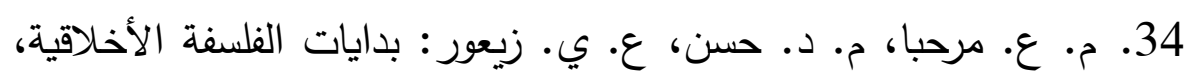

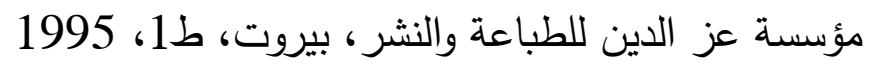




\section{مجلة وادي النيل للاراسات والبحوث الإنسانية والاجتماعية ـ مجلة علمية محكمة}

(ISSN: 2536 - 9555)

35. ححم أبو بكر أبو عزة: الأخلاق المهنية في العمل الطبي، المجلة الليبية للدراسات، دار الزاوية للكتاب، ليبيا، ابريل 2014 36. حمح بن اسماعيل البخاري: صحيح البخاري بشرح فتح الباري، شركة البريل الطباعة الفنية، 249/21

37. د محمد صلاح: حق المريض في الحصول على المعلومات الطبية:

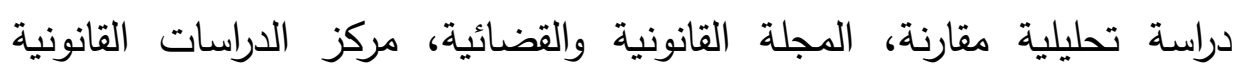
والقضائية، قطر، السنة العاشرة، العدد 2، 2016 38. حمح محمد عبد اللطيف: مشكلات المسئولية الطبية أمام القضاء الإداري،

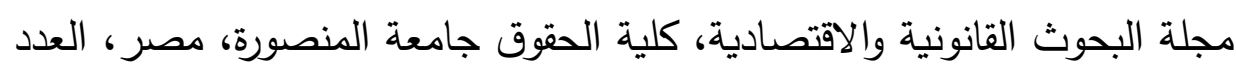

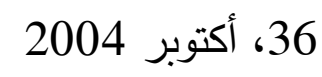
39. مختار عيواج: حرية البحث الطبي العلمي في ظل إشتراطات الحق

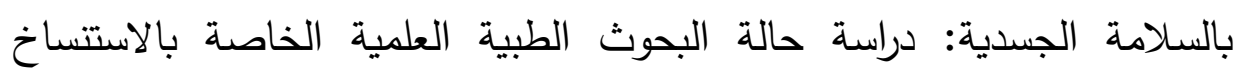
البشري، مجلة جيل حقوق الانسان، مركز جيل البحث العلمي، الجزائر، العدد 10، يوليو 2016

40. مراد ابن صغير: مدى التزام الطبيب بتبصير المريض: دراسة علمية تأصيلية مقارنة، مجلة الحقوق، الكويت، المجلد 34، العدد 4، ديسمبر 2010

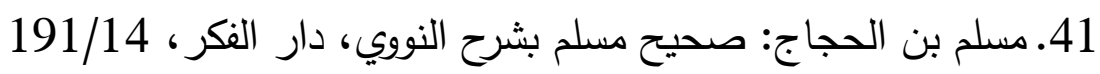

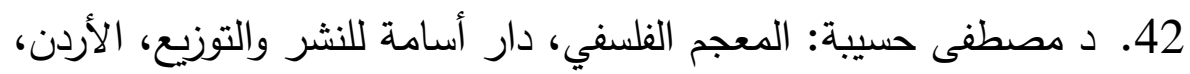
ط1، 2009

43.منذر عبد الحسين الفضل: التجربة الطبية على الجسم البشري ومدى

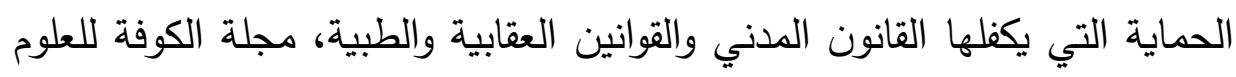
القانونية والسياسية، العراق، المجلد 2، العدد 7، أكتوبر 2010 
44. منصور مصطفي: حقوق المريض على الطبيب، مجلة الحقوق والشريعة،

الكويت، المجلد 5، العدد 2، يونيو 1981

45. ناهدة البقصي: الهندسة الوراثية والأخلاق، عالم المعرفة، الكويت، العدد

$$
\text { 174، يونيو } 1993
$$

46. الدكتور • هيثم حامد خليل المصاروة: مدى الاعتداد بإرادة المريض في

الأعمال الطبية، مجلة الفكر الشرطي، الإمارات، المجلد 24، العدد 93، ابريل

47. يوسف الكيلاني: سر المهنة الطبية، مجلة الحقوق والثريعة، الكويت،

المجلد 5، العدد 2، يونيو 1981

القواعد الإرشادية الدولية لآداب المهنة فى مجال بحوث الطب الطب الإحيائي

المتضمنة لحالات دراسة بشرية، إعداد مجلس المنظمات الدولية للعلوم الطبية

بالتعاون مع منظمة الصحة العالمية، مجلس المنظمات الدولية للعلوم الطبية، جنيف، 2002، ص 29، 30

\section{مراجع باللغة الانجليزية}

1-Danielle Bromwich, Annette Rid: Can informed consent to research be adapted to risk?, journal of medical ethics, , vol 41,2015

2-Grant R Gillett: Informed consent and moral integrity, Journal of medical ethics, vol 15, 1989

3- J C Garnham: Some observationsns on iofrmed consent in non-theraeutic research, Journal of Medical Ethics, vol.1, 1975.

4-Kenneth Boyd: The impossibility of informed consent?, Journal of Medical Ethics, vol 41, 2015

5-L Doyal: Good clinical practice and informed consent are inseparable, Hear, vol.87, 2002 
6- Karsten Witt: Identity change and informed consent, journal of medicl ethics, vol. 43, 2017

7-Lokesh P. Nijhawan, Manthan D. Janodia, B. S. Muddukrishna, K. M. Bhat, K. L. Bairy, N. Udupa, and Prashant B. Musmade: Informed consent: Issues and challenges, Journal of Advanced Pharmaceutical Technology \& Research, v4 (issue 3), jul-sep 2013

8-M Stirrat, R Gill: Autonomy in medical ethics after O'Neill, journal of medical ethics, 31, 2005

9-N G Messer: Professional-patient relationships and informed consent, Medical Journal,80,2004

10- Nir Eyal: Using informed consent to save trust, Jourmal of Medical Ethics 2014

$$
\text { مقالات وأبحاث من شبكة الانترنت باللغة الانجليزية }
$$

1. William Ruddick: MEDICAL ETHICS, Encyclopedia of Ethics. Lawrence and Charlotte Becker, eds. 2nd edition. Garland 1998 , in http://www.nyu.edu/gsas/dept/philo/faculty/ruddick/papers /medethics.html

$$
\text { 2. د: حسن عباس حسن: نظرة في مفهوم الأخلاق الطبية، شبكة أهل }
$$

http://www.ahlolbayt.net/modules.php?name=News\&fil $\mathrm{e}=$ print $\&$ sid $=141$

3. The Bioethics of the Circumcision of Male Children in http://www.cirp.org/library/ethics/

4. Jessica De Bord: Informed Consent, march 2014, University of Washington, in https://depts.washington.edu/bioethx/topics/consent.html

5. The Bioethics of the Circumcision of Male Children, in http://www.cirp.org/library/ethics/

6. What is informed consent and what does it mean? In https://www.cancer.org/treatment/finding-and-paying-for- 
مجلة وادى النيل للاراسات و البحوث الإنسانية والاجتماعية و التربوية

treatment/understanding-financial-and-legalmatters/informed-consent/what-is-informed-consent.html

7. What is informed consent and what does it mean? In https://www.cancer.org/treatment/finding-and-payingfor-treatment/understanding-financial-and-legalmatters/informed-consent/what-is-informed-consent.html 8. Richard A Wagner: informed Consent, in https://www.emedicinehealth.com/informed_consent/articl e_em.htm.

9. The Bioethics of the Circumcision of Male Children in http://www.cirp.org/library/ethics/

10. Committee on Bioethics: Informed Consent, Parental Permission, and Assent in Pediatric Practice, PEDIATRICS, Volume 95 Number 2, Pages 314-317, February 1995, in http://www.cirp.org/library/ethics/AAP 11- M Stirrat, R Gill: Autonomy in medical ethics after O'Neill, journal of medical ethics, 2005, 31, page 127

12- Jessica De Bord: Informed Consent, march 2014, University of Washington, in https://depts.washington.edu/bioethx/topics/consent.html 13- J P H Shield: Children's Consent to Treatment, British Medical Journal, 7 May 1994, Vol 308, Pages 1182, in http://www.cirp.org/library/ethics/shield.

14- J P H Shield: Children's Consent to Treatment, British Medical Journal, 7 May 1994, Vol 308, Pages 1183, in http://www.cirp.org/library/ethics/shield.

15- The Bioethics of the Circumcision of Male Children in http://www.cirp.org/library/ethics/

16- How is informed consent for a clinical trial or research study different from consent for standard treatment? In https://www.cancer.org/treatment/finding-and-paying-fortreatment/understanding-financial-and-legalmatters/informed-consent/clinical-trial-consent.html 17- Belmont Report: 
مجلة وادي النيل للاراسات والبحوث الإنسانية والاجتماعية ـ مجلة علمية محكمة

(ISSN: 2536 - 9555)

https://en.wikipedia.org/wiki/Belmont_Report

18- Lizbeth A. Adams, Timothy Callahan, Research Ethics,in

https://depts.washington.edu/bioethx/topics/resrch.html 19- List of medical ethics cases: in https://en.wikipedia.org/wiki/List_of_medical_ethics_cases 20- Kenneth Boyd: The impossibility of informed consent?, Journal of http://www.islamset.com/arabic/alwseka/nazeh/word. 